Linköping Studies in Science and Technology Dissertation No. 1927

\title{
Mesoporous material systems for catalysis and drug delivery
}

\author{
Aylin Atakan
}

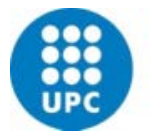

UNIVERSITAT POLITÈCNICA

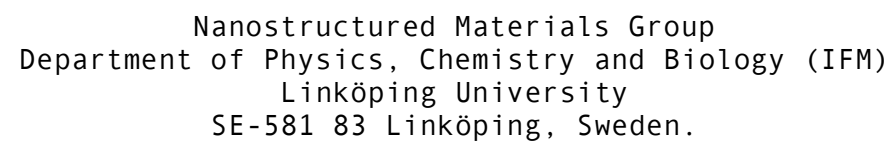

Biomaterials, Biomechanics and Tissue Engineering Group Department of Materials Science and Metallurgical Engineering Universitat Politécnica de Catalunya 08034 Barcelona, Spain.

\section{Part of}

The Joint European Doctoral Programme in Materials Science and Engineering (DocMASE) 
(C) Aylin Atakan, 2018

Printed in Sweden by LIU-Tryck, Linköping 2018

ISSN 0345-7524

ISBN 978-91-7685-330-6 


\section{Abstract}

Hybrid material systems possess multi-functional properties which make them intriguing for the materials science community since very early dates. However, it is not straightforward to produce such material systems. A smart and efficient approach is necessary to extract the desired properties of each component under the desired conditions. This study evolved to its last form primarily around this notion, where the development of a hybrid material is the core of the work. This hybrid material is then further explored for two different applications in the catalysis and drug delivery fields.

A nanoassembly was established around a mesoporous silica support. SBA-15 was picked as this support among the other mesoporous silica due to its well-defined pore structure and accessible pore volume. The silica framework was doped with $\mathrm{Zr}$ atoms and the pores were partly infiltrated with $\mathrm{Cu}$ nanoparticles resulting in a hybrid material with tunable properties. SBA-15 was synthesized by a sol-gel method where a micellar solution was employed as a template for the silica framework. To achieve the doped version, a $\mathrm{Zr}$ precursor was added to the synthesis solution. The effects of different synthesis conditions, such as the synthesis catalyst ( $\mathrm{F}^{-}$or a $\mathrm{Cl}^{-}$salt) and the Si source (tetraethyl orthosilicate (TEOS) or sodium metasilicate (SMS)) on the characteristics of the final material were investigated. It was observed that these changes in the synthesis conditions yielded different particle morphology, pore size (11-15 nm), and specific surface area $\left(400-700 \mathrm{~m}^{2} / \mathrm{g}\right)$. Cu nanoparticles (NPs) were grown in the (Zr-)SBA-15 support using infiltration (Inf) or evaporation induced wetness impregnation (EIWI) methods. The infiltration method is based on functionalizing the (Zr-)SBA-15 support surfaces before the $\mathrm{Cu}$ ion attachment whereas EIWI is based on slow evaporation of the liquid from the (Zr-)SBA-15 - Cu aqueous suspension. Both methods are designed to yield preferential growth of $\mathrm{Cu}$ NPs in the pores with a diameter smaller than $10 \mathrm{~nm}$ and in oxidized form. However, depending on the loading method used, different chemical states of the final material were achieved, i.e. $\mathrm{Zr}$ content and porous network properties are different.

$\mathrm{Cu}-\mathrm{Zr}$-SBA-15 nanoassemblies produced under various synthesis conditions were used for the catalytic conversion of $\mathrm{CO}_{2}$ into valuable fuels such as methanol and dimethyl ether (DME). The effect of different chemical states of the catalyst arising from variations in the synthesis parameters was investigated. It was found that the Si precursor (TEOS or SMS) had a considerable impact on the overall performance of the catalyst whereas the $\mathrm{Cu}$ 
loading method (Inf or EIWI) changed the catalytic selectivity between DME and methanol. The activity of the catalyst was further investigated in a time-evolution study where the accumulation of each product in the gas phase and the molecular groups attached to the catalyst surface were recorded over time. Accordingly, thermodynamic equilibrium was achieved on the 14 th day of the reaction under $250^{\circ} \mathrm{C}$ and 33 bar. The resulting total $\mathrm{CO}_{2}$ conversion was $24 \%$, which is the thermodynamically highest possible conversion, according to theoretical calculations. It was also concluded from the experimental results that, $\mathrm{DME}$ is formed by a combination of two methoxy surface groups. Additionally, the formation of DME boosts the total $\mathrm{CO}_{2}$ conversion to fuels, which otherwise is limited to $9.5 \%$.

The design of Cu-Zr-SBA-15 was also investigated for drug delivery applications, due to its potential as a biomaterial, e.g., a filler in dental composites, and the antibacterial properties of $\mathrm{Cu}$. Also, the bioactivity of $\mathrm{SiO}_{2}$ and $\mathrm{ZrO}_{2}$ was considered to be an advantage. With this aim, Cu infiltrated $\mathrm{Zr}$ doped SBA-15 material was prepared by using TEOS as the silica precursor and the Inf-method to grow $\mathrm{Cu}$ NPs. The performance of the final material as a drug delivery vehicle was tested by an in-vitro delivery study with chlorhexidine digluconate. The nanoassemblies show a drug loading capacity of $25-40 \%$ $[\mathrm{mg}$ drug / $\mathrm{mg}$ (drug+carrier) ]. The drug release was determined to be composed of two steps. First, a burst release of the drug molecules that are loosely held in the voids of the mesoporous carrier followed by the diffusion of the drug molecules that are attached to the carrier surface. The presence of $\mathrm{Zr}$ and $\mathrm{Cu}$ limits the burst release and beneficially slows down the drug release process.

The effect of pore properties of SBA-15 was explored in a study where the antibiotic doxycycline hyclate was loaded in SBA-15 materials with different pore sizes. It was observed that the pore size is directly proportional to the drug loading capacity [mg drug / $\mathrm{mg}$ (drug+carrier)] and the released drug percentage (the released drug amount/total amount of loaded drug). The drug release was fast due to its weak interactions with the SBA-15 materials.

In summary, this work demonstrates the multifunctional character of a smart-tailored nanoassembly which gives valuable insights for two distinct applications in catalysis and drug delivery. 


\section{Popularvetenskaplig sammanfattning}

Hybridmaterial består av minst två komponenter, vilket ger dem mångfacetterade egenskaper. Detta har gjort att denna typ av material attraktiva sedan länge. Det är dock inte enkelt att tillverka dessa materialsystem. Ett enkelt och effektivt tillvägagångssätt behövs för att tillvara ta de önskade egenskaperna hos varje komponent och få dem att samverka. Denna avhandling bygger huvudsakligen på utvecklingen av ett hybridmaterial. Materialet testas sedan i två olika tillämpningar: katalys och läkemedelstransport.

Ett hybridmaterial med en sammansättning bestämd på nanonivå, tillverkades med mesoporös kiseldioxid, SBA-15, som stomme. SBA-15 valdes framför andra typer av mesoporös kiseldioxid på grund av dess väldefinierade porstruktur och stora, tillgängliga porvolym. Kiseldioxiden dopades med zirkoniumatomer och porerna fylldes delvis med kopparnanopartiklar, vilket resulterade i ett hybridmaterial med egenskaper som kunde varieras. SBA-15 tillverkades via en våtkemisk metod där en micellösning används som mall för kiseldioxidens struktur. Vid dopningen tillsätts en zirkoniumkälla till synteslösningen. Effekterna av olika tillverkningsparametrar, till exempel salter med katalytiska egenskaper (salter med F- eller Cl-), olika kiselkällor (tetraetyl ortosilikat eller natriummetasilikat), på materialens egenskaper studerades. Variationer av dessa parametrar ger material med olika form, porstorlekar $(11-15 \mathrm{~nm})$ och specifik yta (400 - $700 \mathrm{~m}^{2} / \mathrm{g}$ ). Kopparnanopartiklar växtes i (Zr-)SBA-15-stommarna med två metoder: infiltration (Inf) eller indunstningsinducerad våtimpregnering (EIWI). Inf baseras på funktionalisering av (Zr-)SBA-15-stommen innan kopparjoner fick reagera med ytan. EIWI bygger på en blandning av (Zr-)SBA-15 och kopparsalt i en lösning där vätskan långsamt får avdunsta. Båda metoderna är designade för framställning av oxiderade kopparnanopartiklar, mindre än $10 \mathrm{~nm}$ i diameter, som ska växa i stommens porer. Dock påverkar infiltrationsmetoden den kemiska sammansättningen hos det slutliga materialet då Zr-koncentrationen och porositeten i stommen ändras.

Cu-Zr-SBA-15-sammansättningar, tillverkade med varierande syntesparametrar, användes som katalysatorer för omvandling av $\mathrm{CO}_{2}$ till bränslen såsom metanol och dimetyleter (DME). Resultaten visar att valet av kiselkälla har en stor inverkan på katalysatorns prestanda, samt att metoden för att introducera koppar ändrar den katalytiska selektiviteten mellan DME och metanol. Katalysatorns aktivitet undersöktes även över tid. Ackumuleringen av varje produkt, både i gasfas och på katalysatorns yta, registrerades över tid. Termodynamisk jämvikt nåddes efter att reaktionen fortgått $\mathrm{i}$ fjorton dagar vid $250{ }^{\circ} \mathrm{C}$ och 33 bar. Den totala $\mathrm{CO}_{2}$-omvandlingen var $24 \%$, vilket, enligt 
teoretiska beräkningar, är den termodynamiskt högsta möjliga omvandlingen. Det observerades att DME bildas genom en kombination av två metoxygrupper på katalysatorns yta, samt att bildandet av DME ökar den totala omvandlingen av $\mathrm{CO}_{2}$ till bränsle, vilken annars är begränsad till $9.5 \%$.

Cu-Zr-SBA-15-sammansättningen användes även i läkemedelstillämpningar. De kan användas som biomaterial, e.g., fyllnadsmaterial i tandkompositer, och koppar har antibakteriella egenskaper. Dessutom kan kiseldioxid och zirkoniumdioxid vara bioaktiva vilket ses som en fördel. För denna tillämpning tillverkades Cu-Zr-SBA-15 med TEOS som kiselkälla och Inf-metoden för att växa kopparnanopartiklar. Cu-Zr-SBA-15 lämplighet som bärare av läkemedelet klorhexidindiglukonat testades in vitro. I detta fall uppvisar bäraren en laddningskapacitet [massa laddat läkemedel/ (massa laddat läkemedel +massa bärare) ] på 25 - 40 \%. Frisättningen av läkemedel skedde i två steg. Först frisattes en stor mängd läkemedelsmolekyler. Dessa var löst placerade i håligheter i de mesoporösa stommarna. Därefter frisattes läkemedel via diffusion av molekyler som bundit till stommens yta. De två stegen representerar växelverkan mellan läkemedel - läkemedel- och läkemedel - bärare. Närvaron av zirkonium och koppar begränsar den första frisättningen och förlänger den aktiva tiden, vilket är fördelaktigt ur tillämpningsperspektiv.

Effekten av porstorlek hos SBA-15 vid läkemedelsfrisättning undersöktes också i en studie där SBA-15 fylldes med doxycyklinhyklat. Laddningskapaciteten och mängden frisatt läkemedel och andelen av laddat läkemedel som frisätts var båda direkt proportionella mot porstorleken där frisättningen av doxycyklinhyklat dominerades av läkemedel läkemedelsväxelverkan. Doxycyklinhyklat är en mindre molekyl jämfört med klorhexidindiglukonat och växelverkar svagare med SBA-15 på grund av sin mer anjoniska natur.

Sammanfattningsvis visar arbetet den multifunktionella karaktären hos en skräddarsydd nanosammansättning, vilket ger värdefulla insikter i två användningsområden: katalys och läkemedelstransport. 


\section{Resumen}

Los sistemas de materiales híbridos poseen propiedades multifuncionales, lo que ha suscitado el interés de la comunidad científica de materiales desde fechas muy tempranas. Sin embargo, no es sencillo producir dichos materiales. Es necesario un enfoque inteligente y eficiente para extraer las propiedades deseadas de cada componente, en las condiciones deseadas. Este estudio evoluciona en torno a esta noción, siendo el desarrollo de un material híbrido el núcleo del trabajo. Adicionalmente, este material híbrido se explora para dos aplicaciones diferentes que son la catálisis y la administración de fármacos.

En este trabajo se desarrolló un nanoensamblaje alrededor de un soporte de sílice mesoporoso. Como soporte se seleccionó SBA-15 debido a su estructura de poro bien definida y volumen de poro accesible. La matriz de sílice fue dopada con átomos de $\mathrm{Zr}$ y los poros se infiltraron parcialmente con nanopartículas de $\mathrm{Cu}$ dando como resultado un material híbrido con propiedades ajustables. La síntesis de SBA-15 se realizó mediante un método de sol-gel en el que se empleó una solución micelar como plantilla para el sílice. Para lograr la versión dopada, se añadió un precursor de Zr a la solución de síntesis. Se investigaron los efectos de diferentes condiciones de síntesis, como el catalizador (sales de F o de $\mathrm{Cl}$ ) así como la fuente de $\mathrm{Si}$ (ortosilicato de tetraetilo (TEOS) o metasilicato sódico (SMS) ) en las características del material final. Se observó que los cambios en estas condiciones de síntesis dieron lugar a partículas con distinta morfología, tamaño de poro (11-15 nm) y área superficial específica $\left(400-700 \mathrm{~m}^{2} / \mathrm{g}\right)$. Las nanopartículas de $\mathrm{Cu}(\mathrm{NP})$ se hicieron crecer en el sustrato (Zr-) SBA-15 usando los métodos de infiltración (Inf) o de impregnación húmeda inducida por evaporación (EIWI). El método de infiltración se basa en funcionalizar las superficies de soporte (Zr-) SBA-15 antes de la unión del ion Cu, mientras que EIWI se basa en la evaporación lenta del líquido de la suspensión acuosa (Zr) SBA-15-Cu. Ambos métodos se han diseñado para producir un crecimiento preferencial de $\mathrm{Cu}$ NP en los poros con un diámetro inferior a $10 \mathrm{~nm}$ y en forma oxidada. Sin embargo, dependiendo del método de infiltración utilizado, se logran diferentes estados químicos del material final, es decir, el contenido de $\mathrm{Zr}$ y las propiedades de red porosa son diferentes.

Los nanoensamblajes de Cu-Zr-SBA-15 producidos bajo diversas condiciones de síntesis se usaron para la conversión catalítica de $\mathrm{CO}_{2}$ en combustibles valiosos tales como 
metanol y dimetil éter (DME). Se investigó el efecto de diferentes estados químicos del catalizador obtenidos modificando los parámetros de síntesis. Se encontró que el precursor de $\mathrm{Si}$ (TEOS o SMS) tuvo un impacto considerable en el rendimiento global del catalizador mientras que el método de carga de $\mathrm{Cu}$ (Inf o EIWI) cambió la selectividad catalítica entre DME y metanol. Por otra parte, la actividad del catalizador se investigó evaluando la acumulación de cada producto en la fase gaseosa y los grupos moleculares unidos a la superficie del catalizador a lo largo del tiempo. Se llegó al equilibrio termodinámico en el día 14 de la reacción a $250^{\circ} \mathrm{C}$ y 33 bar. La conversión total resultante de $\mathrm{CO}_{2}$ fue del $24 \%$, que es la conversión termodinámicamente más alta posible, según los cálculos teóricos. También se concluyó a partir de los resultados experimentales que, el DME está formado por una combinación de dos grupos superficiales metoxilados. Asimismo, la formación de DME también aumenta la conversión total de $\mathrm{CO}_{2}$ en los combustibles, que de lo contrario se limita al 9,5\%.

El material híbrido sintetizado Cu-Zr-SBA-15 también se investigó para aplicaciones de administración de fármacos, debido a su potencial como material de relleno en compuestos dentales y las propiedades antibacterianas del $\mathrm{Cu}$. Por otra parte, la bioactividad de $\mathrm{SiO}_{2}$ y $\mathrm{ZrO}_{2}$ podría ser ventajosa para esta aplicación. Con este objetivo, se preparó SBA-15 dopado con Zr e infiltrado con Cu utilizando TEOS como el precursor de sílice y el método Inf para cultivar $\mathrm{Cu}$ NP. El rendimiento del material final como vehículo de administración de fármacos se probó mediante un estudio de liberación in vitro con digluconato de clorhexidina. Los materiales desarrollados muestran una elevada capacidad de carga de fármaco (25-40\%). Los perfiles de liberación del fármaco muestran dos etapas: una primera etapa de liberación rápida de las moléculas del fármaco unidas con interacciones más débiles al sustrato mesoporoso, seguida por la difusión de las moléculas del fármaco que están unidas a la superficie del portador. La presencia de $\mathrm{Zr}$ y Cu limita la liberación inicial y reduce la velocidad de liberación del fármaco.

En otro estudio se evaluó el efecto del tamaño de poro de SBA-15 en la liberación del antibiótico hiclato de doxiciclina. Se observó que el tamaño de poro es directamente proporcional a la capacidad de carga de fármaco, el porcentaje y la cantidad de fármaco liberado. En este estudio el perfil de liberación fue rápido, debido a las interacciones débiles del fármaco con el SBA-15 y el menor tamaño de molécula del fármaco en relación al digluconato de clorhexidina del estudio anterior. 
En resumen, este trabajo demuestra el carácter multifuncional de una nanomatriz diseñada a medida que proporciona información valiosa para dos aplicaciones en catálisis y liberación de fármacos. 


\section{Preface}

This thesis is the result of my doctoral studies conducted within the framework of the Joint European Doctoral Program in Material Science and Engineering (DocMASE) between September 2012 and October 2017. Starting from October 2015, 33\% of the Ph.D. time was devoted to a part-time job with Nanolith Sverige AB until October 2017 after which this employment became full time.

This thesis shows different production methods for an advanced functional material on a complex matrix to be able to serve selected applications in catalysis and drug delivery areas. These application areas may seem very different, but similar nanostructures can be favorable for both, in various ways. Thus, the focus evolved around the material characteristics and synthesis optimization. The key results are presented in the appended papers.

The part of the work related to material synthesis and catalysis was performed in Nanostructured Materials Group at the Department of Physics, Chemistry and Biology (IFM) at Linköping University, Linköping, Sweden and the part related to drug delivery was performed in Biomaterials, Biomechanics and Tissue Engineering Group at the Department of Materials Science and Metallurgical Engineering of the Universitat Politècnica de Catalunya, Barcelona, Spain.

This work was financially supported by EU (DocMASE), Vinnova (FunMat-II), Swedish Energy Agency, and Knut and Alice Wallenberg Foundation. 


\section{Included Papers}

\section{Paper 1}

Synthesis of a Cu-infiltrated Zr-doped SBA-15 catalyst for $\mathrm{CO}_{2}$ hydrogenation into methanol and dimethyl ether

A. Atakan, P. Mäkie, F. Söderlind, J. Keraudy, E.M. Björk, and M. Odén

Phys. Chem. Chem. Phys. 19 (2017) 19139

DOI: $10.1039 / \mathrm{C} 7 \mathrm{CP} 03037 \mathrm{~A}$

\section{Paper 2}

Effects of the chemical state of mesoporous $\mathrm{CuO}_{\mathrm{x}}-\mathrm{Zr}-\mathrm{SiO}_{2}$ catalysts on $\mathrm{CO}_{2}$ hydrogenation

A. Atakan, J. Keraudy, P. Mäkie, C. Hulteberg, E.M. Björk, and M. Odén

Submitted for publication

\section{Paper 3}

Time evolution of the $\mathrm{CO}_{2}$ hydrogenation to fuels over Cu-Zr-SBA-15 catalysts

A. Atakan, E. Erdtman, P. Mäkie, L. Ojamäe, and M. Odén

J. Catal. 362 (2018) 55

DOI: $10.1016 /$ j.jcat.2018.03.023

\section{Paper 4}

$\mathrm{Cu}$ and $\mathrm{Zr}$ modified SBA-15 as drug carriers

A. Atakan, C. Canal, P. Mäkie, M. Odén, and M. Ginebra

Submitted for publication

\section{Paper 5}

Tuning the pore size of a mesoporous carrier as means for control of antibiotic release A. Atakan, C. Canal, P. Mäkie, M. Odén, and M. Ginebra In manuscript

\section{Related, Not Included Papers}

\section{Paper 6}

Formation of block-copolymer-templated mesoporous silica

E.M. Björk, P. Mäkie, L. Rogström, A. Atakan, Norbert Schell, and M. Odén JColloid Interface Sci 521 (2018) 183

DOI: $10.1016 /$ j.jcis.2018.03.032 


\section{Contribution to the Included \\ Papers}

\section{Paper 1}

I planned the study, performed the material synthesis, conducted the GC-MS measurements, analyzed all the results and wrote the first draft of the paper. I also took part in the material characterization, catalytic reactions, and DRIFTS analysis.

\section{Paper 2}

I planned the study, performed the material synthesis, conducted the GC-MS measurements, analyzed all the results and wrote the first draft of the paper. I also took part in the material characterization, catalytic reactions, and DRIFTS analysis.

\section{Paper 3}

I planned the study, performed the material synthesis, conducted the GC-MS measurements, analyzed all the results and wrote the first draft of the paper. I also took part in the material characterization, catalytic reactions, and DRIFTS analysis.

\section{Paper 4}

I performed the material synthesis, drug delivery tests, analyzed the results and wrote the first draft of the paper. I also took part in the planning of the study and antibacterial tests.

\section{Paper 5}

I performed the material synthesis, drug delivery tests, antibacterial tests, analyzed all the results and wrote the first draft of the paper. I also took part in the planning of the study. 


\section{Acknowledgements}

I would like to thank all the people who were, willingly or not, involved in my Ph.D. studies. In particular,

My supervisor Prof. Magnus Odén for giving me the opportunity to work in this project, and for all the support, guidance, and patience when I get 'dramatic'..

My supervisor Prof. Maria Pau Ginebra for letting me a part of her research group in UPC, the opportunity to work in drug delivery and all your support during this time.

My co-supervisor Dr. Cristina Canal for supporting me in my studies in UPC, and teaching me the 'bio' side of materials science.

My co-supervisor Dr. Fredrik Söderlind for the support and guidance especially in operating the GC-MS.

Peter Mäkie for being a great help and support for many years in Ph.D. and my 'calm down' person to help me step down on earth. I will forever be grateful!

Emma Björk for all the guidance and input, especially for during paper-writing stages and of course for teaching me how to synthesize SBA-15. I appreciate your encouragement to keep pushing in my Ph.D. studies.

Sven Andersson for helping with technical issues numerous times and supporting me in abandoning my 'forever leak-source' reactor.

My dear friends, I got during the last six years, especially Isabella, Fei and the members of the 9 o'clock coffee club: Mathias, Sebastian, Daniel, Eric. Special thanks to Lida and Mercan for your sincere and comforting friendship. Without you, I wouldn't be able to 'keep my cool' during Ph.D.

All my colleagues in the Nanostructured Materials in Linköping as well as in the Biomaterials, Biomechanics and Tissue Engineering Group group in Barcelona.

My mother Şirin Atakan, my father Erol Atakan, and my sister Simay Atakan for being my biggest emotional and technical support despite the kilometers between us.

I am forever grateful to my beloved husband Julien Keraudy for his guidance and patience. (especially the patience $(-)$ ). Even at the most stressful times, he managed to put a smile on my face. 


\section{Symbols and abbreviations}

\begin{tabular}{|c|c|}
\hline$\lambda$ & wavelength \\
\hline$\theta$ & scattering angle \\
\hline$\mu$ & chemical potential \\
\hline ATR & attenuated total reflectance \\
\hline BASF & Baden aniline and soda factory \\
\hline $\mathrm{BJH}$ & Barret-Joyner-Halenda pore size distribution determination method \\
\hline$c_{\text {ini }}$ & initial drug concentration \\
\hline$c_{s}$ & drug solubility \\
\hline $\mathrm{CHX}$ & chlorhexidine digluconate \\
\hline CRI & Carbon Recycling International \\
\hline $\mathrm{D}$ & diffusion coefficient \\
\hline $\mathrm{d}_{\mathrm{hkl}}$ & lattice spacing \\
\hline DME & dimethyl ether \\
\hline DMFC & direct methanol fuel cells \\
\hline Doxy & doxycycline hyclate \\
\hline DRIFTS & in situ diffuse reflectance infrared Fourier transform spectroscopy \\
\hline EDS/EDX & energy dispersive $\mathrm{x}$-ray spectroscopy \\
\hline FID & flame ionization detector \\
\hline FTIR & Fourier transform infrared spectroscopy \\
\hline $\mathrm{H}$ & enthalpy \\
\hline G & Gibbs free energy \\
\hline GC & gas chromatography \\
\hline ICI & Imperial Chemical Industries \\
\hline IUPAC & International Union of Pure and Applied Chemistry \\
\hline $\mathrm{k}$ & drug release rate constant \\
\hline $\mathrm{k}_{0}$ & zero order drug release constant \\
\hline $\mathrm{k}_{\mathrm{H}}$ & Higuchi dissolution constant \\
\hline KJS & Kruk-Jaroniec-Sayari pore size correction method \\
\hline LPG & liquefied petroleum gas \\
\hline $\mathrm{MeOH}$ & methanol \\
\hline $\mathrm{M}_{0}$ & initial drug amount \\
\hline $\mathrm{M}_{\mathrm{t}}$ & amount of drug released in time $t$ \\
\hline $\mathrm{M}_{\infty}$ & amount of drug released in time infinity \\
\hline MEC & minimum effective concentration \\
\hline MS & mass spectrometry \\
\hline MTC & minimum toxic concentration \\
\hline P123 & PPO-PEO-PPO triblock copolymer \\
\hline $\mathrm{P}_{1}$ and $\mathrm{P}_{2}$ & the percentage of the drug released during phase 1 and 2 \\
\hline $\mathrm{PEO}$ & polyethylene oxide \\
\hline $\mathrm{PPO}$ & polypropylene oxide \\
\hline RWGS & reverse water gas shift reaction \\
\hline
\end{tabular}


SEM scanning electron microscopy

TEOS tetraethyl orthosilicate

TG thermogravimetry

TMOS tetramethyl orthosilicate

UV/vis ultraviolet-visible spectroscopy

WGS water gas shift reaction

XPS $\quad \mathrm{x}$-ray photoelectron spectroscopy

XRD $\quad x$-ray diffraction

$t$ time

$\mathrm{t}_{1} \quad$ lag time

$\mathrm{T}$ temperature

TCD thermal conductivity detector

TEM transmission electron microscopy 


\section{Table of Contents}

$\begin{array}{lll}\text { ABSTRACT III } & \text { IIT }\end{array}$

POPULARVETENSKAPLIG SAMMANFATTNING V V

$\begin{array}{lll}\text { RESUMEN } & \text { VII }\end{array}$

PREFACE

$\begin{array}{ll}\text { INCLUDED PAPERS } & \text { XIII }\end{array}$

RELATED, NOT INCLUDED PAPERS XIII

CONTRIBUTION TO THE INCLUDED PAPERS $\quad$ XIV

ACKNOWLEDGEMENTS $\quad$ XV

$\begin{array}{ll}\text { SYMBOLS AND ABBREVIATIONS } & \text { XVII }\end{array}$

TABLE OF CONTENTS $\quad$ XIX

$\begin{array}{ll}\text { INTRODUCTION } & 21\end{array}$

$\begin{array}{lll}1.1 & \text { MOTIVATION } & 21\end{array}$

$\begin{array}{lll}1.2 \text { OUTLINE } & 23\end{array}$

$\begin{array}{ll}\text { MESOPOROUS SILICA } & 25\end{array}$

$\begin{array}{lll}2.1 & \text { POROUS MATERIALS } & 25\end{array}$

2.2 SBA-15 26

$\begin{array}{lll}2.2 .1 & \text { SBA-15 SYNTHESIS } & 27\end{array}$

2.2.2 SBA-15 MODIFICATION ROUTES 29

$\begin{array}{ll}\text { CATALYSIS } & 31\end{array}$

3.1 INDUSTRIAL REVOLUTION AND GREENHOUSE GASES 31

$\begin{array}{lll}3.2 & \mathrm{CO}_{2} \text { UTILIZATION } & 32\end{array}$

3.2.1 METHANOL 34

3.2.2 DIMETHYL ETHER (DME) 38

3.2.3 CATALYSTS FOR $\mathrm{CO}_{2}$ HYDROGENATION 39

$\begin{array}{ll}\text { DRUG DELIVERY } & 45\end{array}$

4.1. DRUG DELIVERY SYSTEMS 46

4.2. DRUG RELEASE MODELS 47

4.3. DRUG SUPPORTS: NANOCARRIERS AND ANTIBACTERIAL AGENTS 49

$\begin{array}{lr}\text { ANALYSIS METHODS } & 57\end{array}$ 
$\begin{array}{llr}\text { 5.1. PHYSISORPTION } & 58\end{array}$

5.2. TEMPERATURE PROGRAMMED DESORPTION 60

5.3. X-RAY DIFFRACTOMETRY 61

5.4. ELECTRON MICROSCOPY AND ENERGY DISPERSIVE X-RAY SPECTROSCOPY 62

5.5. INFRARED SPECTROSCOPY [FTIR, DRIFTS, AND ATR] 62

5.6. UV/VIS SPECTROSCOPY $\quad 64$

5.7. X-RAY PHOTOELECTRON SPECTROSCOPY 64

5.8. GAS CHROMATOGRAPHY AND MASS SPECTROMETRY 65

5.9. THERMOGRAVIMETRY 65

$\begin{array}{ll}\text { SUMMARY AND DISCUSSIONS OF THE PAPERS } & 67\end{array}$

$\begin{array}{lll}6.1 & \text { PAPER } 1 & 67\end{array}$

$\begin{array}{lll}6.2 & \text { PAPER } 2 & 68\end{array}$

$\begin{array}{lll}6.3 & \text { PAPER } 3 & 70\end{array}$

$\begin{array}{lll}6.4 & \text { PAPER } 4 & 71\end{array}$

$\begin{array}{lll}6.5 & \text { PAPER } 5 & 72\end{array}$

$\begin{array}{ll}\text { CONCLUSIONS AND FUTURE WORK } & 75\end{array}$

$\begin{array}{ll}\text { REFERENCES } & 77\end{array}$

$\begin{array}{lr}\text { APPENDED PAPERS } & 95\end{array}$ 
Introduction

\section{INTRODUCTION}

Modifying materials for achieving certain functionalities goes back to the prehistoric ages where men first used stone as a tool for different purposes such as modifying surfaces, farming or hunting. These ages of humanity are named after their primary source of tool materials: 1) stone, 2) bronze and 3) iron age. The first use of ceramics was during the stone age with flint, whereas the glass was not produced until late iron age. Until this day, tremendous progress was made in synthesis, processing, modifying, and analysis of many material types and the field has evolved around metals, ceramics, polymers and different composites.

Materials science serves many application areas such as energy, medicine, electronics, and machinery and it is typically multidisciplinary where a material can be investigated for many different purposes. It is quite remarkable that a material with certain properties can have various functions and thus have different identities such as a catalyst, a drug carrier, a nano-mold or a coating. Therefore, a cross-disciplinary outlook on different application fields of materials is a source for further improvement of material properties.

\subsection{Motivation}

The motivation of this thesis lies in the multidisciplinary character of materials science. The focus is to modify a mesoporous silica, SBA-15, to gain advantageous properties for two different applications areas: catalysis and drug delivery. SBA-15 is a type of mesoporous silica characterized by a large pore volume, considerably large pore size, and 
robustness in terms of hydrothermal and chemical stability allowing it to maintain its hexagonal pore packing structure under rather harsh conditions. Thus, it can serve these two areas very well and be a perfect complementary material for many active substances.

In the field of catalysis, SBA-15 can be used as a support and a promoter for the catalytically active phase. It has been shown to support active metal phases, such as $\mathrm{Cu}$, especially during heterogeneous catalysis of a gas phase reaction. In this work, such a catalyst system was prepared by growing $\mathrm{Cu}$ nanoparticles on a Zr-doped SBA-15 support. This material was later used for $\mathrm{CO}_{2}$ hydrogenation reaction to convert one of the most significant anthropogenic greenhouse gas $\mathrm{CO}_{2}$ to valuable fuels such as methanol and DME. Although $\mathrm{CO}_{2}$ hydrogenation into methanol has been studied earlier, the search for a suitable catalyst is an on-going process due to the thermodynamic limits. On the other hand, $\mathrm{CO}_{2}$ hydrogenation to DME is a considerably new field, and the findings so far indicate that it requires a complex catalyst that can catalyze both $\mathrm{CO}_{2}$ hydrogenation to methanol and methanol dehydration to DME.

Another field where SBA-15 has been recognized and used is drug delivery. Due to its favorable porous structure, it can accommodate many different sizes of drug molecules and thus can be used as a drug carrier. Its large pore volume can host a drug amount higher than the minimum effective concentration of a chosen drug. $\mathrm{Cu}$ is a common antibacterial agent and in this thesis, it is investigated as nanoparticles embedded in the mesopores of an SBA-15 framework with the aim of prolonged ion release. Moreover, $\mathrm{Cu}$ nanoparticles can form obstacles in the pores and can cause partial blockage, which results in prolonged ion release. Zirconia, as a bioactive material, was also used as a complementary unit to the SBA-15 framework in order to improve the number of active sites on the surface contributing to the drug loading.

The aim of this project was to produce a Cu-Zr-SBA-15 material by doping $\mathrm{Zr}$ into the $\mathrm{SiO}_{2}$ framework and loading $\mathrm{Cu}$ nanoparticles into the mesoporous structure. This material was then tested as a high-performance catalyst for $\mathrm{CO}_{2}$ hydrogenation as well as a favorable drug carrier for in-vitro delivery of Chlorhexidine digluconate (an antiseptic agent) and Doxycycline hyclate (an antibiotic) for dental applications such as implantation or dental composites. 
Introduction

\subsection{Outline}

In this thesis, a general overview of SBA-15 synthesis and modification is presented in Chapter 2, where its structural properties, synthesis mechanisms, and modification methods are discussed. Environmental significance of $\mathrm{CO}_{2}$ utilization is described in Chapter 3 where the mechanisms behind the $\mathrm{CO}_{2}$ hydrogenation to methanol and DME and the applicability of these two fuels in the industry are explained. Chapter 4 is dedicated to the general aspects of drug delivery, drug delivery systems, drug release profiles and models and lastly nanostructured drug carriers. Chapter 5 includes short information regarding the analysis methods used during this work. Chapter 6 summarizes the results and discussions of the appended papers and in Chapter 7 conclusions and future work is discussed. At last, papers are appended. 


\subsection{Porous materials}

Porous materials are solid materials with voids within their structural configuration. The voids which are deeper than they are wide are called pores, and they have a great range of morphologies that are typically channels but also cavities and interstices. The pores can have an open or closed nature. The closed pores can be used for altering the overall material properties (e.g., density), mechanical properties (e.g. hardness and elasticity), and conductivity. On the other hand, open porosity provides extra surface and inner volume to the material improving its carrier properties for guest molecules ${ }^{1}$.

Pores, according to IUPAC's definition, can be classified into three groups: macropores with the pore width larger than $50 \mathrm{~nm}$, mesopores with the pore width between 2 and 50 $\mathrm{nm}$ and micropores with the pore width smaller than $2 \mathrm{~nm}^{2}$. Among the unlimited possibilities of the porous world, mesoporous materials, amorphous or crystalline, have gained a significant amount of attraction due to their large internal surface and pore volume allowing them to host molecules of various morphologies and sizes ${ }^{3}$.

Mesoporous silica was first reported by researchers at Mobil Corporation in 1992 ${ }^{4}$, and they named this 'first of its kind' mesoporous silica MCM-X where MCM represents 'Mobil Crystalline Material' and X represents different structural properties within the same material group. The ordered porosity of this silica material was obtained by a liquid- 
crystal templating approach that enables the formation of silicate walls between the surfactant micelles with an ordered hexagonal pattern. As a result, cylindrical pores between the walls with a narrow pore size distribution are obtained ${ }^{3,4}$. Moreover, with its large surface and pore volume, mesoporous silica is very suitable for hosting various molecules and particles, and thus it is used in many applications such as catalysis, drug delivery, sensing, and separation ${ }^{5,6}$. The uniform and organized pores enable controlled loading and release of guest molecules depending on the nature of the attachment between the guest and the host ${ }^{5-9}$. They also show high thermal, chemical ${ }^{10}$ and mechanical stability and are therefore favorable for applications that require extreme conditions ${ }^{11}$.

\subsection{SBA-15}

SBA-15 was the next breakthrough in the field of mesoporous silica synthesis after MCM. This type of mesoporous silica was first reported in 1998 by Zhao et al. and named as SBA$\mathrm{X}$ where SBA stands for 'Santa Barbara Amorphous' and X stands for different pore structures and surfactants ${ }^{12}$. SBA-15 has similar hexagonal pore packing structure as MCM-41, but a larger tunable pore width and higher hydrothermal and chemical stability due to its thicker walls. These features make SBA-15 more popular compared to its MCM ancestors $^{6,12,13}$. Also among all the other SBA materials, SBA-15 is particularly attractive due to its highly stable structure offering flexibility in the synthesis conditions and possibilities to affect structural parameters such as particle morphology and pore size without destroying the SBA-15 structure ${ }^{14}$.

The morphologies of SBA-15 reported so far include rods ${ }^{15}$, fibers ${ }^{16}$, sheets ${ }^{17}$, spheres ${ }^{18}$ and hollow spheres ${ }^{10}$ (Figure 1). It has cylindrical pores with a cross-sectional diameter between 5-30 nm, although pore size above $11 \mathrm{~nm}$ is rare $^{12,19}$. Its mesopores are interconnected with micropores, which can constitute a significant portion of the total pore volume. For example, a microporosity of $50 \%$ has been reported by Hartmann et.al. and $15-30 \%$ by Björk et.al. ${ }^{14,20,21}$. SBA- 15 has been successfully used in various applications because of its combination of these interesting characteristics, e.g., a template, catalyst support, drug carrier, selective adsorbent etc ${ }^{11,14}$. 


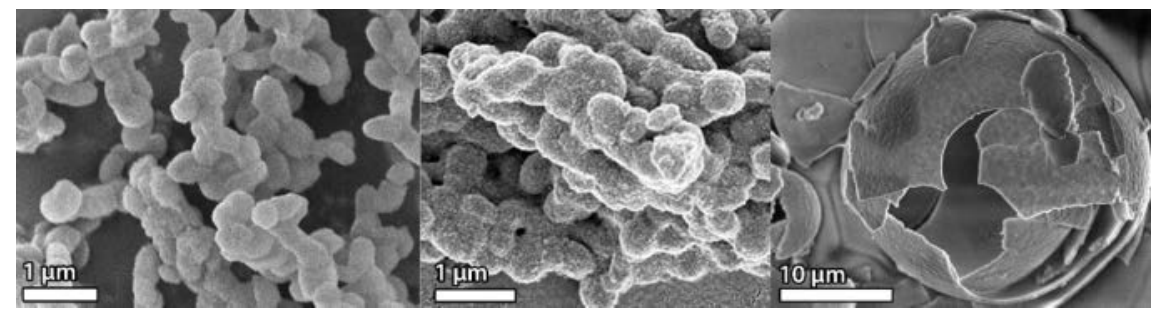

Figure 1. Different particle morphologies of SBA-15: small particles (left), long fibers (middle), sheets (right) ${ }^{16}$.

\subsubsection{SBA-15 synthesis}

SBA-15 is typically synthesized via a sol-gel technique where a solution, sol, of templating micelles is prepared at a suitable $\mathrm{pH}$ and then mixed with a silica precursor. As a result, a silica network forms through a series of hydrolysis and condensation reactions constituting a gel that typically separates from the solution. During hydrolysis, silicon hydrolizes and become silicic acid and then condenses to form Si-O-Si framework as seen in Eq. 2.1 and $2.2^{22}$.

During

Hydrolysis $\equiv \mathrm{Si}-\mathrm{OR}+\mathrm{H}_{2} \mathrm{O} \rightarrow \mathrm{Si}(\mathrm{OH})_{4}+\mathrm{ROH}$

Condensation $\quad \equiv \mathrm{Si}-\mathrm{OH}+\mathrm{HO}-\mathrm{Si} \equiv \rightarrow \mathrm{Si}-\mathrm{O}-\mathrm{Si} \quad+\mathrm{H}_{2} \mathrm{O}$

Upon condensation, a maturation period is typically needed and the final material is obtained after removal of the micelles.

For the modification of the morphological (pore or particle) characteristics, it is also possible to add salt and swelling agent into the synthesis solution.

The micellar solution is an aqueous solution of templating micelles which are based on surfactants. Surfactants are amphiphilic low molecular weight materials or block copolymers possessing a hydrophilic head group (ionic or non-ionic) and a hydrophobic non-polar chain. Due to this structure, they can self-assemble in an aqueous solution with a concentration that is above the critical micelle concentration. This self-assembly forms a liquid crystal in the end by creating water-oil interfaces within some degree of ordering ${ }^{23,24}$. 
For the synthesis of SBA-15, the surfactants mostly reported in the literature are Pluronics, $\mathrm{CTAB}$, and PEO surfactants. Pluronics are non-ionic block polymers made up of a polypropylene oxide block $(\mathrm{PO})_{\mathrm{x}}$ placed in the middle of two polyethylene oxide blocks (EO) . Pluronics, when combined with an acidic solution, form sphere-like micelles hiding the hydrophobic part in the center of the sphere and exposing the hydrophilic ends to the solution forming a corona ${ }^{25}$. Therefore the length of the chains can affect the shape and size of the micelles.

Among the pluronics, a symmetric block copolymer P123 (PEO-PPO-PEO) has been shown to yield a consistent and robust structure when synthesizing SBA-15 with different particle morphologies, including platelets and short rods with easily accessible pores ${ }^{21}$. Insitu SBA-15 synthesis studies have shown that P123 form spherical micelles which then open up to cylindrical structures as silica condensation proceeds and form cylindrical pores $^{15,22,26}$.

The silica precursor is typically chosen from alkoxides, which is mostly tetramethyl orthosilicate (TMOS) and tetraethyl orthosilicate (TEOS). Some studies also have reported sodium metasilicate to form the hexagonal SBA-15 structure ${ }^{20}$.

Additives can be used in the synthesis of SBA-15 and are typically salts or oils.

Salts can act as catalysts for SBA-15 synthesis affecting the reaction rate by changing the cloud point, and it can also decrease the critical micelle temperature. This occurs because a salt can change the solubility of the surfactants by its salting out or salting in effect. For example, when an anion, such as $\mathrm{F}^{-}$, is released to the synthesis medium by compound dissolution, it demonstrates salting out effect that leads to partial dehydration of EO chains and causes hydrophobic core enlargening inside the micelles ${ }^{16,25}$. Cations were shown to demonstrate a similar but weaker effect ${ }^{27}$. The salting out effect during SBA-15 synthesis is typically achieved with $\mathrm{F}^{-}, \mathrm{Cl}^{-}$or $\mathrm{I}^{-}$by using $\mathrm{NH}_{4} \mathrm{~F}$ or $\mathrm{NaI}$ salts and it leads to increased pore $\operatorname{size}^{25,28}$.

Swelling agents are organic materials such as alkanes, amines or substituted benzene compounds $\mathrm{s}^{29,30}$. When added to the synthesis solution, they can penetrate into the micellar structures and settle in the hydrophobic centre causing micelle swelling. During SBA-15 synthesis, since the micelle size determines the pore size, an addition of a swelling agent can directly affect the pore size ${ }^{31}$. Alkanes can increase the pore size to around $26 \mathrm{~nm}$ while maintaining the hexagonal pore order ${ }^{32}$. By changing the pore order, e.g., changing to 
MCF (mesostructured cellular foam), much wider pores can be obtained ${ }^{31}$. It was also shown that heptane could increase the pore size above $12 \mathrm{~nm}$ when used in a low temperature synthesis of SBA- 15 together with $\mathrm{NH}_{4} \mathrm{~F}$ salt ${ }^{21}$.

Hydrothermal treatment or aging, constitutes the maturation period of SBA-15. Hydrothermal treatment is a post-synthesis re-structuring procedure typically required in case of using non-ionic oligomeric surfactants, such as P123. Aging at high temperature, which is typically around $100^{\circ} \mathrm{C}$, causes dissolution-reprecipitation of $\mathrm{Si}$ atoms to the formed walls. During reprecipitation of the silicate species, they get rearranged to a more thermodynamically favorable position minimizing the surface energy, i.e., become smoother ${ }^{33}$.

Surfactant removal can be performed by a chemical assisted extraction method that involves stirring the freshly prepared SBA-15 with an oxidizing agent. However, a more straightforward method is calcination where the polymer is decomposed and combusted with air at high temperature, typically higher than $500^{\circ} \mathrm{C}^{34}$.

\subsubsection{SBA-15 modification routes}

SBA-15 has been modified with numerous types of different atoms, molecules and molecular groups as described in earlier reports. Many earlier studies focusing on modification of SBA-15 are based on physical mixing ${ }^{35}$, however, improved procedures can improve the interface between different components of hybrid materials that promote their activity in the target application ${ }^{36-38}$. The most common methods are in-situ incorporation $^{39-43}$, co-precipitation / deposition-precipitation ${ }^{4-48}$, post-grafting ${ }^{49,50}$, impregnation $^{51-55}$, incipient wetness impregnation ${ }^{31,42,56-58}$, and infiltration ${ }^{59,60}$. A crucial issue for almost all of these methods is to obtain uniform distribution of the modifier throughout the catalyst ${ }^{61}$. The selection of the proper method depends on the desired characteristics of the catalyst. For example, to prepare a Zr doped SBA-15, an in-situ incorporation technique can be used.

In-situ incorporation ${ }^{62-66}$ can be performed by adding the relevant precursor into the synthesis batch of a chosen material to induce doping. It is typically used to add functional groups or atoms into the framework of a matrix such as SBA-15. It was also shown for polymer growth in SBA-15 porous network ${ }^{67}$. For example, adding a precursor into the 
synthesis solution of SBA-15 right before the gel formation leads to a mesoporous heteroatomic network with $\mathrm{Si}, \mathrm{O}$, and the additional atom obtained from the precursor.

The impregnation ${ }^{67-69}$ method includes stirring of the main supporting matrix, e.g., SBA15, MCM-41, H-ZSM-15 with a precursor solution (e.g., a sulfate or nitrate salt), filtration, washing, and drying.

The Incipient Wetness Impregnation ${ }^{66,70,71}$ is a modified version of impregnation; however, due to the high level of interest by the research community and many reports focusing on this method, it deserves to be mentioned separately. It is, indeed, performed in a very similar way to impregnation technique except for the part where the same volume of precursor solution of the metal salt as the pore volume of the relevant porous material is used. The aim is to direct the metal ions into the pores such that out-of-particle aggregation is minimized.

Post-grafting g, $^{495,66,71,72}$ takes place when the SBA-15 is suspended in a precursor solution typically with a solvent like ethanol or toluene, stirred for a long time under high temperature, filtered, washed with the same solvent and dried at high temperature. The most significant differences between grafting and impregnation appears in the surface properties. During grafting the attachment of the guest to host occurs on a molecular level where chemical bonds are formed, while impregnation only causes deposition of the guest on the surface of the porous host. Grafting can be referred as a post-synthesis surface doping method.

Infiltration ${ }^{59,73}$ is a technique that focuses on the minimization of the outer-mesoporous particle attachment of the metal nanoparticles. For that purpose, the outer surface of the mesoporous particles is first passivated, and then the inner surface of the mesopores is activated with functional groups. The functionalization enables the metal ions to attach to the inner functional groups so the nanoparticles can grow only on the inside the pores. However, it is a challenging process, and in some cases, metal nanoparticles are still obtained on the outer surface of the mesoporous particles. 


\section{CATALYSIS}

\subsection{Industrial revolution and greenhouse gases}

The industrial revolution started in the 1760s in Britain with the discovery of new fuel sources and the development of new industrial processes replacing the hand-based production methods. This revolution was triggered by the invention of the steam engine by Thomas Newcomen in early 1700s, although there are records of using steam power for processing purposes in different parts of the world at earlier dates. The steam engine can provide steam power not only for industry but also for the transportation, and was typically achieved by burning fossil fuels such as coal, oil, and gas. A vast amount of energy could be released through the combustion of these fuels which were at that time abundant in nature. Consequently, the society became dependent on them. However, the fossil fuel combustion emits tons of $\mathrm{CO}_{2}$ and $\mathrm{H}_{2} \mathrm{O}$ to the atmosphere causing global warming and environmental changes ${ }^{7-76}$. Since that era, the concentration of $\mathrm{CO}_{2}$ in the atmosphere has been increasing rapidly, from $280 \mathrm{ppm}$ before 1750 to $400 \mathrm{ppm}$ in $2016^{77}$. The high concentration of $\mathrm{CO}_{2}$ can trap the heat and energy absorbed by earth from solar radiation and prevent the infrared radiation from earth back into space. This natural phenomenon is defined as the greenhouse effect, and it is well-known to be responsible for a rise in the earth's surface temperature, also referred to as global warming which leads to climate 
change, constituting a real threat to human and nature ${ }^{78-80}$. Global warming is also known to cause increased acidity and thus decreased the efficiency of the carbon sinks classified as land, forests, and oceans, which ultimately results in increasing $\mathrm{CO}_{2}$ accumulation and thus the global warming ${ }^{78,81}$. The probability of a catastrophe due to the greenhouse effect and global warming has triggered the society to take precautions and solid action plans for decreasing the concentrations of the greenhouse gases in the atmosphere. The most common greenhouse gases found in the nature are $\mathrm{CO}_{2}$, water vapor, $\mathrm{CH}_{4}$ and $\mathrm{N}_{2} \mathrm{O}$, chlorofluorocarbons (CFC) and hydrofluorocarbons (HFC) ${ }^{82}$. Among them, $\mathrm{CO}_{2}$ became the main anthropogenic greenhouse gas due to human activity ${ }^{83-87}$. The critically rising trend of $\mathrm{CO}_{2}$ concentration in the atmosphere can be reversed by adopting two types of strategies: (1) preventing the $\mathrm{CO}_{2}$ emissions and (2) utilizing the $\mathrm{CO}_{2}$ that is constantly being emitted by running processes, i.e., recycling ${ }^{84,88}$. The first strategy includes exchanging firmly established processes with new ones. This is a challenging task from a scientific (technical) point of view since it requires demolishment before rebuilding and therefore has high risks regarding industrial feasibility and financial balance of firms. The second strategy considered so far, has a better chance in surviving the economical limits of industry, since it includes only addition of a new process at the end of an existing production line in order to capture and convert $\mathrm{CO}_{2}$ into different sustainable products.

\section{$3.2 \mathrm{CO}_{2}$ utilization}

Elimination of $\mathrm{CO}_{2}$ from the environment by recycling emissions has three stages of action: (1) capture, (2) storage and (3) consumption/expenditure ${ }^{83,85,86,89,90}$.

$\mathrm{CO}_{2}$ capture involves mainly separation ${ }^{68}$ and collection of emitted $\mathrm{CO}_{2}$ from an industrial site or a natural source such as geothermic wells and delivering to a facility where it can be stored, typically in geological structures underground which is a rather established issue in these days ${ }^{76,89,91}$. It was shown that capture of $\mathrm{CO}_{2}$ on site has a higher efficiency than from the atmosphere because higher concentration facilitates capturing materials and techniques $^{62}$. The capture is typically done with the use of adsorbents such as amine solutions or hydroxides ${ }^{76,87}$. Capture and storage of $\mathrm{CO}_{2}$, as important as they are, do not constitute the ultimate solution of $\mathrm{CO}_{2}$ elimination but provide more of 'swipe under the rug' type of solution. Therefore, it is a crucial task to develop and improve processes where $\mathrm{CO}_{2}$ can be used up. 
Consumption/expenditure of $\mathrm{CO}_{2}$ as an eco-friendly, value-added chemical feedstock has attracted a great deal of attention among the scientific community to develop several innovative processes where $\mathrm{CO}_{2}$ is recycled and employed as a building block for producing hydrocarbons and alcohols ${ }^{68,82,92,93}$. However, $\mathrm{CO}_{2}$ is a poor reactant, and its activation is a challenging task due to its high thermodynamic stability originating from the fact that $\mathrm{CO}_{2}$ is the highest oxidized state of carbon ${ }^{68,87,94}$. At this oxidation state, carbon does not have any tendency of changing its chemical environment. In order to transform $\mathrm{CO}_{2}$, one needs to overcome its Gibbs energy of formation $\left(\Delta \mathrm{G}^{\circ}{ }_{298.15 \mathrm{~K}}=-394.4\right.$ $\mathrm{kJ} \mathrm{mol}^{-1}$ ), which means that a considerable amount of energy is required to be applied ${ }^{95}$. Therefore, it is important to develop techniques to catalyze this type of reaction with a proper mechanism and a suitable catalyst.

Several methods have been developed to break down $\mathrm{CO}_{2}$ through catalytic reactions and manufacture different organic compounds such as urea, salicylic acid, and various carbonates. $\mathrm{CO}_{2}$ is also used in certain applications in the food industry, dry cleaning and decaffeination of tea and coffee and most of these processes are commercially implemented ${ }^{82,87,91}$. Another well-established process to use $\mathrm{CO}_{2}$ as a reactant is RWGS (reverse water-gas shift) reaction where $\mathrm{H}_{2}$ is used to convert $\mathrm{CO}_{2}$ to $\mathrm{CO}$ (Eq. 3.1) which can then be used to produce several hydrocarbons like gasoline by employing the FisherTropsch process ${ }^{82}$.

A strong application candidate for $\mathrm{CO}_{2}$ expenditure is through a hydrogenation reaction which follows through an artificial photosynthesis mechanism ${ }^{76,96}$. Syngas $\left[\mathrm{CO}+\mathrm{CO}_{2}+\mathrm{H}_{2}\right]$ is an established reactant mixture for creating hydrogenation mechanism to produce valuable fuel candidates such as methanol and dimethyl ether $(\mathrm{DME})^{74,75}$. A similar mechanism can be used to convert pure $\mathrm{CO}_{2}$ in the presence of $\mathrm{H}_{2}$ and high pressure. During pure $\mathrm{CO}_{2}$ hydrogenation the RWGS (reverse water-gas shift reaction) ${ }^{68}$ also occurs due to its endothermic character causing formation of $\mathrm{CO}^{83}$.
$\mathrm{CO}_{2}+\mathrm{H}_{2} \leftrightarrow \mathrm{CO}+\mathrm{H}_{2} \mathrm{O}$ (3.1)
$\Delta \mathrm{H}_{(298 \mathrm{~K})}=41.2 \mathrm{~kJ} \mathrm{~mol}^{-1}$

The total reaction rate of $\mathrm{CO}_{2}$ hydrogenation strictly depends on the water gas shift reaction due to forming $\mathrm{CO}$ and $\mathrm{H}_{2} \mathrm{O}$ in the catalytic medium. The $\mathrm{CO}$ that is produced with RWGS can be a secondary C source for the targeted product (e.g., methanol), and can affect the reaction balance. $\mathrm{H}_{2} \mathrm{O}$ is another product of the targeted methanol formation process so additional $\mathrm{H}_{2} \mathrm{O}$ introduced by RWGS into the reaction environment 
can inhibit the reaction which makes the product removal very important. Moreover, the formed $\mathrm{CO}$ and $\mathrm{H}_{2} \mathrm{O}$ can be converted back to $\mathrm{CO}_{2}$ and $\mathrm{H}_{2}$ by a water-gas shift reaction (WGS), as the concentrations of the reactants decrease due to the main catalytic reaction, the WGS can be a reactant supplying mechanism. It was reported earlier by Skrzypek et al. that adding $\mathrm{CO}$ to the feed gas can increase the $\mathrm{CO}_{2}$ conversion due to consumed $\mathrm{H}_{2} \mathrm{O}$ and recovered $\mathrm{CO}_{2}$ by RWGS ${ }^{97}$.

The hydrogenation of $\mathrm{CO}_{2}$ is a catalytic reaction and can be done in a single-phase (homogeneous catalysis) or multi-phase (heterogeneous catalysis) manner ${ }^{98-100}$. It was shown in earlier studies that homogeneous catalysts had higher $\mathrm{CO}_{2}$ conversion performance compared to heterogeneous catalysts. However, the recovery and regeneration of homogeneous catalysts is much more difficult causing extra costs in larger scale, and thus not ideal ${ }^{68}$.

$\mathrm{CO}_{2}$ hydrogenation via heterogeneous catalysis typically follows three reaction steps: (1) reactant adsorption on the catalyst surface, (2) diffusion of the adsorbed molecules on the surface until attaching on an active site, (3) transformation until a stable phase is reached and (4) desorption of the final material. It is typically conducted in a fluidized bed, or fixed bed reactor, whereas batch reactor or stirred tank reactors are less common for this type of a reaction ${ }^{99,101}$. These reactions are typically conducted with metal-based catalysts such as $\mathrm{Co}, \mathrm{Fe}$, and $\mathrm{Cu}$ which is chosen according to the target product ${ }^{91}$.

The existence of many possible reaction pathways of a $\left[\mathrm{CO}_{2}+\mathrm{H}_{2}\right]$ mixture makes it crucial to control the reaction environment carefully, especially by providing a suitable catalyst that would realize the primary aim. This way, it is possible to reach a specific target product such as methanol and $\mathrm{DME}^{76}$.

\subsubsection{Methanol}

Methanol is an important and established chemical feedstock and solvent in different industries such as chemical, petrochemical, pharmaceutical, and polymer ${ }^{80,102,103}$. It is a critical alternative energy source which is not based on petroleum. It is a safe alternative fuel due to its soot or smoke-free burning characteristic. One risk of methanol to human life and health is its toxicity in case of oral consumption in large amounts ${ }^{74-76,83}$. Therefore 
it can replace the traditional fuels or can be used as an additive to traditional diesel or gasoline fuels due to its high octane number $(\sim 105)^{68,104}$.

Methanol, besides being a fuel, can also be used as a feedstock or intermediate for producing many different compounds. Another aspect of methanol has energy implications since it can be used to store hydrogen. Storage of hydrogen is otherwise a significant challenge due to a high risk of catastrophic combustion ${ }^{75,105}$, hence methanol storage constitutes a more safe way to store hydrogen ${ }^{83,104,106}$. As a result, many research groups have started to investigate direct methanol fuel cells (DMFC) ${ }^{76,102,107}$.

The first industrial-scale methanol synthesis used syngas as the feedstock for a hydrogenation process (BASF 1923) ${ }^{106,108}$ and methanol production from syngas is still used in the industry by $\mathrm{ICI}^{83}$. For many years, scientists focused on producing methanol from syngas due to a constant supply of syngas via the burning of fossil fuels. However, it is not an easy challenge since methanol is the least probable (thermodynamically) product of $\mathrm{CO}$ and $\mathrm{CO}_{2}$ hydrogenation. Typically higher alcohols and hydrocarbons demonstrate larger negative $\Delta \mathrm{G}^{0}$ values, and therefore they have a higher likelihood to be the final product of this type of reaction ${ }^{109}$.

CO was known as the primary source of methanol, but it was also essential to have a small amount of $\mathrm{CO}_{2}$ as a complementary to $\mathrm{CO}$, making syngas a perfect feed mixture for methanol production $88,96,99,102,106,110$. However, later on, an isotope labeling study showed that $\mathrm{CO}_{2}$ is the main carbon source of the synthesized methanol molecule and $\mathrm{CO}$ conversion to methanol proceeds through the $\mathrm{CO}_{2}$ intermediate, as confirmed by also other studies ${ }^{84,90,96,97,103,106,111}$. Due to this reason, also considering with the environmental concerns mentioned in an earlier section, hydrogenation of pure $\mathrm{CO}_{2}$ has become the focus of methanol production studies. During the $\mathrm{CO}_{2}$ hydrogenation into methanol (Eq 3.2), RWGS also runs as a parallel reaction. The forming $\mathrm{CO}$ then can either converted back to $\mathrm{CO}_{2}$ by water gas shift (WGS) reaction as in Eq 3.1 or can proceed with another route to form methano ${ }^{96}$. The reaction mechanisms are shown in Eq 3.2 and 3.3.

$$
\begin{array}{ll}
\mathrm{CO}_{2}+3 \mathrm{H}_{2} \leftrightarrow \mathrm{CH}_{3} \mathrm{OH}+\mathrm{H}_{2} \mathrm{O}(3.2) & \Delta \mathrm{H}_{(298 \mathrm{~K})}=-49.5 \mathrm{~kJ} \mathrm{~mol}^{-1} \\
\mathrm{CO} \text { (produced by RWGS) }+2 \mathrm{H}_{2} \leftrightarrow \mathrm{CH}_{3} \mathrm{OH}(3.3) & \Delta \mathrm{H}_{(298 \mathrm{~K})}=-90.8 \mathrm{~kJ} \mathrm{~mol}^{-1}
\end{array}
$$

These reactions may involve different intermediate steps and compounds depending on the reaction route driven by the catalyst surface. By using a catalyst consisting of $\mathbf{C u}$ as the 
main active phase, two main reaction routes for methanol synthesis from $\mathrm{CO}_{2}$ hydrogenation are presented in the literature ${ }^{106}$ which are formate/formyl route and hydrocarboxyl route ${ }^{12}$.

Formate/formyl route ${ }^{97,99,112-116}$ advances through the formation of HCOO (formate) by $\mathrm{CO}_{2}$ and a hydrogen atom which then continues by further addition of $\mathrm{H}$ atoms at each step. Finally, it forms methoxy $\left(\mathrm{CH}_{3} \mathrm{O}^{-}\right)$and then methanol. Formyl route proceeds in a very similar manner to formate route, but with an additional first step of $\mathrm{CO}_{2}$ conversion to $\mathrm{CO}$ by RWGS. In the next step, one molecule of $\mathrm{CO}$ merges with an $\mathrm{H}$ atom forming $\mathrm{HCO}$ (formyl) compound which is then further converted to methoxy and methanol. The basic schemes of these reaction routes can be found in Figure 3.1.

Hydrocarboxyl route ${ }^{112,114,117}$ advances through the formation of $\mathrm{COOH}$ (carboxyl) by $\mathrm{CO}_{2}$ and a hydrogen atom which then continues with the further addition of hydrogen atoms at each step. The basic schemes of these reaction routes are as below.

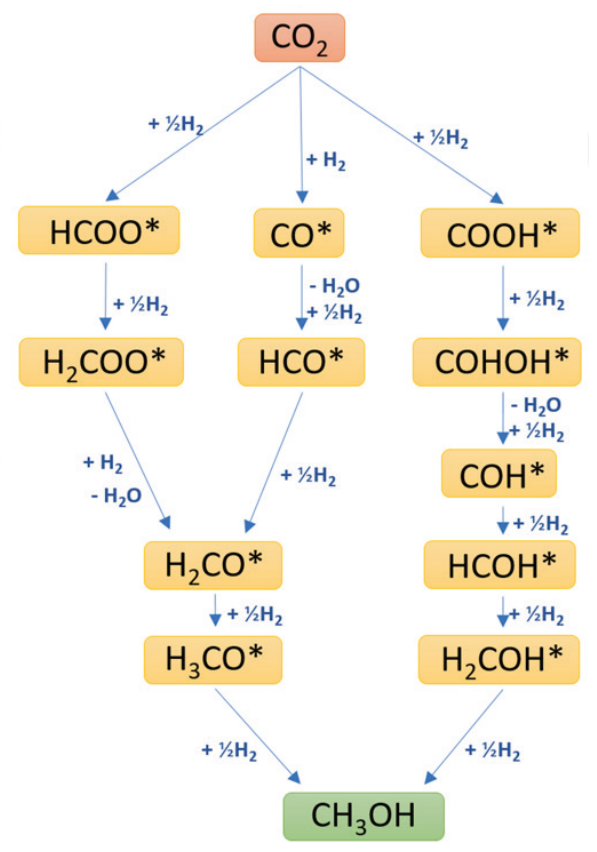

Figure 3.1- Formate/formyl and hydrocarboxyl routes of methanol formation from $\mathrm{CO}_{2}$ hydrogenation 
Among these two, formate route is the one that is mostly adopted in many studies since methoxy and formate were proven to be existent on the catalyst surface by infrared studies $^{68,111,118}$. Moreover, it was theoretically shown that the energy barrier of the $\mathrm{COOH}$ formation is much higher than HCOO, making it less likely ${ }^{112}$.

The methanol formation as a result of one $\mathrm{CO}_{2}$ molecule merging with three $\mathrm{H}_{2}$ molecules has a negative enthalpy indicating that it is an exothermic reaction ${ }^{68}$. Therefore, decreasing the reaction temperature, in principle, should favor the reaction to the products' side (methanol and water) but it is hardly the case due to the necessity of catalyst activation by a sufficiently high temperature ${ }^{68}$. The pressure, on the other hand, can be increased if one aims to increase the $\mathrm{CO}_{2}$ conversion according to the Le Chatelier principle since every 4 moles of reactants $\left[\mathrm{CO}_{2}+\mathrm{H}_{2}\right]$ gives 2 moles of products $\left[\mathrm{CH}_{3} \mathrm{OH}+\mathrm{H}_{2} \mathrm{O}\right]^{105,114,119,120}$.

So far, the scientific studies which employed syngas as the reactant, obtain methanol at temperatures between $200-450{ }^{\circ} \mathrm{C}$ and $30-100$ bar with a Cu-based catalyst ${ }^{84,97,99,110}$. The industrial-scale methanol production from syngas is performed by ICI (Imperial Chemical Industries, Ltd. $)^{121}$ at temperatures between $220-300{ }^{\circ} \mathrm{C}$ and pressure between $50-100$ bars using a $\mathrm{Cu} / \mathrm{ZnO} / \mathrm{Al}_{2} \mathrm{O}_{3}$ catalyst ${ }^{83,105,111,116}$. An industrial-scale methanol production from captured $\mathrm{CO}_{2}$ is currently conducted by at least two companies under similar conditions (temperature and pressure). The tow companies are CRI (Carbon Recycling International) in the George Olah facility on Iceland and Mitsui Chemicals Inc. in Osaka, $\mathrm{Japan}^{89,122,123}$. In this temperature range, thermodynamics is a limiting factor for this type of reaction due to its highly exothermic character. Without any recycling one-time pass $\mathrm{CO}_{2}$ conversion to methanol by hydrogenation reaction is thermodynamically limited to a maximum of $25 \%{ }^{115}$ and similarly at $200{ }^{\circ} \mathrm{C}$ and 50 bars theoretical $\mathrm{CO}$ conversion to methanol is around $20 \%{ }^{116}$. On the other hand, under milder conditions such as $250^{\circ} \mathrm{C}$ and 30 bar, the reported $\mathrm{CO}_{2}$ conversion to methanol with a $\mathrm{Cu}$ based catalyst is typically between $5-15 \%{ }^{84,90,124-128}$. The thermodynamic limitations can be overcome by making alterations on the process characteristics, such as removal of a product or recycling the unreacted feed gas. However, in order to accelerate the reaction, the most crucial element is the catalyst. The catalysts studied and used so far for methanol synthesis are typically $\mathrm{Cu}$ based material systems where $\mathrm{Cu}$ constitutes the active phase with a support and/or a promoter. 


\subsubsection{Dimethyl ether (DME)}

Dimethyl ether (DME) is a significant feedstock for hydrocarbon manufacturing industry and an environmentally benign alternative fuel as a replacement or an additive to liquefied petroleum gas (LPG) which can be used in household utilities or internal combustion engines in the automative industry ${ }^{76,82,85,129,130}$. Although it is volatile, DME is not toxic, not carcinogenic or mutagenic and therefore is already in use as a propellant and coolant $^{74,101,104,131}$. It has good combustion performance compared to traditional fossil fuels due to its high cetane index (around 55-60) 61,68,132. Moreover, it burns by emitting a quite low amount of $\mathrm{NO}_{\mathrm{x}}$ compound and without any soot or $\mathrm{SO}_{2}$ and producing almost no smoke ${ }^{68,101,130}$. The properties of DME are similar to those of LPG, and thus the delivery and storage means that are or can be employed for LPG are also suitable for DME transportation ${ }^{35,74,133}$. As a result of this ready infrastructure, DME is a quite attractive alternative fuel.

The main synthesis route of DME is catalytic dehydration of methanol as shown in Eq 3.4 ${ }^{85,134}$.

$2 \mathrm{CH}_{3} \mathrm{OH} \leftrightarrow \mathrm{CH}_{3} \mathrm{OCH}_{3}+\mathrm{H}_{2} \mathrm{O}(3.4) \quad \Delta \mathrm{H}_{(298 \mathrm{~K})}=-23.5 \mathrm{~kJ} \mathrm{~mol}^{-1}$

This reaction is typically catalyzed by a solid acid catalyst ${ }^{135}$. However, the surface acidity of a methanol dehydration catalyst is not a direct measure of the conversion to DME. It was determined that the acid site concentration could directly correlate to the value of methanol conversion to DME whereas this is not the case for the strength of these acid sites $^{132}$. A high amount of moderate strength/weak acid sites can selectively produce DME whereas high strength of the acidic sites can further convert DME to other hydrocarbons ${ }^{35,36,131,133}$. Sites with strong acidity can accelerate water poisoning of the catalyst surface and also attract coke ${ }^{35}$. A considerable amount of sites with moderate acidity was reported to have a better catalytic performance compared to highly acidic sites $^{68}$. It was also reported earlier that basic sites also play a role in methanol dehydration to DME along with the acidic sites ${ }^{133}$.

DME can also be synthesized via a direct hydrogenation route from $\mathrm{CO}_{2}$ or syngas ${ }^{135,136}$. This direct route, in reality, consists of two subsequent mechanisms. The first one is $\mathrm{CO}_{2}$ hydrogenation to methanol, or its surface adsorbed form called methoxy (Eq 3.2 and 3.3) and the second one is the dehydration of methanol to DME (eq 3.4). Methanol dehydration is not only a convenient method to produce DME, but a way to overcome the 
thermodynamic limits of methanol production from $\mathrm{CO}_{2}$ hydrogenation by consuming methanol which eventually increases the amount of $\mathrm{CO}_{2}$ converted to methanol ${ }^{96,133,136}$. However, direct DME production from $\mathrm{CO}_{2}$ hydrogenation is not straightforward. A reason for this is the fact that the second step of this direct route, i.e., DME synthesis by methanol dehydration, requires higher reaction temperature compared to the $\mathrm{CO}_{2}$ hydrogenation to methanol step. Another reason is that methanol synthesis from $\mathrm{CO} / \mathrm{CO}_{2}$ hydrogenation proceeds on a metallic (typically $\mathrm{Cu}$ based) catalyst whereas methanol dehydration to DME requires an acidic catalyst. The catalytically active sites for $\mathrm{CO}_{2}$ hydrogenation to methanol are on the metal-metal oxide interfaces and the ones for methanol dehydration to DME are surface acid sites ${ }^{36,61,68,82}$. It was also shown in earlier works that the traditional methanol catalyst $\mathrm{Cu} / \mathrm{ZnO} / \mathrm{Al}_{2} \mathrm{O}_{3}$ is not sufficient for methanol dehydration to DME and it requires a more acidic component such as a zeolite ${ }^{61}$. As a result, a smart catalyst with dual functionality needs to be designed to carry out such a multi-site reaction ${ }^{124,131,135,137}$.

It is suggested in some reports that for two methanol to dehydrate to one DME molecule, one methanol molecule needs to get adsorbed on the catalyst surface and become methoxy $\left(\mathrm{CH}_{3} \mathrm{O}^{-}\right)$on an acidic site. The second methanol molecule, on the other hand, needs to get protonated to form $\mathrm{CH}_{3} \mathrm{OH}_{2}{ }^{+}$on a basic site and then these two molecules merge to form $\mathrm{DME}^{36,136,138}$. However, it is still a topic of debate.

DME synthesis from methanol dehydration is typically performed under $250-400{ }^{\circ} \mathrm{C}$ temperature and pressures up to $10 \mathrm{bar}^{101,130,132}$. Depending on the reaction conditions, the methanol conversion to DME can exceed $90 \%{ }^{35,70}$. However, in a combined catalytic system which catalyzes both $\mathrm{CO}_{2}$ hydrogenation to methoxy/methanol and methanol dehydration to DME reactions, the $\mathrm{CO}_{2}$ conversion to DME strictly depends on the $\mathrm{CO}_{2}$ conversion to methanol which is the limiting factor.

\subsubsection{Catalysts for $\mathrm{CO}_{2}$ hydrogenation}

According to IUPAC, a catalyst is 'a substance that increases the rate of a reaction without modifying the overall standard Gibbs energy change in the reaction ${ }^{98}$. A catalyst can be used in a reaction, and yet not consumed. Although it can accelerate the reaction in a particular direction, it cannot alter the thermodynamically most stable outcome. The main activity of a catalyst originates from its surface active sites and their affinity to the reactants 
which leads to reactant adsorption on the catalyst surface irreversibly such that the desorption time is much longer than the reaction time ${ }^{106}$ and this way it promotes their transformation into products ${ }^{99}$. The conversion of the reactants to products does not typically occur in one step but rather through a series of reactions via several unstable intermediates at the catalyst-reactant interphase. In the final step, the products are formed ${ }^{99}$. Besides being catalytically active, a catalyst also needs to be stable, easy-toproduce and cheap to maintain ${ }^{87}$.

There are many catalytically active elements that have been studied for heterogeneous catalysis of $\mathrm{CO}_{2}$ hydrogenation process, and the selection of one or two of these elements depend mostly on the desired product. $\mathrm{Ru}^{100}, \mathrm{Rh}^{139}, \mathrm{Pd}^{59,88,140}, \mathrm{Ir}^{59}$ and $\mathrm{Pt}^{140}$ based catalysts have been investigated widely due to their high efficiency in dissociating $\mathrm{H}_{2}$ and the fact that they are more coke resistant ${ }^{59,68,80}$. However, $\mathrm{Cu}, \mathrm{Ni}$ and Co-based catalysts maintained their popularity due to their low cost-to-yield ratio ${ }^{68}$. As for the products of the $\mathrm{CO}_{2}$ hydrogenation process, $\mathrm{Cu}$ based catalysts ${ }^{46,53,59,84,86}$ can yield $\mathrm{CO}$, various hydrocarbons such as gasoline, alcohols and fuels like methanol and dimethyl ether via methanol route ${ }^{68}$ whereas $\mathrm{Ni}$ or Co-based catalysts mostly yield methane ${ }^{68,141}$. Dimethyl ether production mainly depends on the acidity of the final catalyst. Thus, the way of $\mathrm{Cu}$ couples with the other species in the material systems that constitute the catalyst such as supports and promoters is crucial.

The fabrication of combinations of different atoms or molecules that will act as the primary units of a catalyst assembly has been dominated by co-precipitation ${ }^{37,46,61,120}$ technique, also referred to as deposition-precipitation. For example, in the case of producing a $\mathrm{Cu}$ catalyst together with a promoter such as $\mathrm{ZnO}$, one has been typically chosen to prepare the catalysts by co-precipitation such that both phases are in contact as nanoparticles ${ }^{61}$. This method is typically used for an assembly with no inter-particular pores but instead intra-particular voids. It is done by stirring a batch of promoter in a solution of the relevant precursor using a predetermined amount corresponding to a monolayer of coverage. The final material is typically obtained by direct evaporation under vacuum. Co-precipitation is the most common method of preparing $\mathrm{Cu} / \mathrm{ZnO}$ based catalyst for methanol production from syngas ${ }^{83}$. This method can be coupled with an ultrasonic treatment stage to improve the dispersion ${ }^{131}$. Deposition-precipitation is conducted via vigorous stirring of the support material with the relevant metal solution with an assisting material such as urea or ammonia, followed by solvent evaporation by heating and calcination. It can also 
be referred to as evaporation-induced wetness impregnation in case water is used as solvent with no other chemical aid. On the other hand, in case of porous supporting material usage, different methods such as infiltration or impregnation can also be used as described in Section 2.2.2 where SBA-15 modification techniques were described.

$\mathrm{Cu}$ based catalysts, as clear by the name, contain $\mathrm{Cu}$ as their main component in combination with promoters and supports ${ }^{68,81} . \mathrm{Cu}$, in metal form, was discovered to be active in adsorbing and dissociating $\mathrm{CO}_{2}$ and thus it is catalytically active for methanol production through hydrogenation of $\mathrm{CO}_{2}{ }^{68,99,142}$. $\mathrm{Cu}$ has shown the highest methanol yield from $\mathrm{CO}_{2}$ hydrogenation among other metals ${ }^{96}$. On the other hand, $\mathrm{Cu}$ has been the focus of methanol synthesis studies not only due to this high catalytic activity but also due to its low price, ease of handling and low risk to human health (toxic effects appear only if it is ingested in large amounts $)^{52,68}$.

The catalytic activity of $\mathrm{Cu}$ was earlier attributed to its metal phase, and the metallic surface area of $\mathrm{Cu}$ was claimed to be directly proportional to the catalytic activity ${ }^{68}$, however later it was discovered that also the +1 oxide state is required which corroborates with the metal phase for catalyzing $\mathrm{CO}_{2}$ conversion due to their synergistic effect ${ }^{84,143}$. Freshly synthesized $\mathrm{Cu}$ nanoparticles are typically a mixture of various oxidized forms of $\mathrm{Cu}$, and unlike the reduced $\mathrm{Cu}$ metallic state, oxides are stable upon exposure to air. Therefore, storing and transporting catalysts comprising of $\mathrm{Cu}$ nanoparticles in oxidized form is a good strategy from a stability point of view. The $\mathrm{Cu}$ oxides on the material can be reduced to get +1 oxide $\left(\mathrm{Cu}_{2} \mathrm{O}\right)$ and metal forms right before usage in $\mathrm{CO}_{2}$ hydrogenation reaction $^{102}$.

The phase of the catalytically active species is not the only yield-determining parameter. There are other factors contributing to the activeness of the catalyst such as metalpromoter relationship ${ }^{46,83,84,131,144}$. In the following section, promoter types will be reviewed.

Promoter ${ }^{53,68,86,99}$ is a modifier which can enhance the activity of a catalyst material, either by enhancing the activity of each site or increasing the number of active sites. The synergistic effect of multi metal oxide systems can improve the number of the active sites on the catalyst by introducing additional interface ${ }^{46,90,109,111,145}$. It was reported earlier that pure $\mathrm{Cu}$ is not sufficiently active to catalyze methanol formation through $\mathrm{CO} / \mathrm{CO}_{2}$ hydrogenation ${ }^{143,146}$. Therefore, it is crucial, from the activity and selectivity point of view, 
to complement $\mathrm{Cu}$ with a suitable promoter to boost the $\mathrm{CO}_{2}$ conversion efficiency. The choice of the promoter depends on the type of reaction and the targeted yield, selectivity, and conversion. More than one promoter can be used for a synergetic effect. In some instances, one promoter can also show both textural and electronic effects on the active phase. The supporting materials investigated so far are mainly binary and ternary oxides with different composition and morphologies. The most common reported promoters for $\mathrm{Cu}$ active phase in a heterogeneous catalysis of $\mathrm{CO}_{2}$ hydrogenation to methanol and DME are $\mathrm{ZnO}, \mathrm{Al}_{2} \mathrm{O}_{3}, \mathrm{TiO}_{2}$, zeolites, $\mathrm{ZrO}_{2}$ and $\mathrm{SiO}_{2}{ }^{68,99}$.

Zinc oxide $(\mathrm{ZnO})$ is the most preferred electronic promoter for the $\mathrm{Cu}$ active phase for $\mathrm{CO}_{2}$ hydrogenation reaction due to reports indicating its high efficiency ${ }^{136}$. This promoter is currently used in the commercial $\mathrm{Cu}$ catalyst for methanol production from $\mathrm{CO}_{2}$ hydrogenation and also used in many scientific studies due to its beneficial properties for $\mathrm{Cu}$. $\mathrm{ZnO}$ was observed to increase the dispersion and stability of the $\mathrm{Cu}$ metal phase and also contribute to the catalytic activity since the $\mathrm{Cu}-\mathrm{Zn}$ interface is active for this type of reaction $^{68,83}$. However, this hydrophilic phase can be quickly inhibited due to water produced during methanol and DME synthesis ${ }^{84,135}$.

Alumina $\left(\mathrm{Al}_{2} \mathrm{O}_{3}\right)$, is the most common support used for $\mathrm{Cu} / \mathrm{ZnO}$ catalyst system for $\mathrm{CO}_{2}$ hydrogenation to methanol ${ }^{36}$. It provides stability to the metal/oxide compounds ${ }^{83}$. However, it was also reported that due to its high concentration of Lewis acid sites, it attracts water and causes early deactivation of the catalyst ${ }^{90,136}$. On the other hand, due to its high surface acidity, $\mathrm{Al}_{2} \mathrm{O}_{3}$ is also known to catalyze methanol dehydration to $\mathrm{DME}$ and other hydrocarbons ${ }^{68}$.

Titania $\left(\mathrm{TiO}_{2}\right)$, is typically used as a photocatalyst due to its redox property in the photoexcited state inducing water splitting reaction ${ }^{147-150}$. $\mathrm{TiO}_{2}$ has been reported to catalyze $\mathrm{CO}_{2}$ hydrogenation to produce methanol, alone or, as a promoter to improve the selectivity towards methanol by contributing to active metal sites ${ }^{81,96,151}$. It was also used as an additive to $\mathrm{Al}_{2} \mathrm{O}_{3}$ to improve the catalytic activity by minimizing the coke formation during the reaction. However, it requires a quite high temperature to operate at its optimum and therefore was never the primary choice for this reaction ${ }^{136}$.

H-ZSM-5 has been typically used for methanol dehydration to DME as well as hydrocarbon formation due to its surface acidity ${ }^{36}$. However, due to possessing small pore diameter, H-ZSM-5 has a limited diffusion into the porous network ${ }^{136}$. 
Zirconia $\left(\mathrm{ZrO}_{2}\right)$, with its high stability under severe conditions (such as high $\mathrm{T}$ and $\mathrm{P}$, reducing and oxidizing environments), is a very promising binary oxide catalyst support ${ }^{68}$. $\mathrm{ZrO}_{2}$ was also shown to increase the catalytic efficiency of the active $\mathrm{Cu}$ phase for producing methanol by both syngas and pure $\mathrm{CO}_{2}$ hydrogenation reactions ${ }^{37,120,136,142}$. The promotive effect of zirconia is mainly due to its ability to increase the dispersion of $\mathrm{Cu}$ metal and improve the active surface by providing additional sites on the catalyst system, both acid and base ${ }^{37,68,86,90,99,142,144,152,153}$. Zirconia was also shown to be better catalyst support compared to alumina due to its lower hydrophilicity since water poisoning of the catalyst is a bottleneck of such a reaction ${ }^{90}$. It can also ease the reduction capacity of $\mathrm{CuO}^{135}$, and it has an affinity to $\mathrm{CO}_{2}$ and thus can chemisorb and coordinate. This $\mathrm{CO}_{2}$ affinity leads to carbonate formation on the $\mathrm{Zr}$ surface, and therefore it constitutes the perfect couple for the hydrogen coordinating $\mathrm{Cu}^{68,91,154}$.

According to earlier reports, the catalyst systems with $\mathrm{ZrO}_{2}$ are typically composed of randomly shaped nanoparticles of oxides prepared with co-precipitation method and therefore has exhibited only up to $200 \mathrm{~m}^{2} / \mathrm{g}$ specific surface area ${ }^{86,144,152,155,156}$. However, studies that focus on testing different morphologies and states of zirconia to improve the support/promoter properties are very rare.

Silica has been reported as a high stability support for $\mathrm{Cu}$ active phase to be used in various hydrogenation and dehydration reactions ${ }^{46,68,99,157}$ and it was shown to increase the methanol yield through $\mathrm{CO}_{2}$ hydrogenation by providing additional positive surface charge due to the $\mathrm{Cu}-\mathrm{SiO}_{2}$ bonds at the interface ${ }^{106,158,159}$. Mesoporous silica can be prepared with a very high specific surface area (can be more than $700 \mathrm{~m}^{2} / \mathrm{g}$ ) and uniform pore size distribution enabling improved dispersion and controllable particle size of the active phase nanoparticles ${ }^{53,59,147}$. High surface area of the support is beneficial not only to obtain a large catalytically active metal surface but also for keeping the active sites isolated from each other which can otherwise interact with each other instead of gas phase reactant molecules ${ }^{99}$. It was demonstrated in an earlier study the proximity between active sites can cause interaction hindrances and thus diminish the activity of the catalyst ${ }^{118}$ and since metals such as $\mathrm{Cu}$ tend to agglomerate in order to minimize their surface energy, choosing a favorable environment such as mesoporous silica for supporting $\mathrm{Cu}$ is crucial. The pores of mesoporous silica act as nano-shelters for $\mathrm{Cu}$ nanoparticles to prevent melting and sintering under high temperature ${ }^{46,68,145,160}$. On the other hand, silica can also be functionalized or doped with different atoms or molecules enabling functional 
Catalysis

modifications ${ }^{99}$. The most common mesoporous silica types reported as catalyst support for $\mathrm{Cu}$ are MCM-41 and SBA-15 46,51,52,57,59,71,158. 


\section{DRUG DELIVERY}

The term 'drug delivery' describes the means and methods of drug administration into the body for a targeted therapeutic outcome. Controlled drug delivery has been in focus with increasing interest in the last decades due to the possibility to individualize therapies and ease dose compliance with the ultimate goal of ensuring patient comfort especially when they are life-long such as insulin administration for diabetes ${ }^{161,162}$. Controlled drug delivery primarily relies on ensuring the administration of the right amount of a chosen drug to a target organ with the right dosage by enabling gradual release over time ${ }^{163}$.

A pharmaceutical drug is the formulation of an active ingredient (drug) in its suitable dosage form and selecting an efficient and safe drug delivery system for this dosage form is a crucial factor for determining the pharmacological action of a drug and thus tuning the therapeutic profile ${ }^{164}$. Administration of a drug delivery system should also be safe, reliable and repeatable ${ }^{165}$. Development of drug delivery systems, which can entrap the drug molecules within their structure due to their target-specific morphology, is considered as an important topic not only in the development of an effective disease therapy but also in different areas such as food/cosmetic industry as well as gene delivery ${ }^{166}$. In some applications, it is also possible to load the drug in a carrier and charge it on an implant which is then placed into the body, e.g., dental or hip implants ${ }^{164,167}$.

A suitable carrier can improve the drug dissolution in the body ${ }^{69,168}$ by modulating the three main parameters of a release: location of the relevant site, drug concentration at this site (i.e., release rate) and duration of a chosen drug concentration at this site ${ }^{165,169}$. The 
drug concentration at the target site should be within the therapeutic range which is defined as the region between the minimum effective concentration (MEC) and the minimum toxic concentration (MTC) ${ }^{165}$ against a particular microbiological agent. Drug support can also provide protection for this therapeutic molecule under severe conditions such as rapid $\mathrm{pH}$ change on the gastrointestinal tract ${ }^{166}$ and for ensuring a shelf life of a minimum two years for the drug it is carrying.

Drug delivery mechanism of a carrier can be qualified by its drug loading capacity and drug release profile. Drug loading capacity represents the amount of drug held by the unit weight of its carrier under certain loading conditions. Drug release profile is the timedependent evolution of accumulated drug concentration in a release medium.

\subsection{Drug delivery systems}

Drug delivery systems can be classified through different parameters. The classification can be made according to the physical state of the drug carriers which includes solid, semisolid (i.e., ointment), liquid or gaseous, or possibly multiphasic systems ${ }^{165}$. Drug delivery systems can also be classified according to their route of administration which can be oral, parenteral (intravenous or intramuscular), transdermal (topical or rectal) or aerosol ${ }^{164}$. Drug administration from implants is considered as parenteral administration route. This method presents a unique advantage by enabling local drug delivery straight to the therapeutical site, which overcomes several challenges related to the conventional administration routes. For example, oral administration is well known to require quite high dosages of the drug to be able to reach the target site at desired concentrations. Another type of classification is based on the release profiles (Figure 4.1) which can be separated into two main branches referred as immediate release and modified release. Immediate release is the most conventional type of release profile that occurs by dissolution of the drug to the medium in a single and rapid action causing the drug concentration to quickly reach a maximum in the blood plasma and then to decrease. This profile is typically found in conventional oral dosage forms (e.g., paracetamol pills). Modified release, on the other hand, involves the release of a drug in a delayed or extended manner. Delayed release allows the release of a drug with a certain delay after administration of the drug. Extended release can be performed by either sustained release which enables release over time or by controlled release which extends the release in such a way that the drug concentration level in the plasma stays constant during a chosen duration ${ }^{165}$. 


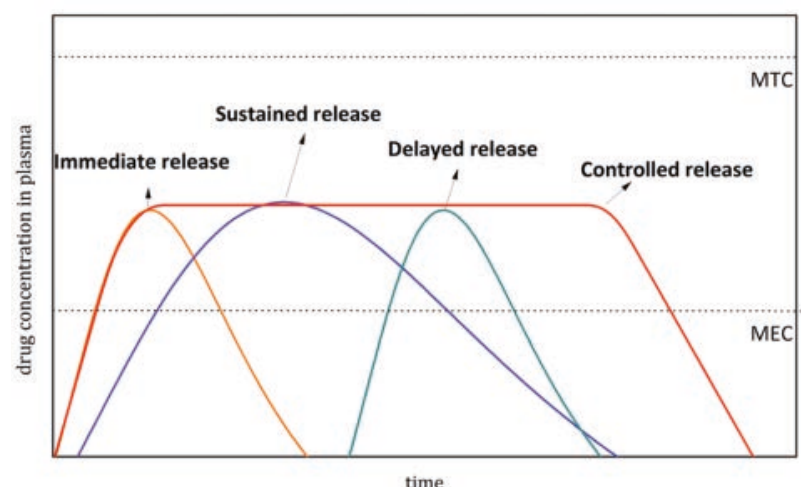

Figure 4.1. Drug release profiles

Controlled drug delivery systems are capable of maintaining a constant drug concentration in the release medium, i.e., relevant site of the body, for the adequate time frame required for the therapy. Thus, a significant amount of research on pharmaceutical technology has been devoted to this issue. The controlled drug delivery has been mostly concentrated on polymeric materials and also some hybrid inorganic material systems ${ }^{5}$.

In controlled drug release, many strategies have been employed such as varying the morphology or physicochemical properties of the drug carrier to achieve good control over the release kinetics. Also functionalizing drug carriers is a significant strategy for enhancement of the drug-carrier interactions and thus limiting the drug release rate $^{166}$.

\subsection{Drug release models}

Drug release profiles strictly depend on the behaviour of the drug carrier in the release medium which can either be biodegradable or biostable (un-dissolving) ${ }^{170}$. The diffusioncontrolled systems typically employ un-dissolving drug carrier ${ }^{171}$, and several theories/kinetic models can be used to describe this type of release from immediate and modified release dosage forms ${ }^{172}$. Most of these models are based on Fick's diffusion equation under proper boundary conditions, and the most significant models for nondegrading drug delivery systems include zero-order release, first-order release, Higuchi, Korsmeyer-Peppas, and Weibull ${ }^{170}$.

Zero-order release ${ }^{173}$ is only valid when the drug release rate is constant, i.e., release rate is independent of the drug concentration in the release medium. It represents a linear drug accumulation over time where the release time is 'infinitive' ${ }^{171}$. 
$M_{0}-M_{t}=k_{0} t$

where the $M_{t}$ is the amount of drug released in time $t, M_{0}$ the initial drug amount, and $k_{0}$ the zero order release constant.

First-order release ${ }^{173}$ is valid when the release rate is dependent only on the drug concentration in the release medium.

$\ln \left(\frac{M_{0}}{M_{t}}\right)=k t$

where the $M_{t}$ is the amount of drug released in time $t, M_{0}$ the initial drug amount, and $k$ the first order release constant.

Higuchi model ${ }^{5,170,174}$ is valid when the drug is homogeneously distributed in a nondegradable drug delivery system which acts as a planar surface (monolithic delivery). It is good at estimating the cases where the drug concentration is much higher than the solubility limit of the drug.

$M_{t}=k_{H} t^{1 / 2}$

$k_{H}=\left[2 D c_{\text {ini }} c_{S}\right]^{1 / 2}$

where the $\mathrm{M}_{t}$ is the amount of drug released in time $t, \mathrm{k}_{\mathrm{H}}$ the Higuchi dissolution constant, $\mathrm{D}$ the diffusion coefficient, $c_{\text {ini }}$ the initial drug concentration in the medium and $\mathrm{c}_{\mathrm{s}}$ the drug solubility.

Korsmeyer-Peppas model ${ }^{5,170,173}$ is a more comprehensive model for drug release from a matrix. It represents diffusional release and typically used for polymeric systems.

$\frac{M_{t}}{M_{\infty}}=k t^{n}$

where the $M_{t}$ is the cumulative released drug mass at a time $t, M_{\infty}$ the cumulative released drug mass at the time infinity (maximum released amount), $k$ the release rate constant, $t$ release time, and $\mathrm{n}$ the release exponent. The release exponent here mentioned hints whether the release follows Fick's law or displays a more complex behavior.

Finally, Weibull model ${ }^{175,176}$ is typically suitable for drug release from a matrix where the diffusion is in effect. It was earlier shown that this model can fit a release profile from mesoporous silica materials where not only diffusional release took place, but also desorption ${ }^{177}$. 
$\frac{M_{t}}{M_{\infty}}=1-e^{-k\left(t-t_{l}\right)}$

where the $M_{t}$ is the cumulative released drug mass at a time $t, M_{\infty}$ the cumulative released drug mass at the time infinity (maximum released amount), $\mathrm{k}$ the rate constant, and $\mathrm{t}_{1}$ the lag time for a dissolution process.

\subsection{Drug supports: nanocarriers and antibacterial agents}

Pharmaceutical nanotechnology is a new area focusing on the development of drug delivery vehicles with advanced properties ${ }^{178}$ in nano-level, i.e., nanocrystalline and nanostructured materials.

One of the main aims of this discipline is to achieve nano-sized or atomic level modifications to the previously studied drug delivery systems in order to improve drug bioavailability and develop more patient-friendly treatments by reducing the total dosage and side effects ${ }^{7,164,179}$. There are many nanotechnological drug delivery systems studied so far, including inorganic materials (such as silica, carbon, metals or polymers) as well as biological agents (such as chitosan) $)^{180}$.

Nanoparticles, meanwhile, came to attention of the scientific community due to their high stability in the release medium ${ }^{5,181}$, high surface-to-volume ratio leading to high adsorption capacity not only for drugs but also for genes, proteins, and probes ${ }^{7,182}$, small enough size to penetrate into the smallest blood vessels and cells and still deliver a suitable amount of drug ${ }^{164,169,180}$, controllable morphology and surface properties, and their biocompatibility ${ }^{164,180}$. Economically they are favorable too since the same nanoparticle synthesis method can be used to produce different morphological properties and also they might be applied in many drug administration routes including oral, intravenous or topical and even for drug storage $e^{69,161,165}$.

Mesoporous materials became popular as drug delivery matrices due to their high surface area and pore volume, narrow pore size distribution and pore size range of 2-50 $\mathrm{nm}$ which is suitable for hosting many different sized drug molecules ${ }^{183,184}$. They are not only suitable for drug delivery, but also for long-term drug storage . $^{5}$

Mesoporous silica has been proposed as an active drug delivery system due to its biocompatibility ${ }^{65,176,183}$. Its ordered network of bi-axially aligned pores covered with 
silanol groups provide controllable mass transfer of fluids into and out of the ordered network, enabling good control of drug loading and release ${ }^{8,183}$.

Silica sol was primarily studied as a drug carrier. However, mixing the drug molecules yielded unhomogeneous distribution of the drug in the carrier which resulted in inconsistent release profiles between different batches ${ }^{5,185}$. Mesoporous silica has been a good biocompatible alternative to the traditional systems due to its high hydrolytic stability $^{186}$.

The use of mesoporous silica for drug delivery studies was pioneered by Vallet-Regi et al. with a report from 2001 where they showed the drug delivery feature of MCM-41 ${ }^{185}$. Mesoporous silica is a suitable candidate as a drug delivery system due to its ordered pore packing structure, high specific surface area, and large pore volume as well as its convenience of surface functionalization due to silanol rich domain ${ }^{183}$. They can accommodate drugs with a hydrophobic and unstable character as well as the ones for which the cellular uptake is a challenge, such as the cancer drugs ${ }^{7}$. They are also favorable candidates for targeted delivery by functional groups which require the porous system in an entirely homogenous structure ${ }^{183}$. After MCM-41, larger pore mesoporous silica types such as SBA-15, SBA-16, and SBA-1, as well as hollow mesoporous silica spheres were evaluated as drug carriers, but due to good control over the characteristics, the focus stayed on SBA- $15^{5}$.

SBA-15 is a bioactive molecule with a pore size range of 5-15 nm and therefore has a considerable potential for hosting large drug molecules ${ }^{5,183}$. Its well-defined cylindrical pores are packed in a hexagonal order, and they run parallel to each other which is a perfectly aligned morphology for controlling the drug loading and release behaviour ${ }^{65,177,182}$. These properties are similar for MCM-41, which was the start of many drug release studies. However, there are some reports suggesting lack of bioactive property of MCM- $41^{5}$ unless functionalized with a biocompatible element such as phosphorus ${ }^{5,187}$. Moreover, the presence of -OH end groups on the well-defined surface of the SBA-15, its high specific surface area, and pore-connectivity make SBA-15 favorable for loading and controlled release of a drug depending on the ionic attractions ${ }^{5,184,188}$. SBA-15 has especially shown to interact with positively charged molecules, but even without strong electrostatic forces, it can still hold a considerable amount of a drug by physical mixing and capillary forces due to its extensive porous network ${ }^{7,69,189}$. Therefore SBA-15 is quite advantageous for drug delivery applications. SBA-15 has good hydrothermal and chemical 
stability which enables long-term survival under harsh body conditions such as rapidly changing $\mathrm{pH}^{5}$. Bulky mesoporous structures were earlier determined to be limited to their capacity of the drug amount they can carry. For this reason, some studies are leaning towards hollow mesoporous spheres which perform as a reservoir system during the diffusional drug release ${ }^{171,183}$. Therein, a high pore volume and large SSA material such as SBA- $15^{190}$ with homogenous monodispersed rod morphology can spare the scientists from developing hollow structures which typically have exhaustive multi-step synthesis routes and a great challenge to have a good synthesis yield with homogeneous powder morphology $y^{191,192}$.

It has been shown in earlier studies ${ }^{16,21}$ that there are several ways of modifying the adsorption performance of SBA-15 by altering physicochemical properties of SBA-15, and this can provide good control over the drug release kinetics. Moreover attaching functional groups on its $-\mathrm{OH}$ terminating surface is a very convenient way to increase the drug attachment ${ }^{193}$. One very significant functional group studied so far is amine group $\left(\mathrm{NH}_{2}{ }^{-}\right)$ which has influence on the drug loading potential and release behavior of SBA-15,188,194,195. It was shown before that amino functionalized SBA-15 is capable of a zero-order release which can be favorable especially for local delivery of drugs to repair bone defects ${ }^{183}$. In some cases, functionalization can be comprised of certain chemical groups that control the pore openings and regulate the encapsulation as well as the release of the drug loading ${ }^{190}$. These chemical groups can respond to different stimuli such as lights, $\mathrm{pH}$ or temperature and can change their configuration and they are referred as gate-keepers or gate-like ensembles ${ }^{65,183,196,197}$. This type of functionalization can become quite critical when a sensitive tuning in targeted delivery is required, especially in treatments such as cancer ${ }^{186}$.

Moreover, SBA-15 is a potential dental filler which is promising for local delivery in dental applications involving dental composites ${ }^{198}$. It has been a common practice to utilize spherical nonporous silica particles as dental fillers in the composite materials ${ }^{199}$. The idea of using porous glass fillers was first introduced in 1976 by Bowen et.al. ${ }^{200}$. Later it came to attention that the large pores of SBA-15 can host molecules with a wide range of sizes and morphologies and can release them into a suitable medium by diffusion ${ }^{5}$. The high pore volume and large specific surface area of SBA-15 allow minimization of the amount of SBA-15 powder to be loaded in a dental composite since this concentration variable is also directly proportional to the collective toxicity of the drug delivery system ${ }^{183}$. Also, it was 
shown earlier that SBA-15 and MCM-48 allow the formation of an apatite-like layer which also indicates a potential use in implantology ${ }^{10,167}$.

The kinetics of the release from a mesoporous network depends a lot on the morphology and physical properties of the carrier material. Although this was investigated in earlier studies, some more research devoted to this is of interest, since kinetics can be much different when the material demonstrates considerably larger pores but also the high specific surface area. There is no universal view in the literature regarding the drug release kinetics of mesoporous silica, and earlier reports have revealed different release profiles. In these studies, it has been shown that the kinetics of the drug release from mesoporous silica can follow Korsmeyer-Peppas model ${ }^{5}$, zero order release ${ }^{201}$ or Higuchi model ${ }^{5}$ depending on the system. On the other hand, there are also many studies which indicate that there are two phases of drug release from mesoporous silica and therefore such a model needs two exponential terms to form the formula to represent different phases. The first phase is typically a burst release of the drug molecules that are free in bulk form within the carrier without being adsorbed to the carrier (physically encapsulated molecules) and the second phase is where the adsorbed molecules of the silica walls are desorped (chemically encapsulated molecules) ${ }^{163,202,203}$. The drug-drug interactions are dominant in the first phase whereas drug-carrier interactions become dominant in the second phase ${ }^{203}$. Depending on the electrostatic attraction between the drug and the carrier mesoporous silica, the significance of these phases can change, e.g., with a type of a drug weakly attached on the silica surface, the second phase can be ignored or not existent ${ }^{202}$. A double exponential function (Eq. 4.7) was reported by Demuth et al., which can be observed to be based on Weibull model, to explain this two-phase behavior for a cationic dye attached on a mesoporous silica ${ }^{5,203}$.

$\frac{M_{t}}{M_{\infty}}=P_{1}\left(1-e^{-k_{1} t}\right)+P_{2}\left(1-e^{-k_{2} t}\right)$

where the $M_{t}$ is the cumulative released drug mass at a time $t, M_{\infty}$ is the cumulative released drug mass at the time infinity (maximum released amount), $\mathrm{P}_{1}$ and $\mathrm{P}_{2}$ are the percentages released during phase 1 and $2, \mathrm{k}_{1}$ and $\mathrm{k}_{2}$ are the release rate constant of phase 1 and $2^{203}$. It was also observed earlier that for certain mesoporous silica-drug molecule coupling, the absorption could be strong enough not to allow full release of the loadings ${ }^{5}$.

Zirconia $\left(\mathrm{ZrO}_{2}\right)$ is a biocompatible inorganic ceramic material which shows high stability under high temperature, pressure, oxidizing environments and changing $\mathrm{pH}$ conditions 
and thus it is being investigated for bone implant applications as well as dentistry and dental implantology ${ }^{168,204}$. Moreover, it was studied as a drug and gene carrier ${ }^{168,205}$. Zirconia is currently in clinical use for the preparation of hip implants and suggested as a new generation of dental implants to replace or complement titanium to form hybrid implants for the clinical practice. This function of zirconia originates from the fact that it is osteoconductive, i.e., promotes bone formation when it becomes in contact with the injured bone, it helps to inhibite plaque formation, and improves soft tissue interactions, thus promotes periointegration ${ }^{204}$.

On the other hand, when zirconia enters the body, it can get reduced in the cells by mitochondria and therefore can cause an increase in the ROS (reactive oxygen species) such as superoxide ${ }^{*} \mathrm{O}_{2}{ }^{2}$, and hydrogen peroxide $\mathrm{H}_{2} \mathrm{O}_{2}$. These species can cause cytotoxicity, therefore, the form and amount of $\mathrm{ZrO}_{2}$ taken into the body are crucial ${ }^{205-207}$. The $\mathrm{ZrO}_{2}$ concentration limit that can cause toxicity in the cells due to elevated oxidative stress was earlier published as $250 \mu \mathrm{g} / \mathrm{ml}^{168,205}$. The literature results have no common ground on the toxicity of $\mathrm{Zr}$, and the debate is still going on. However, it became explicit that, the toxicity differs with test conditions as well as the physical form of zirconia which effects its oxidizing (getting reduced) properties ${ }^{204}$. For example, nanoparticle morphology can cause higher toxicity than the case where it is doped in the framework of a stable amorphous matrix. Doping method can overcome the oxidizing tendency. However, literature is lacking these type of trials. On the other hand, the oxidizing properties of $\mathrm{ZrO}_{2}$ can be additionally advantageous in the drug delivery applications due to its contribution to antibacterial effect ${ }^{206,208}$.

Copper $(\mathrm{Cu})$ has been utilized by the humankind since 5000s BC and was reported in the oldest medical record the Smith Papyrus written until 2600s BC to function for sterilization of chest wounds ${ }^{209}$. Cu was first acknowledged to be a material with antibacterial properties in the 1800 s when the scientists realized that $\mathrm{Cu}$ mine workers were immune to cholera and since then it has been used in medicine widely ${ }^{209,210} . \mathrm{Cu}$, either in metal or oxide form, is a cheaper alternative to noble metals (gold or silver) for several antibacterial and antifungal applications such as preparation of dental cements, medical implants, and producing antibacterial coatings/materials to be used in public places such as hospitals, transportations vehicles, and food packaging ${ }^{209-215}$.

In views of conferring or enhancing its antibacterial activity, $\mathrm{Cu}$ can be used as nanoparticles to obtain high specific surface area. The antibacterial activity of $\mathrm{Cu}$ 
nanoparticles at the size range of $2-10 \mathrm{~nm}$ was shown to have antibacterial activity against both gram positive and gram negative bacteria ${ }^{179,213}$. Moreover, $\mathrm{Cu}$ nanoparticles, compared to $\mathrm{Cu}^{+}$ions attached on the surface of the carrier, have higher stability under body conditions (e.g., changing $\mathrm{pH}$ ) leading to slower ion release from the nanoparticles which provides a long period of antibacterial activity and a lower potential of being toxic against mammal cells ${ }^{199,211-213,216}$. Also, their long lifetime can enable them to be used in contact therapies such as wound plaster ${ }^{213}$.

The antibacterial activity of materials such as $\mathrm{Cu}$ or $\mathrm{Ag}$ has become more attractive especially due to the increasing resistance of microorganisms to various broad spectrum antibiotics and antiseptic chemicals ${ }^{217}$. Due to their bacterial toxicity, $\mathrm{Cu}$ nanoparticles were used as a complementary agent to antibacterial drugs or antibiotics in many drug delivery studies ${ }^{216,217}$.

The antibacterial activity of $\mathrm{Cu}$ nanoparticles can be both a contact-driven or ion releasing process which runs by cell wall destruction, production of ROS in the bacterial cells and DNA degradation leading to cell death ${ }^{209,212,216,218}$. The copper ions released from each nanoparticle are the toxic agent, and its release rate can determine how harmful the administered material is to bacterial cells and how safe it is to mammal cells ${ }^{216}$.

Chlorhexidine digluconate ( $\mathrm{CHX})$ is an organic antibacterial and antiseptic drug which is well-established in dentistry and successfully used in the clinic for more than 20 years, especially for the treatment of periodontal deseases ${ }^{199,219,220}$. Moreover, it is used in handwashing and oral products due to its broad spectrum effect and low cytotoxicity which minimizes skin irritation ${ }^{220,221}$. It has both antibacterial and bacteriostatic activity, and it is effective against many gram-positive and gram-negative bacteria as well as fungi ${ }^{219,222}$, but it can not kill bacterial spores or myobacteria ${ }^{221,223}$. It is bactericidal by contact to which it is attached to the cell membrane of the microorganism. Afterwards, it goes through an easy uptake by bacteria by diffusion and it attacks the inner membrane causing the bacterial membrane disruption and thus the intracellular contents to leak. The second phase starts where the high concentration of CHX in the cell can cause the cellular contents to coagulate ${ }^{221}$. Chlorhexidine is a cationic molecule, and its antibactericidal property is originated from this charge which reacts with the lipopolysaccharides which contain negatively charged phosphate groups ${ }^{222}$. This molecular charge of $\mathrm{CHX}$ is also a valuable characteristic for loading it into any acidic carrier ${ }^{219}$. 


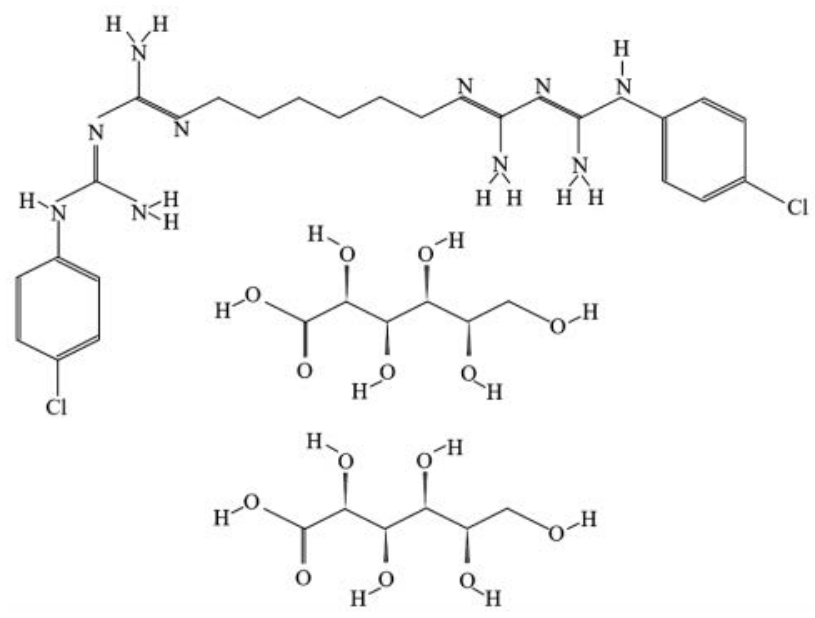

Figure 4.2.

Chlorhexidine digluconate

Doxycycline Hyclate (Doxy) is a semi-synthetic wide spectrum antibiotic from tetracycline family which is effective against periodontal pathogens and shows antiinflammatory effect ${ }^{176,224}$.

The topical administration of Doxy has been demonstrated to improve the management of periodontitis via systemic administration because by topical administration the amount of antibiotic delivered on-site is much higher, it is possible to apply it one time only and thus preventing any systemic side-effect ${ }^{224-226}$.

$\mathrm{HCl}$

$1 / 2 \mathrm{H}_{2} \mathrm{O}$

$1 / 2 \mathrm{C}_{2} \mathrm{H}_{5} \mathrm{O}$

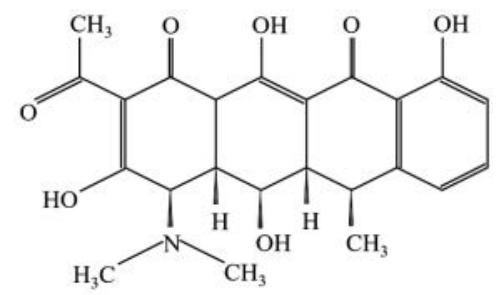

Figure 4.3. Doxycycline hyclate 


\section{ANALYSIS METHODS}

The characterization of mesoporous silica can be done with a wide range of techniques. The morphological identification can be made by imaging, more explicitly scanning electron microscopy (SEM) and transmission electron microscopy (TEM). The porous network is investigated with physisorption and small angle x-ray diffraction methods. Fourier transform infrared spectroscopy (FTIR) is utilized for identification of the silica network whereas Synchrotron radiation and in situ horizontal attenuated total reflectance (ATR) can help clarify the mesoporous silica network formation mechanism. The surface acidity is assessed by $\mathrm{NH}_{3}$-temperature programmed desorption (TPD) measurements.

Using SBA-15 in applications, however, require slightly different analysis methods. In order to analyze the resulting gas from the $\mathrm{CO}_{2}$ hydrogenation, gas chromatography-mass spectrometry (GC-MS) were used in combination to get quantitative results. In situ diffuse reflectance infrared Fourier transform spectroscopy (DRIFTs) gives insights to the reactions occurring on the catalyst surface during $\mathrm{CO}_{2}$ hydrogenation.

In drug delivery applications, the drug loading amount can be measured by thermogravimetry (TG), and drug release amounts can be calculated from the drug concentration in the release medium detected by a UV spectrometer. The antibacterial properties of a material are typically measured with agar diffusion test to obtain qualitative information and the microplate technique to obtain quantitative information. 


\subsection{Physisorption}

Physisorption (physical sorption) is the attachment of free gas molecules to the surface atoms of a material by weak van der Waals forces. A gas, at or near its boiling point, is used to expose the sample to different pressures, which are typically lower than the vapor pressure of the gas itself. The applied gas pressure is increased stepwise. During each step, the pressure is held constant to allow for adsorption and for the adsorbent temperature to equilibrate. The pressure change, as well as the amount of the dosed gas, are used to calculate the adsorbed amount which is then plotted against the adsorptive pressure to obtain isotherms ${ }^{227}$. Employing this technique, it is possible to determine the specific surface area and pore size distribution of porous materials by using nitrogen gas $^{228}$.

There are six types of isotherms according to the IUPAC classification ${ }^{2,229}$, and they are schematically depicted in Figure 5.1. They are based on multilayer coverage of gas molecules forming on the adsorbent. The first stage is monolayer adsorption, and it occurs when the surface of the mesoporous material is covered with one row of gas molecules. Then the gas molecules accumulate layer by layer forming a multilayer. As the final step of adsorption, the condensed gas molecules fill up the rest of the empty space. The desorption occurs in the opposite direction.

Type I is typically observed for microporous materials. Indeed, due to micropores with a small diameter, the quantity of the adsorbed gas shows a fast increase at low pressures which approaches an equilibrium value as the accessible pores are filled. Type II isotherms represent non-porous or macroporous adsorbents where monolayer is formed until the first knee point, and the multilayer coverage goes up high as the partial pressure increases to high values after the second knee point. The type III isotherm occurs when the adsorbent-adsorbate interaction is very weak. Due to this reason, the gas molecules accumulate on the very few active sites on the adsorbent surface, and thus full layer coverage cannot be achieved. The mesoporous materials are represented by type IV which starts similar to type II but also shows a hysteresis due to capillary condensation. This phenomenon occurs with the gas condensing in the pores at pressures higher than the saturation pressure which causes delayed condensation, and finally the condensed molecules fill the pores. During desorption, however, the liquid stays in the pores until the equilibrium vapor pressure is reached, and at the right time, the gas molecules evaporate their way out of the pores. The type V isotherm is similar to Type III where the adsorbent- 
adsorbate attraction is very weak and a capillary condensation occurs. Finally, type VI is when multilayer gas deposition occurs on a nonporous or a very uniform surface ${ }^{2,229}$.
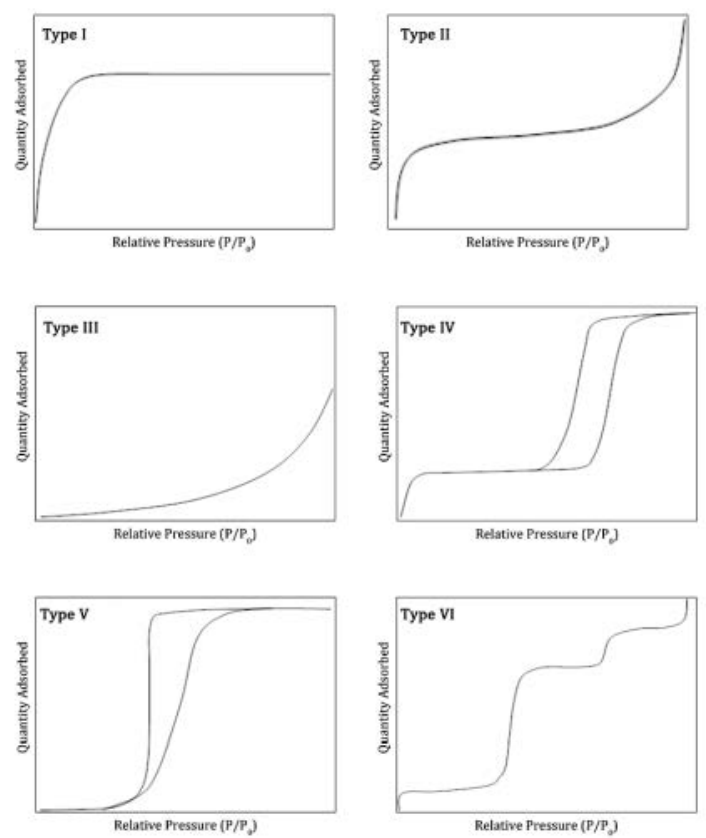

Figure 5.1. Isotherm types

Hysteresis can occur in 5 different shapes depending on the pore shape of the material (Figure 5.2). H1 loop occurs for uniform, cylindrical mesopores as in MCM-41 or SBA15 where all the pores are filled and emptied at once. $\mathrm{H} 2$ is typically observed when the sample has pore blockings or bottle-necks causing percolation of the liquid. H3 loop typically represents a sample made up of platelet-shaped particle aggregates or slit-shaped pores with pore blockings. $\mathrm{H} 4$ is when the sample is made up of aggregated crystals of zeolites or slit-shaped pores without any pore blocking. Finally, H5 loop belongs to the samples where there are both blocked, partially blocked and open pores ${ }^{229,230}$. 

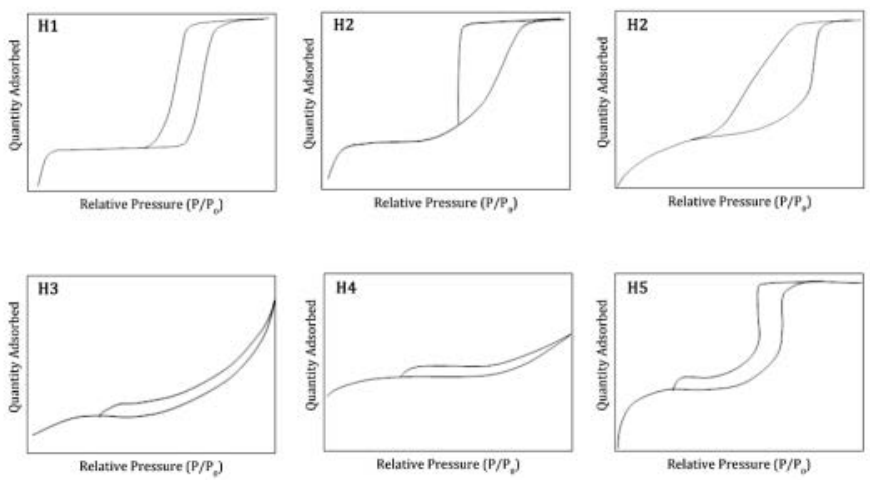

Figure 5.2.

Hysteresis

loops

The surface area is typically calculated by the BET (Brunauer-Emmet-Teller) method ${ }^{231}$. This method includes using a multilayer coverage capacity to calculate the accessible surface for the gas molecules. The number of molecules forming the first layer can then be used with a molecular cross-section area to find the whole surface area. This theory assumes that the surface active sites are identical and adsorbed molecules do not interact with each other ${ }^{1,229}$.

Pore size distribution is typically calculated by the KJS (Kruk-Jaroniec-Sayari) method for mesoporous silicas with ordered and cylindrically-shaped pores ${ }^{232,233}$. This method depends on $\mathrm{BJH}$ method which was determined to underestimate the pore size, and thus KJS method includes a correction to BJH method. BJH method assumes that all the pores are cylindrical and it calculates the pore radius by taking advantage of the capillary condensation from the Kelvin equation which is the basis of explaining partial pressure dependence of the curvature at the liquid-gas interface. Later, by comparing the XRD data of the MCM-41 type of mesoporous silica with the sorption data, the BJH method was improved $^{228,229,232,234}$.

\subsection{Temperature Programmed Desorption}

Temperature programmed desorption (TPD) is a chemisorption (chemical sorption) based technique. Chemisorption is the attachment of free gas molecules to the surface atoms of a bulk material by covalent or ionic bonds. It is a common method to analyze the 
surface properties of solid catalysts and their affinity to the gas molecules in a heterogeneous reaction system. It is irreversible and a monolayer activity ${ }^{235}$.

During TPD measurements a probe molecule, such as ammonia or carbon monoxide, is used to determine the properties and the density of the surface acid sites of a solid catalyst. A solid catalyst of a known weight is first saturated with the adsorbate flow at a temperature typically between $100-150^{\circ} \mathrm{C}$ for a sufficient amount of time to ensure a complete coverage. Afterwards, physisorbed molecules are removed from the catalyst surface by an inert carrier gas flow. The remaining chemisorbed molecules are then forced to desorb by increasing the temperature. While heating, the adsorbate concentration in the carrier stream is measured by using a thermal conductivity detector. The acquired TPD spectra are normalized with the weight of the sample powder and plotted versus temperature. TPD spectra exhibit peaks at specific temperatures at which the adsorbate molecules are detached from the acid sites. Therefore, stronger is the acid site, higher is the temperature required for desorption ${ }^{236-238}$.

\subsection{X-ray diffractometry}

Electromagnetic radiation with a wavelength of about $10^{-10} \mathrm{~m}$ is called X-rays. When Xrays penetrate matter, they can interact with electrons and scatter, be emitted or absorbed in specific ways depending on the nature of the interacting atoms. Diffracted $x$-rays can be analyzed to determine the atomic structure of a crystalline phase. The diffraction technique requires long-range periodicity of the lattice planes in the material of interest. These planes cause scattering due to constructive interference, and this can be shown with a relationship between the scattering angle and lattice spacings called Bragg's law ${ }^{239}$ :

$n \lambda=2 d_{h k l} \sin \theta$

where $\lambda$ is the wavelength of the x-ray beam, $d_{h k l}$ is the lattice spacing, $\theta$ is the scattering angle and $n$ is the order of reflection.

Small angle $\mathrm{x}$-ray diffraction is conducted in transmission geometry for ordered powders by analyzing the diffracted beam as a result of an incident beam striking the sample at a shallow angle. The diffracted angle of the incident beam $(2 \theta)$ is typically recorded between $0-2.5^{\circ}$ for mesoporous silica. In this angle range, the hexagonal pore stacking 
system of SBA-15 results in at least three peaks corresponding to $100,110,200$ when using $\mathrm{Cu}$ radiation.

The phase and size of the nanoparticles with well-defined crystallographic planes can typically be determined by $x$-ray diffraction at angles between $20-60^{\circ}$. Crystallite size, i.e., nanoparticle size for a single crystal material, with a size between 5 and $100 \mathrm{~nm}$ can be calculated by the Scherrer equation, utilizing the full width half maximum of the strongest peak of the material. ${ }^{240,241}$

\subsection{Electron microscopy and energy dispersive $x$-ray spectroscopy}

Electron microscopy enables imaging by projecting a beam of accelerated electrons onto the sample. In Transmission Electron Microscopy (TEM) the electrons that penetrate a specimen, are transmitted through the sample, and the resultant beam is recorded at the exit by suitable lenses whereas in Scanning Electron Microscopy (SEM) the reflected (secondary) electrons are used for imaging. TEM is more suitable for thin samples, while SEM is typically used for thick or very absorbent samples where electrons cannot be transmitted properly ${ }^{242}$. Dark-field images can be produced by TEM method by using only the diffracted electrons and avoiding the direct beam by an objective aperture. This method can provide enough contrast between different crystal structures ${ }^{87}$. Energy dispersive $\mathrm{x}$-ray spectroscopy technique (EDS/EDX) is a common method for determination of the atomic content of a sample and it relies on the emitted x-rays from the sample which have a characteristic energy depending on the atomic content of the sample. This measurement is typically conducted with an SEM or a TEM equipped with an integrated $\mathrm{x}$-ray detector.

\subsection{Infrared spectroscopy [FTIR, DRIFTS, and ATR]}

Infrared spectroscopy $(I R)$ is a technique to analyze the presence of atoms, molecules and molecular interactions which are active under infrared beam, i.e., absorb/emit the IR beam. These vibrations include mainly stretching (bond elongation) and bending (bond angle change). IR spectroscopy relies on these vibrations to get excited under IR radiation and change their energy levels. As a result of this energy adsorption, less energy from the 
incident radiation is transmitted at the relevant wavenumber which appears as peak formations on a spectrum. With Fourier transform infrared spectroscopy (FTIR), the main beam is split, and the partial beams are reflected back to the splitter where they recombine. The interference of the partial beams is interpreted in an interferometer by the Fourier transformation technique ${ }^{243}$.

Attenuated total reflectance ( $A T R$ ) employs an internal reflection element, e.g., a crystal, with high refractive index enabling multiple reflection of the IR beam while going through this element. During that time, the beam is absorbed by the sample, and finally, the attenuated beam is measured (Figure 5.3). It is typically utilized to measure samples in liquid or solids that produce very strong peaks with the transmission IR technique ${ }^{243}$.

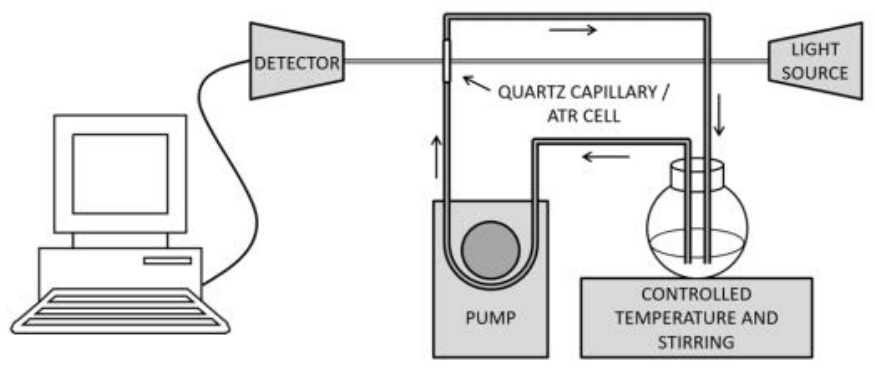

Figure 5.3.

ATR setup schematic

In situ diffuse reflectance infrared Fourier transform spectroscopy (DRIFTs) is performed in a drifts cell which enables reflection of the beam over a solid sample(Figure 5.4). When the beam hits the sample, it is reflected by specular and diffuse reflectance. Specular reflectance occurs when the reflected beam is equal to the incident beam, which is valid for flat surfaces. The diffuse beam, however, is observed when the reflected light is scattered due to a rough surface causing various reflection angles. A rough sample can absorb a huge amount of the beam in case of transmission mode, and therefore the DRIFTS method is quite sensitive compared to traditional FTIR and thus is a convenient method of determining surface groups on a catalyst during a reaction ${ }^{243-245}$. 


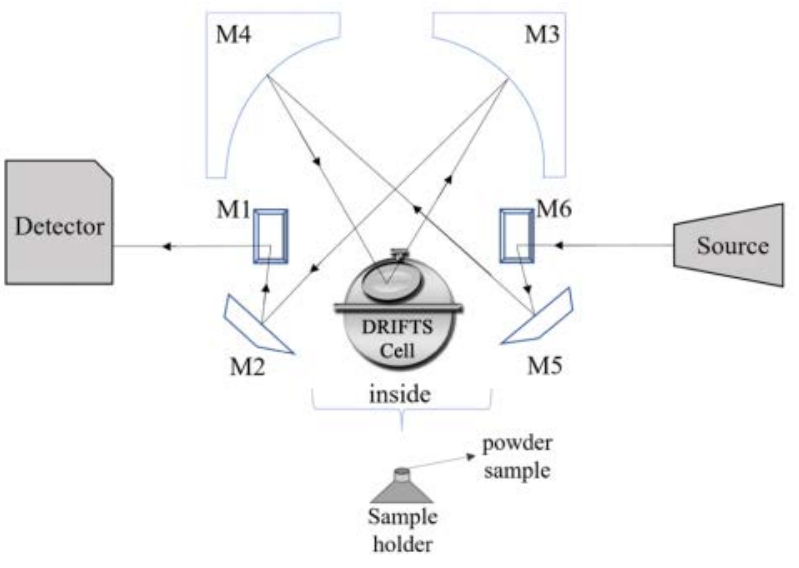

Figure 5.4. DRIFTs setup schematic. M1M5 represent the mirrors in a specific order from detector towards the source.

\subsection{UV/vis spectroscopy}

$\mathrm{UV} /$ vis spectroscopy works by exposing the material of interest (typically dissolved in a solution) to a beam in the UV and visible range and detects the transmittance/absorbance by the measured material due to electron excitation. The resulting change in the beam is reflected through the detector and outcome is presented as a spectrum where peaks/bands give clues regarding molecular structure ${ }^{246}$. The most common use of this method is in the determination of the concentration of a substance in a liquid such as metal ion or a drug molecule.

\subsection{X-ray photoelectron spectroscopy}

X-ray photoelectron spectroscopy (XPS) is a surface-sensitive analysis technique that measures the elemental composition of the top surface (typically 1-10 $\mathrm{nm}$ ) and provides information regarding the chemical state of the elements that compose the material being analyzed. XPS measurements are conducted in vacuum by irradiating a material with an X-ray monochromatic beam (commonly $\mathrm{Al} \mathrm{K} \alpha$ or $\mathrm{Mg} \mathrm{Ka}$ ), which causes photo-emission of core-level electrons. As a result, the kinetic energy distribution of these emitted electrons is measured and used to identify and determine the concentrations of the elements present ${ }^{247,248}$. 


\subsection{Gas chromatography and mass spectrometry}

Gas chromatography is an analysis method where a gas mixture is separated into its components by a stationary phase (capillary column) by using their different affinity to the analytes, and each component is identified/quantified. The sample gas mixture in question is transmitted through the detector with a non-polar and non-reactive carrier gas such as $\mathrm{Ar}, \mathrm{He}$, and $\mathrm{H}_{2}$. There are many different types of GC detectors, and they have their specific operation principle depending on a physical property of the molecules. For example, thermal conductivity detector (TCD) operates by measuring the changing thermal conductivity of the flowing gas and therefore determines the concentration in the gas while flame ionization detector (FID) burns the input gas with $\mathrm{H}_{2}$ and gets its signal from the mass of the formed ions. ${ }^{249,250}$

Mass spectrometry (MS) provides identification of the components in a mixture by measuring the mass dependent deflection of the ionized molecules from the sample ${ }^{251}$. An ion source is employed to produce ions from the entering molecules. These molecules undergo fragmentation into radicals and ions when exposed to the ion flux from the ion source. Finally, the ions from the sample are passed through an electric field that deflects them differently depending on their kinetic energy. The abundance of ions are grouped according to their mass-to-charge ratio and presented as a bar graph which provides the mass-to-charge ratio of the species within the sample that is fed into the mass spectrometer $^{251,252}$.

\subsection{Thermogravimetry}

Thermogravimetric analysis is done by changing (typically elevating) the ambient temperature of a material gradually and measuring its mass over time. The measured sample is typically a solid. As it is heated, desorption, phase transition and thermal decomposition can occur. It is a destructive method which can be used for quantification and determination of the composition of materials, as well as their water and solvent content, impurity levels, and the thermal stability ${ }^{237}$. 


\section{SUMMARY AND DISCUSSIONS OF THE PAPERS}

The papers appended to this thesis focus on synthesizing hybrid materials based on mesoporous silica for catalysis and drug delivery applications.

\subsection{Paper 1}

Synthesis of Cu-infiltrated $\mathrm{Zr}$-doped SBA-15 catalyst for $\mathrm{CO}_{2}$ hydrogenation into methanol and dimethyl ether

In Paper 1, a rapid sol-gel route ${ }^{15}$ was used to synthesize a Zr-doped SBA-15 matrix with $\mathrm{Cu}$ nanoparticles grown on its surface. The effects of $\mathrm{Cu}$ and $\mathrm{Zr}$ modifications were investigated from a chemistry viewpoint, and the catalytic efficiency in a $\mathrm{CO}_{2}$ hydrogenation system was evaluated.

Zr-doped SBA-15 materials (Zr-SBA-15) demonstrated very similar porous network as for SBA-15 with additional $\mathrm{Zr}-\mathrm{O}-\mathrm{Si}$ bonds with an overall $\mathrm{Si} / \mathrm{Zr}$ atomic ratio of about $10 \mathrm{Zr}$ doping has yielded pore size increase from 11 to $15 \mathrm{~nm}$ while the SSA remained constant around $700 \mathrm{~m}^{2} / \mathrm{g}$. The particles for both SBA-15 and Zr-SBA-15 were rod-shaped, but wider in case of $\mathrm{Zr}$ doping. This structural difference was determined to be due to the decrease in $\mathrm{F}^{-}$ion concentration in the solution caused by the $\mathrm{Zr}$ salt addition which otherwise acts as a catalyst in SBA-15 formation. By changing the static duration in the synthesis and the hydrothermal treatment conditions, it was observed that the pore 
characteristics of the Zr-SBA-15 could further be altered. When the synthesis catalyst salt $\mathrm{NH}_{4} \mathrm{~F}$ was changed to $\mathrm{NaCl}$ the particle morphology was evolved to spheres due to slower formation rate in the presence of $\mathrm{Cl}^{-}$ions compared to $\mathrm{F}^{-}$ions. $\mathrm{Cu}$ nanoparticles grown on Zr-SBA-15 were determined to have a smaller average size compared to the ones grown on SBA-15. The reason for the improved $\mathrm{Cu}$ distribution in the presence of $\mathrm{Zr}$ is ascribed to the increase in the number of acid sites on the $\mathrm{Zr}$-doped silica surface. In both cases, various oxidation states of $\mathrm{Cu}\left(\mathrm{Cu}^{2+}, \mathrm{Cu}^{3+}\right.$, and $\left.\mathrm{Cu}^{+} / \mathrm{Cu}^{0}\right)$ were detected to coexist in the sample despite reducing the samples under $\mathrm{H}_{2}$ flow at high temperature. On the other hand, $\mathrm{Zr}$ was detected only in $\mathrm{Zr}^{4+}$ oxidation state.

The Cu-Zr-SBA-15 material was catalytically active for selective $\mathrm{CO}_{2}$ hydrogenation to methanol and $\mathrm{DME}$ with $15 \% \mathrm{CO}_{2}$ conversion at the end of 5 days at $250^{\circ} \mathrm{C}$ and 33 bars, whereas SBA-15 and Zr-SBA-15 have shown less than $1 \% \mathrm{CO}_{2}$ conversion. Moreover, the $\mathrm{Cu}-\mathrm{SBA}-15$ material yielded a $\mathrm{CO}_{2}$ conversion lower than $1 \%$ which demonstrates the importance of improved acidity with $\mathrm{Zr}$ existence in the mesoporous framework. The final conversion was still increasing after 5 days which indicates that a higher conversion can be expected from the $\mathrm{Cu}-\mathrm{Zr}$-SBA-15 catalyst at improved reaction conditions.

\subsection{Paper 2}

\section{Effects of the chemical state of mesoporous $\mathrm{CuO} \mathrm{O}_{\mathrm{x}}-\mathrm{Zr}_{\mathrm{r}}-\mathrm{SiO}_{2}$ catalysts on $\mathrm{CO}_{2}$ hydrogenation}

In Paper 2, the investigation of the synthesis conditions for Cu-Zr-SBA-15 catalytic nanoassembly, which started in Paper 1, was taken one step further by altering the chemical state of the catalyst with different silica precursors, and $\mathrm{Cu}$ loading procedures and observing the impact of this alteration on the catalytic activity. The tested silica precursors were tetraethyl orthosilicate (TEOS) and sodium metasilicate (SMS) whereas the experimented $\mathrm{Cu}$ loading methods were infiltration (Inf) and evaporation induced wetness impregnation (EIWI).

The Zr-SBA-15 particles synthesized with SMS were observed to yield wider particles, i.e., platelets compared to TEOS which yielded rods. This was attributed to the $\mathrm{NaOH}$ occurrence with SMS hydrolysis which increases the dissolution of the PEO chains of the micelles in the water media. The improved PEO solubility causes easier entanglement of 
the PEO chains in the solution, and thus, the micelles and early-stage particles aggregate to become wider. On the other hand, Zr-SBA-15 produced with SMS showed lower microporosity also causing lower SSA. The dropped microporosity is due to the silica clusters being readily formed in the pre-hydrolized SMS which cause a rapid silica formation. As a result, the silica network formation terminates before PEO chains can penetrate into the silica walls. This rapid formation of SMS based Zr-SBA-15 has shown its impact also on the pore size. When SMS was used, the mesopores were observed to have smaller diameter since there was not enough time for heptane to penetrate the centers of the micelles to cause swallowing and pore enlarging, as in the case of TEOS based $\mathrm{Zr}$ SBA-15. Moreover, TEOS can also act as a swelling agent causing further pore enlarging which is not the case for SMS. The use of SMS as the silica precursor also resulted in weaker bonds of the $\mathrm{Zr}$ atoms to the $\mathrm{SiO}_{2}$ framework. The $\mathrm{Cu}$ reduction and re-oxidation were detected to be more efficient for SMS particles compared to TEOS particles. This is attributed to the weaker surface interaction of SMS with the Cu NPs compared to TEOS which facilitatess the reduction efficiency of the $\mathrm{Cu}$ nanoparticles. Using TEOS as the silica precursor in the $\mathrm{Cu}-\mathrm{Zr}$-SBA-15 catalyst was shown to provide a higher concentration of surface acid sites which ultimately results in a higher total $\mathrm{CO}_{2}$ conversion compared to SMS.

As for the $\mathrm{Cu}$ infiltration methods, Inf method has yielded lower $\mathrm{Zr}$ content, smaller surface as well as less surface-OH groups compared to EIWI catalysts. Also, the reaction results have demonstrated that the Inf method promotes higher selectivity for DME than methanol. This is attributed to the higher strength of the medium acid sites of Inf which have more affinity for methoxy than the weaker ones which can adsorb hydrogen. As the surface methoxy concentration becomes higher for Inf methods, DME can be formed from two surface methoxy groups interacting with each other. It was shown in this paper that the medium acid sites were determined to be the most effective among the others in both activity and selectivity in $\mathrm{CO}_{2}$ hydrogenation whereas the strong acid sites can promote methanol selectivity and the weak acid sites do not show any considerable activity. 


\subsection{Paper 3}

\section{Time evolution of the $\mathrm{CO}_{2}$ hydrogenation to fuels over $\mathrm{Cu}-\mathrm{Zr}-\mathrm{SBA}-15$ catalysts}

In Paper 3, the time evolution of catalytic $\mathrm{CO}_{2}$ hydrogenation to methanol and dimethyl ether (DME) has been investigated at $250^{\circ} \mathrm{C}$ and 33 bars in a closed batch reactor where products accumulate over time. Two types of $\mathrm{Cu}-\mathrm{Zr}$-SBA-15 were prepared with the chemical routes described in Paper 1 and Paper 2. TEOS was used as the silica precursor, and $\mathrm{Cu}$ nanoparticles were loaded into the $\mathrm{Zr}$-doped SBA-15 matrix with both Inf and EIWI methods in order to compare the trends of different reaction systems. The catalysis results were compared with the thermodynamical equilibrium calculations.

The Cu-Zr-SBA-15 catalyst produced via Inf method has yielded $24 \% \mathrm{CO}_{2}$ conversion to methanol and DME. This percentage was shown to be the thermodynamically highest theoretical conversion where only DME and methanol are the products. When the EIWI $\mathrm{Cu}$ loading method was used, the resulting catalyst was methanol selective. In this case, when DME is not formed, calculations indicate $\mathrm{CO}$ as a product suggesting its involvement in DME formation. In both cases, several other molecules (such as methane, methyl formate, and butane) were detected on the catalyst surface by DRIFTS method. However, these molecules were, interestingly, not observed in the final gas mixture which was analyzed by GC-MS. Theoretical calculations showed that in case of formation of any (one or more) of these molecules, no conversion to methanol and DME is possible. Therefore, we concluded that the Cu-Zr-SBA-15 catalysts used in this study were not selective for any of the aforementioned molecules.

DRIFTS measurements also showed increased surface $\mathrm{CH}_{3} \mathrm{O}^{-}$formation which drops during the reaction for the catalyst prepared via Inf method. EIWI, on the other hand, demonstrated a lower $\mathrm{CH}_{3} \mathrm{O}^{-}$concentration which stayed stable during the whole reaction where methanol was being formed. Therefore, we inferred that DME was formed by two $\mathrm{CH}_{3} \mathrm{O}^{-}$molecules reacting with each other, as also mentioned in Paper 2. The difference in the surface methoxy concentration is attributed to the strength of the medium acid sites which demonstrate a higher affinity for methoxy as they become stronger.

The time evolution of methanol and DME formation was determined to be a sigmoidal function which indicates a seeding period followed by acceleration and deceleration until an equilibrium value is reached. The importance of seeding was also proven by repeated 
reactions using a reacted catalyst isolated from the atmosphere. Methanol formation was determined to be faster than DME since it requires only one methoxy formation, rather than two. Since DME is formed of two methoxy groups, a higher surface methoxy concentration, i.e., a higher seeding duration, is needed.

After the half-time of the reaction ( 7 days), the conversion increased from $20 \%$ to $24 \%$ which is a rather small contribution. It indicates that finalizing this reaction at its half-time can cut the energy usage by half but sacrifice only $4 \%$ of the total conversion. This is an important finding not only from economical but also from an environmental point.

\subsection{Paper 4}

\section{$C u$ and $Z r$ modified $S B A-15$ as drug carriers}

Mesoporous silica has potential use in the biomedical field as a drug carrier. Thus, a modified form of SBA-15 was investigated in Paper 4 as the means of releasing Chlorhexidine digluconate (CHX), an antibacterial drug.

For this study, SBA-15, Zr-doped SBA-15, and Cu nanoparticle infiltrated Zr-doped SBA15 were prepared with the chemical routes described in Paper 1 and investigated as drug carriers. TEOS was used as the silica precursor, and $\mathrm{Cu}$ nanoparticles were loaded on the Zr-doped SBA-15 matrix by an infiltration procedure.

The prepared materials were loaded with a $2 \% \mathrm{CHX}$ solution and yielded a loading percentage of $25-40 \%$. The chemical bonding between the drug and the carrier was confirmed by FTIR via N-H and O-H vibration bands. $\mathrm{Cu}$ and $\mathrm{Zr}$ contents of the carrier were observed to increase the drug loading amount per unit surface. This was attributed to increased surface active sites and enhanced acidity which improves the attraction of the drug molecules on the carrier walls. The same trend was also shown in released drug percentage which was the highest for SBA-15 (65\%) and the lowest for Cu-Zr-SBA-15 (28\%), indicating better drug affinity to the carrier when $\mathrm{Zr}$ and $\mathrm{Cu}$ were added to SBA15.

Drug release was shown to occur into two stages: a burst release and a slower release. Burst release involves the drug molecules which are weakly held inside the drug carrier whereas the slower release occurs while the drug molecules held on the carrier surface are desorbed. It was observed that for $\mathrm{Cu}-\mathrm{Zr}-\mathrm{SBA}-15$ and $\mathrm{Zr}-\mathrm{SBA}-15$ the second stage is dominant. This 
indicates that $\mathrm{Zr}$ and $\mathrm{Cu}$ improved the drug attachment to the carrier framework and thus, slowed down the drug release which is attributed to enhanced acidity. This effect was observed for $\mathrm{Cu}$ more dramatically due to its particle morphology which cause partial blockage in the pores.

Antibacterial properties were investigated against Staphylococcus aureus and Escherichia coli qualitatively and quantitatively by employing agar diffusion. It was found that the release from $\mathrm{Cu}$ nanoparticles was too low to cause a considerable boost in the antibacterial properties. The antibacterial inhibition was observed to be in line with the released amounts. The quantitative antibacterial measurements showed that the maximum antibacterial efficiency was achieved between the first 2-6 hours for all the carriers. However, it dropped for Cu-Zr-SBA-15 after a while due to the lower amount of released $\mathrm{CHX}$.

\subsection{Paper 5}

\section{Tuning the pore size of a mesoporous carrier as means for control of antibiotic release}

The study reported in Paper 4 was complemented with Paper 5 where SBA-15 was used as a drug carrier and the effect of its pore size on the control of the release of doxycycline hyclate (Doxy), an antibiotic widely used in dental applications, was investigated.

In this study, the pore size of the SBA-15 carrier was tuned between 6.5 and $14.0 \mathrm{~nm}$ by changing the synthesis conditions such as temperature and time. The SBA-15 particle morphologychanged from platelet to rods under different synthesis conditions as the pores got wider. Also, specific surface area and microporosity dropped as the pore size got bigger whereas the wall thickness increased.

This study showed that the pore size has a strong effect on the amount of the drug loading on SBA-15. As the pore size increased, the drug loading was observed to increase linearly. On the other hand, the effect of the pore volume as well as the specific surface area on the drug loading amount was found to be minimal.

All the drug release profiles were observed to be diffusion controlled, i.e. burst release. The release rates were found to be inversely proportional to the drug loading per pore volume, i.e. drug concentration. This indicates a slower drug release as the drug concentration in 
the pores gets higher. We inferred this behaviour to the drug-drug interactions dominating the release profiles due to weak drug-carrier attachment.

All the drug loading was released for $14 \mathrm{~nm}$ pore-sized sample whereas some sample entrapment was observed for $11.5 \mathrm{~nm}$, and $6.5 \mathrm{~nm}$ pore sized samples. This was inferred to the changing microporosity.

Finally, the antibacterial activity against Staphylococcus aureus and Escherichia coli was observed to follow the drug release amounts, i.e., pore sizes. 


\section{CONCLUSIONS AND FUTURE WORK}

In this work, SBA-15 and its modified forms as Zr-SBA-15 and Cu-Zr-SBA-15 were prepared and their structural properties as well as their activity in catalysis and drug delivery were investigated. I believe these applications can be taken further in more multidisciplinary environments. Moreover, the modifications for SBA-15 can be varied to obtain additional/tunable properties in different application areas such as catalysis and drug delivery.

In Paper 1-3, SBA-15 and Zr-SBA-15 were synthesized with different pore sizes and morphologies by changing synthesis conditions. For all studied conditions, these materials have shown narrow pore size distributions, hexagonal pore arrangements, and large specific surface areas. In Zr-SBA-15, Zr was incorporated into the SBA-15 framework whereas in $\mathrm{Cu}-\mathrm{Zr}-\mathrm{SBA}-15, \mathrm{Cu}$ was incorporated by growing as nanoparticles with a diameter smaller than $10 \mathrm{~nm}$ in the pores of Zr-SBA-15. Cu-Zr-SBA-15 was later shown to be catalytically active and can promote $\mathrm{CO}_{2}$ hydrogenating into DME and methanol. The highest thermodynamically possible $\mathrm{CO}_{2}$ conversion to DME and methanol, which is $24 \%$, was achieved. Changing the silica source and $\mathrm{Cu}$ loading procedure, the catalytic activity and selectivity between DME and methanol was modified. The time evolution of the $\mathrm{CO}_{2}$ hydrogenation have shown that methanol formation is faster than DME. High methanol selectivity requires sufficient surface $\mathrm{H}$ affinity, whereas high DME selectivity requires high surface methoxy concentration. It was concluded that methoxy can join the formation of DME without going through hydrogenation into a methanol molecule. On 
the other hand, the equilibrium point of the conversion was achieved only after 14 days. The slow evolution is due to two reasons: 1) a batch reactor is used for this reactor where each molecule of a product works against the $\mathrm{CO}_{2}$ conversion, and 2) pressure was as low as 33 bars.

As the future work, I suggest a full study employing a flow type reactor which can improve the reactant-catalyst contact and help to remove the products from the catalyst environment simultaneously. On the other hand, under 50 bars it was shown to improve the total $\mathrm{CO}_{2}$ conversion. A full study for the conversion and selectivity at 50 bars or higher should be conducted. Our findings can guide all this suggested conversion improvement efforts. Synthesis-wise, Cu-Zr-SBA-15 systems should further be investigated by using different elements such as $\mathrm{Ni}$ or $\mathrm{Co}$. Also as the dopant, $\mathrm{Zn}$ or $\mathrm{Al}$ can be used in different combinations. As the next step, the industrialization process should take place where the studied catalyst powders can be brought to disc forms and appropriate catalytic systems possibly composed of recycling and additional columns installed in series to the reactor for separation of fuels such as methanol and DME.

A Cu-Zr-SBA-15 material prepared within this thesis work was shown in Paper 4 to respond well as a drug carrier. $\mathrm{Cu}$ and $\mathrm{Zr}$ components were shown to slow down the drug release and improve the drug loading. Moreover, when $\mathrm{Cu}$ was prepared as nanoparticles, the resulting ion release was different from a simple ion doping. Paper 5 have demonstrated that changing the pore size of SBA-15 can affect the drug loading and release amount directly. To achieve a final drug delivery device in the future, the Cu-Zr-SBA-15 powder should further be treated since dental procedures require well mixing of the drug loaded SBA-15 particles with the dental composite is crucial. Also, in vivo pharmacological tests and toxicity measurements are important for future applications. 


\section{References}

(1) Rouquerol, J.; Avnir, D.; Fairbridge, C. W.; Everett, D. H.; Haynes, J. M.; Pernicone, N.; Ramsay, J. D. F.; Sing, K. S. W.; Unger, K. K. Recommendations for the Characterization of Porous Solids (Technical Report). Pure Appl. Chem. 1994, 66 (8), 1739-1758.

(2) Sing, K. S. W. Reporting Physisorption Data for Gas/solid Systems with Special Reference to the Determination of Surface Area and Porosity (Provisional). Pure Appl. Chem. 1982, 54 (11), 2201-2218.

(3) Beck, J. S.; Vartuli, J. C.; Roth, W. J.; Leonowicz, M. E.; Kresge, C. T.; Schmitt, K. D.; Chu, C. T. W.; Olson, D. H.; Sheppard, E. W. A New Family of Mesoporous Molecular Sieves Prepared with Liquid Crystal Templates. J. Am. Chem. Soc. 1992, 114 (27), 10834-10843.

(4) Kresge, C. T. Leonowicz, M. E.Roth, W.J.Vartuli, J.Beck, J. S. C. Ordered Mesoporous Molecular Sieves Synthesized by a Liquid-Crystal Template Mechanism. Nature 1992, 359 (6397), 710712.

(5) Wang, S. Ordered Mesoporous Materials for Drug Delivery. Microporous Mesoporous Mater. 2009, 117(1-2), 1-9.

(6) Park, S.-Y.; Pendleton, P. Mesoporous Silica SBA-15 for Natural Antimicrobial Delivery. Powder Technol. 2012, 223, 77-82.

(7) Mamaeva, V.; Sahlgren, C.; Lindén, M. Mesoporous Silica Nanoparticles in Medicine--Recent Advances. Adv. Drug Deliv. Rev. 2013, 65 (5), 689-702.

(8) Izquierdo-Barba, I.; Martinez, A.; Doadrio, A. L.; Pérez-Pariente, J.; Vallet-Regí, M. Release Evaluation of Drugs from Ordered Three-Dimensional Silica Structures. Eur.J. Pharm. Sci. 2005, $26(5), 365-373$.

(9) Eggenhuisen, T. M.; Zečević, J.; Talsma, H.; De Jong, K. P.; De Jongh, P. E. Quantitative Assessment of Pore Blockage in Supported Catalysts: Comparing Differential Scanning Calorimetry and Physisorption. J. Phys. Chem. C2012, 116 (13), 7480-7490.

(10) Moritz, M.; Geszke-Moritz, M. Mesoporous Materials as Multifunctional Tools in Biosciences: Principles and Applications. Mater. Sci. Eng. C2014, 49, 114-151.

(11) Alothman, Z. A Review: Fundamental Aspects of Silicate Mesoporous Materials. Materials (Basel). 2012, 5(12), 2874-2902.

(12) Zhao, D.; Feng, J.; Huo, Q.; Melosh, N.; Fredrickson, G. H.; Chmelka, B. F.; Stucky, G. D. Triblock Copolymer Syntheses of Mesoporous Silica with Periodic 50 to 300 Angstrom Pores. Science (80-. ). 1998, 279(5350), 548-552.

(13) Mihai, G. D.; Meynen, V.; Mertens, M.; Bilba, N.; Cool, P.; Vansant, E. F. ZnO Nanoparticles Supported on Mesoporous MCM-41 and SBA-15: A Comparative Physicochemical and Photocatalytic Study. J. Mater. Sci.2010, 45 (21), 5786-5794. 
(14) Hartmann, M.; Vinu, A. Mechanical Stability and Porosity Analysis of Large-Pore SBA-15 Mesoporous Molecular Sieves by Mercury Porosimetry and Organics Adsorption. Langmuir 2002, 18(21), 8010-8016.

(15) Johansson, E. M.; Ballem, M. A.; Cordoba, J. M.; Oden, M. Rapid Synthesis of SBA-15 Rods with Variable Lengths, Widths, and Tunable Large Pores. Langmuir 2011, 27 (8), 4994-4999.

(16) Johansson, E. M.; Córdoba, J. M.; Odén, M. The Effects on Pore Size and Particle Morphology of Heptane Additions to the Synthesis of Mesoporous Silica SBA-15. Microporous Mesoporous Mater. 2010, 133(1-3), 66-74.

(17) Yeh, Y.-Q.; Lin, H.-P.; Tang, C.-Y.; Mou, C.-Y. Mesoporous Silica SBA-15 Sheet with Perpendicular Nanochannels. J. Colloid Interface Sci. 2011, 362 (2), 354-366.

(18) Zhao, D.; Sun, J.; Li, Q.; Stucky, G. D. Morphological Control of Highly Ordered Mesoporous Silica SBA-15. Chem. Mater. 2000, 12 (2), 275-279.

(19) Cao, L.; Kruk, M. Synthesis of Large-Pore SBA-15 Silica from Tetramethyl Orthosilicate Using Triisopropylbenzene as Micelle Expander. Colloids Surfaces A Physicochem. Eng. Asp. 2010, 357 (1-3), 91-96.

(20) Fulvio, P. F.; Pikus, S.; Jaroniec, M. Short-Time Synthesis of SBA-15 Using Various Silica Sources. J. Colloid Interface Sci. 2005, 287(2), 717-720.

(21) Björk, E. M.; Söderlind, F.; Odén, M. Tuning the Shape of Mesoporous Silica Particles by Alterations in Parameter Space: From Rods to Platelets. Langmuir 2013, 29 (44), 13551-13561.

(22) Alfredsson, V.; Wennerström, H. The Dynamic Association Processes Leading from a Silica Precursor to a Mesoporous SBA-15 Material. Acc. Chem. Res. 2015, 48 (7), 1891-1900.

(23) Nagarajan, R. Amphiphilic Surfactants and Amphiphilic Polymers: Principles of Molecular Assembly. In ACS Symposium Series; 2011; Vol. 1070, pp 1-22.

(24) Gobin, O. C. SBA-15 Materials - Synthesis, Diffusion and Sorption Properties, 2006.

(25) Teixeira, C. V; Amenitsch, H.; Linton, P.; Lindén, M.; Alfredsson, V. The Role Played by Salts in the Formation of SBA-15, an in Situ Small-Angle X-Ray Scattering/Diffraction Study. Langmuir 2011, 27(11), 7121-7131.

(26) Björk, E. M.; Mäkie, P.; Rogström, L.; Atakan, A.; Schell, N.; Odén, M. Formation of BlockCopolymer-Templated Mesoporous Silica. J. Colloid Interface Sci. 2018, 521, 183-189.

(27) Denkova, A. G.; Mendes, E.; Coppens, M.-O. Effects of Salts and Ethanol on the Population and Morphology of Triblock Copolymer Micelles in Solution. J. Phys. Chem. B2008, 112 (3), 793801.

(28) Linton, P.; Wennerström, H.; Alfredsson, V. Controlling Particle Morphology and Size in the Synthesis of Mesoporous SBA-15 Materials. Phys. Chem. Chem. Phys. 2010, 12 (15), 38523858 .

(29) Jana, S. K.; Mochizuki, A.; Namba, S. Progress in Pore-Size Control of Mesoporous MCM-41 Molecular Sieve Using Surfactant Having Different Alkyl Chain Lengths and Various Organic Auxiliary Chemicals. Catal. Surv. from Asia 2004, 8(1), 1-13. 
(30) Nguyen, T. P. B.; Lee, J.-W.; Shim, W. G.; Moon, H. Synthesis of Functionalized SBA-15 with Ordered Large Pore Size and Its Adsorption Properties of BSA. Microporous Mesoporous Mater. 2008, $110(2-3), 560-569$.

(31) Meynen, V.; Cool, P.; Vansant, E. F. Verified Syntheses of Mesoporous Materials. Microporous Mesoporous Mater. 2009, 125(3), 170-223.

(32) Kruk, M. Access to Ultralarge-Pore Ordered Mesoporous Materials through Selection of Surfactant/Swelling-Agent Micellar Templates. Acc. Chem. Res. 2012, 45 (10), 1678-1687.

(33) Li, Q.; Wu, Z.; Feng, D.; Tu, B.; Zhao, D. Hydrothermal Stability of Mesostructured Cellular Silica Foams. J. Phys. Chem. C2010, 114(11), 5012-5019.

(34) Wan, Y.; Shi, Y.; Zhao, D. Designed Synthesis of Mesoporous Solids via Nonionic-SurfactantTemplating Approach. Chem. Commun. 2007, No. 9, 897-926.

(35) Jin, D.; Zhu, B.; Hou, Z.; Fei, J.; Lou, H.; Zheng, X. Dimethyl Ether Synthesis via Methanol and Syngas over Rare Earth Metals Modified Zeolite Y and Dual Cu-Mn-Zn Catalysts. Fue/2007, 86 (17-18), 2707-2713.

(36) MAO, D.; YANG, W.; XIA, J.; ZHANG, B.; SONG, Q.; CHEN, Q. Highly Effective Hybrid Catalyst for the Direct Synthesis of Dimethyl Ether from Syngas with Magnesium OxideModified HZSM-5 as a Dehydration Component. J. Catal. 2005, 230(1), 140-149.

(37) Liu, X.; Bai, S.; Zhuang, H.; Yan, Z. Preparation of $\mathrm{Cu} / \mathrm{ZrO} 2$ Catalysts for Methanol Synthesis from CO2/H2. Front. Chem. Sci. Eng. 2012, 6(1), 47-52.

(38) Zhong, X.; Barbier, J.; Duprez, D.; Zhang, H.; Royer, S. Modulating the Copper Oxide Morphology and Accessibility by Using Micro-/mesoporous SBA-15 Structures as Host Support: Effect on the Activity for the CWPO of Phenol Reaction. Appl. Catal. B Environ. 2012, 121-122, $123-134$.

(39) Anu Prathap, M. U.; Kaur, B.; Srivastava, R. Direct Synthesis of Metal Oxide Incorporated Mesoporous SBA-15, and Their Applications in Non-Enzymatic Sensing of Glucose. J Colloid Interface Sci2012, 381 (1), 143-151.

(40) Usami, Y.; Hongo, T.; Yamazaki, A. Thermal Stability and Behavior of Platelet-Shaped SBA-15 Containing Zr. J. Porous Mater. 2011, 19 (5), 897-902.

(41) Chandra Mouli, K.; Mohanty, S.; Hu, Y.; Dalai, A.; Adjaye, J. Effect of Hetero Atom on Dispersion of NiMo Phase on M-SBA-15 (M=Zr, Ti, Ti-Zr). Catal. Today2013, 207, 133-144.

(42) Reyes-Carmona, Á.; Arango-Díaz, A.; Moretti, E.; Talon, A.; Storaro, L.; Lenarda, M.; JiménezLópez, A.; Rodríguez-Castellón, E. CuO/CeO2 Supported on Zr Doped SBA-15 as Catalysts for Preferential CO Oxidation (CO-PROX). J. Power Sources 2011, 196 (9), 4382-4387.

(43) Zhang, H.; Tang, C.; Lv, Y.; Sun, C.; Gao, F.; Dong, L.; Chen, Y. Synthesis, Characterization, and Catalytic Performance of Copper-Containing SBA-15 in the Phenol Hydroxylation. J Colloid Interface Sci2012, 380 (1), 16-24.

(44) Aghayan, H.; Mahjoub, A. R.; Khanchi, A. R. Samarium and Dysprosium Removal Using 11Molybdo-Vanadophosphoric Acid Supported on Zr Modified Mesoporous Silica SBA-15. Chem. 
Eng.J.2013, 225(0), 509-519.

(45) Sawant, D. P.; Vinu, A.; Jacob, N. E.; Lefebvre, F.; Halligudi, S. B. Formation of Nanosized Zirconia-Supported 12-Tungstophosphoric Acid in Mesoporous Silica SBA-15: A Stable and Versatile Solid Acid Catalyst for Benzylation of Phenol. J. Catal. 2005, 235 (2), 341-352.

(46) García-Trenco, A.; Martínez, A. A Simple and Efficient Approach to Confine $\mathrm{Cu} / \mathrm{ZnO}$ Methanol Synthesis Catalysts in the Ordered Mesoporous SBA-15 Silica. Catal. Today2013, 215(0), 152161.

(47) Ajaikumar, S.; Golets, M.; Larsson, W.; Shchukarev, a.; Kordas, K.; Leino, a.-R.; Mikkola, J.-P. Effective Dispersion of $\mathrm{Au}$ and $\mathrm{Au}-\mathrm{M}(\mathrm{M}=\mathrm{Co}, \mathrm{Ni}, \mathrm{Cu}$ and $\mathrm{Zn})$ Bimetallic Nanoparticles over TiO2 Grafted SBA-15: Their Catalytic Activity on Dehydroisomerization of $\alpha$-Pinene. Microporous Mesoporous Mater. 2013, 173, 99-111.

(48) Prieto, G.; Zečević, J.; Friedrich, H.; de Jong, K. P.; de Jongh, P. E. Towards Stable Catalysts by Controlling Collective Properties of Supported Metal Nanoparticles. Nat. Mater. 2013, 12 (1), $34-39$.

(49) Tang, Y.; Zong, E.; Wan, H.; Xu, Z.; Zheng, S.; Zhu, D. Zirconia Functionalized SBA-15 as Effective Adsorbent for Phosphate Removal. Microporous Mesoporous Mater. 2012, 155, 192 200.

(50) Katryniok, B.; Paul, S.; Capron, M.; Royer, S.; Lancelot, C.; Jalowiecki-Duhamel, L.; BellièreBaca, V.; Rey, P.; Dumeignil, F. Synthesis and Characterization of Zirconia-Grafted SBA-15 Nanocomposites. J. Mater. Chem. 2011, 21 (22), 8159.

(51) Subbaramaiah, V.; Srivastava, V. C.; Mall, I. D. Catalytic Activity of Cu/SBA-15 for Peroxidation of Pyridine Bearing Wastewater at Atmospheric Condition. AIChE J.2013, 59 (7), 2577-2586.

(52) Tsoncheva, T.; Linden, M.; Areva, S.; Minchev, C. Copper Oxide Modified Large Pore Ordered Mesoporous Silicas for Ethyl Acetate Combustion. Catal. Commun. 2006, 7(6), 357-361.

(53) Dixit, M.; Mishra, M.; Joshi, P. a.; Shah, D. O. Study on the Catalytic Properties of Silica Supported Copper Catalysts. Procedia Eng. 2013, 51 (NUiCONE 2012), 467-472.

(54) Salvador, M. A.; Canales-Vázquez, J.; Ferreira, P.; Figueiredo, F. M. Characterization of Mesoporous Zirconium and Cerium Oxides by Transmission Electron Microscopy. Microsc. Microanal.2012, 18 (Supplement S5), 81-82.

(55) Gutiérrez, O. Y.; Romero, K. A.; Fuentes, G. A.; Klimova, T. New NiMo Catalysts Supported on ZrO2-Modified SBA-15 Materials for 4,6-Dimethyldibenzothiophene Hydrodesulfurization. In Scientific Bases for the Preparation of Heterogeneous Catalysts Proceedings of the 9th International Symposium; E.M. Gaigneaux D.E. De Vos, S. Hermans, P.A. Jacobs, J.A. Martens and P. Ruiz BT - Studies in Surface Science and Catalysis, M. D., Ed.; Elsevier, 2006; Vol. Volume 162 , pp 355-362.

(56) Florek-Milewska, J.; Decyk, P.; Ziolek, M. Catalytic Properties of Cu/SBA-3 in Oxidative Dehydrogenation of methanol-The Effect of the Support Composition. Appl. Catal. A Gen. 2011, $393(1-2), 215-224$.

(57) Ungureanu, A.; Dragoi, B.; Chirieac, A.; Ciotonea, C.; Royer, S.; Duprez, D.; Mamede, A. S.; 
Dumitriu, E. Composition-Dependent Morphostructural Properties of $\mathrm{Ni}-\mathrm{Cu}$ Oxide Nanoparticles Confined within the Channels of Ordered Mesoporous SBA-15 Silica. ACS Appl. Mater. Interfaces 2013, 5(8), 3010-3025.

(58) Tsoncheva, T.; Dal Santo, V.; Gallo, A.; Scotti, N.; Dimitrov, M.; Kovacheva, D. Structure and Catalytic Activity of Hosted in Mesoporous Silicas Copper Species: Effect of Preparation Procedure and Support Pore Topology. Appl. Catal. A Gen. 2011, 406(1-2), 13-21.

(59) Garcia-Cuello, V. S.; Giraldo, L.; Moreno-Piraján, J. C. Oxidation of Carbon Monoxide Over SBA-15-Confined Copper, Palladium and Iridium Nanocatalysts. Catal. Letters 2011, 141 (11), 1659-1669.

(60) Escalera, E.; Ballem, M. A.; Córdoba, J. M.; Antti, M.-L.; Odén, M. Synthesis of Homogeneously Dispersed Cobalt Nanoparticles in the Pores of Functionalized SBA-15 Silica. Powder Technol. 2012, 221, 359-364.

(61) Zha, F.; Ding, J.; Chang, Y. Cu-Zn-Al Oxide Cores Packed by Metal-Doped Amorphous SilicaAlumina Membrane for Catalyzing the Hydrogenation of Carbon Dioxide to Dimethyl Ether. Ind. Eng. ... 2011, 345-352.

(62) Alonso, A.; Moral-Vico, J.; Abo Markeb, A.; Busquets-Fité, M.; Komilis, D.; Puntes, V.; Sánchez, A.; Font, X. Critical Review of Existing Nanomaterial Adsorbents to Capture Carbon Dioxide and Methane. Sci. Total Environ. 2017, 595, 51-62.

(63) Song, H.; Rioux, R.; Hoefelmeyer, J.; Komor, R.; Niesz ..., K. Hydrothermal Growth of Mesoporous SBA-15 Silica in the \nPresence of PVP-Stabilized Pt Nanoparticles: Synthesis, $\backslash$ nCharacterization, and Catalytic Properties \n. J. Am. Chem. Soc 2006, No. 13, 3027-3037.

(64) Wang, N.; Yu, X.; Shen, K.; Chu, W.; Qian, W. Synthesis, Characterization and Catalytic Performance of MgO-Coated Ni/SBA-15 Catalysts for Methane Dry Reforming to Syngas and Hydrogen. Int.J. Hydrogen Energy 2013, 38 (23), 9718-9731.

(65) Slowing, I. I.; Trewyn, B. G.; Giri, S.; Lin, V. S.-Y. Mesoporous Silica Nanoparticles for Drug Delivery and Biosensing Applications. Adv. Funct. Mater. 2007, 17 (8), 1225-1236.

(66) Biswas, P.; Narayanasarma, P.; Kotikalapudi, C. M.; Dalai, A. K.; Adjaye, J. Characterization and Activity of ZrO2Doped SBA-15 Supported NiMo Catalysts for HDS and HDN of Bitumen Derived Heavy Gas Oil. Ind. Eng. Chem. Res. 2011, 50 (13), 7882-7895.

(67) Wei, L.; Hu, N.; Zhang, Y. Synthesis of Polymer-Mesoporous Silica Nanocomposites. Materials (Basel). 2010, 3(7), 4066-4079.

(68) Wang, W.; Wang, S.; Ma, X.; Gong, J. Recent Advances in Catalytic Hydrogenation of Carbon Dioxide. Chem Soc Rev2011, 40 (7), 3703-3727.

(69) Van Speybroeck, M.; Barillaro, V.; Thi, T. Do; Mellaerts, R.; Martens, J.; Van Humbeeck, J.; Vermant, J.; Annaert, P.; Van den Mooter, G.; Augustijns, P. Ordered Mesoporous Silica Material SBA-15: A Broad-Spectrum Formulation Platform for Poorly Soluble Drugs. J. Pharm. Sci. 2009, $98(8), 2648-2658$.

(70) Śliwa, M.; Samson, K.; Ruggiero-Mikołajczyk, M.; Żelazny, a.; Grabowski, R. Influence of Montmorillonite K10 Modification with Tungstophosphoric Acid on Hybrid Catalyst Activity in 
Direct Dimethyl Ether Synthesis from Syngas. Catal. Letters 2014, 144(11), 1884-1893.

(71) Tu, C.-H.; Wang, A.-Q.; Zheng, M.-Y.; Wang, X.-D.; Zhang, T. Factors Influencing the Catalytic Activity of SBA-15-Supported Copper Nanoparticles in CO Oxidation. Appl. Catal. A Gen. 2006, 297(1), 40-47.

(72) Selvaraj, M.; Kawi, S. An Optimal Direct Synthesis of CrSBA-15 Mesoporous Materials with Enhanced Hydrothermal Stability. Chem. Mater. 2007, 19(3), 509-519.

(73) Lin, D.-H.; Jiang, Y.-X.; Wang, Y.; Sun, S.-G. Silver Nanoparticles Confined in SBA-15 Mesoporous Silica and the Application as a Sensor for Detecting Hydrogen Peroxide. $J$. Nanomater. 2008, 2008, 1-10.

(74) Semelsberger, T. A.; Borup, R. L.; Greene, H. L. Dimethyl Ether (DME) as an Alternative Fuel.J. Power Sources 2006, 156 (2), 497-511.

(75) Olah, G. a. Beyond Oil and Gas: The Methanol Economy. Angew. Chem. Int. Ed. Engl. 2005, 44 (18), 2636-2639.

(76) Olah, G. A.; Goeppert, A.; Prakash, G. K. S. Chemical Recycling of Carbon Dioxide to Methanol and Dimethyl Ether: From Greenhouse Gas to Renewable, Environmentally Carbon Neutral Fuels and Synthetic Hydrocarbons. J. Org. Chem. 2008, 74 (2), 487-498.

(77) Blasing, T. J. Recent Greenhouse Gas Concentrations. 2009, No. August 2016, 1-5.

(78) Cox, P.; Jones, C. CLIMATE CHANGE: Illuminating the Modern Dance of Climate and CO2. Science (80-. ). 2008, 321 (5896), 1642-1644.

(79) Royer, D. L.; Berner, R. A.; Park, J. Climate Sensitivity Constrained by CO2 Concentrations over the Past 420 Million Years. Nature 2007, 446(7135), 530-532.

(80) Takht Ravanchi, M.; Sahebdelfar, S. Carbon Dioxide Capture and Utilization in Petrochemical Industry: Potentials and Challenges. Appl. Petrochemical Res. 2014, 4(1), 63-77.

(81) Chang, K.; Wang, T.; Chen, J. G. Hydrogenation of CO2 to Methanol over CuCeTiOx Catalysts. Appl. Catal. B Environ. 2017, 206, 704-711.

(82) Sankaranarayanan, S.; Srinivasan, K. Carbon Dioxide - A Potential Raw Material for the Production of Fuel, Fuel Additives and Bio-Derived Chemicals. 2012, 51, 1252-1262.

(83) Ahouari, H.; Soualah, A.; Le Valant, A.; Pinard, L.; Magnoux, P.; Pouilloux, Y. Methanol Synthesis from CO2 Hydrogenation over Copper Based Catalysts. React. Kinet. Mech. Catal. 2013, 110 (1), 131-145.

(84) Arena, F.; Barbera, K.; Italiano, G.; Bonura, G.; Spadaro, L.; Frusteri, F. Synthesis, Characterization and Activity Pattern of $\mathrm{Cu}-\mathrm{ZnO} / \mathrm{ZrO} 2$ Catalysts in the Hydrogenation of Carbon Dioxide to Methanol. J. Catal.2007, 249(2), 185-194.

(85) Pontzen, F.; Liebner, W.; Gronemann, V.; Rothaemel, M.; Ahlers, B. CO2-Based Methanol and DME - Efficient Technologies for Industrial Scale Production. Catal. Today2011, 171 (1), 242250.

(86) Gao, P.; Li, F.; Xiao, F.; Zhao, N.; Sun, N.; Wei, W.; Zhong, L.; Sun, Y. Preparation and Activity 
of $\mathrm{Cu} / \mathrm{Zn} / \mathrm{Al} / \mathrm{Zr}$ Catalysts via Hydrotalcite-Containing Precursors for Methanol Synthesis from CO2 Hydrogenation. Catal. Sci. Technol. 2012, 2(7), 1447.

(87) Styring, P.; Armstrong, K. Catalytic Carbon Dioxide Conversions to Value-Added Chemicals. Chimica Oggi. 2011, pp 34-37.

(88) Liang, X.-L.; Dong, X.; Lin, G.-D.; Zhang, H.-B. Carbon Nanotube-Supported Pd-ZnO Catalyst for Hydrogenation of CO2 to Methanol. Appl. Catal. B Environ. 2009, 88 (3-4), 315-322.

(89) Pérez-Fortes, M.; Schöneberger, J. C.; Boulamanti, A.; Tzimas, E. Methanol Synthesis Using Captured $\mathrm{CO} 2$ as Raw Material: Techno-Economic and Environmental Assessment. Appl. Energy 2016, 161, 718-732.

(90) Huang, C.; Chen, S.; Fei, X.; Liu, D.; Zhang, Y. Catalytic Hydrogenation of CO2 to Methanol: Study of Synergistic Effect on Adsorption Properties of CO2 and $\mathrm{H} 2$ in $\mathrm{CuO} / \mathrm{ZnO} / \mathrm{ZrO} 2$ System. Catalysts 2015, 5(4), 1846-1861.

(91) Saeidi, S.; Amin, N. A. S.; Rahimpour, M. R. Hydrogenation of CO2 to Value-Added productsA Review and Potential Future Developments. J. CO2 Util. 2014, 5, 66-81.

(92) Jadhav, S. G.; Vaidya, P. D.; Bhanage, B. M.; Joshi, J. B. Catalytic Carbon Dioxide Hydrogenation to Methanol: A Review of Recent Studies. Chem. Eng. Res. Des. 2014, 92 (11), 2557-2567.

(93) Ma, J.; Sun, N.; Zhang, X.; Zhao, N.; Xiao, F.; Wei, W.; Sun, Y. A Short Review of Catalysis for CO2 Conversion. Catal. Today2009, 148 (3-4), 221-231.

(94) Sakakura, T.; Choi, J.-C.; Yasuda, H. Transformation of Carbon Dioxide. Chem. Rev. 2007, 107 (6), 2365-2387.

(95) Suib, S. L.; Homs, N.; Toyir, J.; de la Piscina, P. R. New and Future Developments in Catalysis; Elsevier, 2013.

(96) Arakawa, H. Advances in Chemical Conversions for Mitigating Carbon Dioxide, Proceedings of the Fourth International Conference on Carbon Dioxide Utilization; Studies in Surface Science and Catalysis; Elsevier, 1998; Vol. 114.

(97) Skrzypek, J.; Lachowska, M.; Grzesik, M.; Słoczyński, J.; Nowak, P. Thermodynamics and Kinetics of Low Pressure Methanol Synthesis. Chem. Eng. J. Biochem. Eng.J. 1995, 58 (2), 101108.

(98) IUPAC Compendium of Chemical Terminology. 2009, 2291 (Recommendations 1990), 2293.

(99) Deutschmann, O.; Knözinger, H.; Kochloefl, K.; Turek, T. Heterogeneous Catalysis and Solid Catalysts. In Ullmann's Encyclopedia of Industrial Chemistry; Wiley-VCH Verlag GmbH \& Co. $\mathrm{KGaA}, 2000$.

(100) Huff, C.; Sanford, M. Catalytic CO2 Hydrogenation to Formate by a Ruthenium Pincer Complex. ACS Catal. 2013, 2412-2416.

(101) Kasaie, M.; Sohrabi, M. Kinetic Study on Methanol Dehydration to Dimethyl Ether Applying Clinoptilolite Zeolite as the Reaction Catalyst. J. Mex. Chem. Soc. 2009, 53 (4), 233-238.

(102) Lee, S. Methanol Synthesis from Syngas. In Handbook of Alternative Fuel Technologies; CRC 
Press, 2007; pp 297-321.

(103) Olah, G. A.; Molnár, Á. Hydrocarbon Chemistry; John Wiley \& Sons, Inc.: Hoboken, NJ, USA, 2003.

(104) Olah, G. A.; Prakash, G. K. S. Conversion of Carbon Dioxide to Dimethyl Ether Using BiReforming of Methane or Natural Gas, 2012.

(105) Tidona, B.; Koppold, C.; Bansode, A.; Urakawa, A.; Rudolf Von Rohr, P. CO2 Hydrogenation to Methanol at Pressures up to 950 Bar. J. Supercrit. Fluids 2013, 78, 70-77.

(106) Rozovskii, A.; Lin, G. Fundamentals of Methanol Synthesis and Decomposition. Top. Catal. 2003, $22(3-4), 137-150$.

(107) McGrath, K. M.; Prakash, G. K. S.; Olah, G. A. Direct Methanol Fuel Cells. J. Ind. Eng. Chem. 2004, $10(7), 1063-1080$.

(108) Mittasch, A.; Pier, M. Synthetic Manufacture of Methanol, January 12, 1926.

(109) Klier, K. Methanol Synthesis. Adv. Catal. 1982, 31, 243-313.

(110) van Bennekom, J. G.; Venderbosch, R. H.; Winkelman, J. G. M.; Wilbers, E.; Assink, D.; Lemmens, K. P. J.; Heeres, H. J. Methanol Synthesis beyond Chemical Equilibrium. Chem. Eng. Sci. 2013, 87, 204-208.

(111) Kandemir, T.; Friedrich, M.; Parker, S. F.; Studt, F.; Lennon, D.; Schlögl, R.; Behrens, M. Different Routes to Methanol: Inelastic Neutron Scattering Spectroscopy of Adsorbates on Supported Copper Catalysts. Phys. Chem. Chem. Phys. 2016, No. 4, 17253-17258.

(112) Zhao, Y.-F.; Yang, Y.; Mims, C.; Peden, C. H. F.; Li, J.; Mei, D. Insight into Methanol Synthesis from CO2 Hydrogenation on $\mathrm{Cu}(111)$ : Complex Reaction Network and the Effects of H2O.J. Catal. 2011, 281 (2), 199-211.

(113) Hu, Z.-M.; Takahashi, K.; Nakatsuji, H. Mechanism of the Hydrogenation of CO2 to Methanol on a Cu(100) Surface: Dipped Adcluster Model Study. Surf. Sci. 1999, 442 (1), 90-106.

(114) Grabow, L. C.; Mavrikakis, M. Mechanism of Methanol Synthesis on Cu through CO2and CO Hydrogenation. ACS Catal. 2011, 1 (4), 365-384.

(115) Yang, Y.; White, M. G.; Liu, P. A Theoretical Study of Methanol Synthesis from CO2 Hydrogenation on Metal-Doped Cu(111) Surfaces. J Phys Chem A2011.

(116) Reubroycharoen, P.; Yamagami, T.; Vitidsant, T.; Yoneyama, Y.; Ito, M.; Tsubaki, N. Continuous Low-Temperature Methanol Synthesis from Syngas Using Alcohol Promoters. Energy \& Fuels 2003, 17(4), 817-821.

(117) Gokhale, A. A.; Dumesic, J. A.; Mavrikakis, M. Article On the Mechanism of Low-Temperature Water Gas Shift Reaction on Copper On the Mechanism of Low-Temperature Water Gas Shift Reaction on Copper. J. Am. Chem. Soc. 2008, 130 (33), 1402-1414.

(118) Loyd J. Burcham, †; Laura E. Briand, ₹ and; Israel E. Wachs*, \$. Quantification of Active Sites for the Determination of Methanol Oxidation Turn-over Frequencies Using Methanol Chemisorption and in Situ Infrared Techniques. 1. Supported Metal Oxide Catalysts. Langmuir 
2001, $17(20), 6164-6174$.

(119) Gao, P.; Xie, R.; Wang, H.; Zhong, L.; Xia, L.; Zhang, Z.; Wei, W.; Sun, Y. Cu / Zn / Al / Zr Catalysts via Phase-Pure Hydrotalcite-like Compounds for Methanol Synthesis from Carbon Dioxide. Biochem. Pharmacol.2015.

(120) an, X.; Zuo, Y.; Zhang, Q.; Wang, J. Methanol Synthesis from CO2 Hydrogenation with a $\mathrm{Cu} / \mathrm{Zn} / \mathrm{Al} / \mathrm{Zr}$ Fibrous Catalyst. Chinese J. Chem. Eng. 2009, 17 (1), 88-94.

(121) Pinto, A. Methanol Production. US 4455394 A, 1984.

(122) Shulenberger, A. M.; Jonsson, F. R.; Ingolfsson, O.; Tran, K. C. Process for Producing Liquid Fuel from Carbon Dioxide and Water. US 8198338 B2, 2012.

(123) Matsushita, T.; Haganuma, T.; Fujita, D. Process for Producing Methanol. US 20130237618 A1, 2013.

(124) da Silva, R. J.; Pimentel, A. F.; Monteiro, R. S.; Mota, C. J. A. Synthesis of Methanol and Dimethyl Ether from the $\mathrm{CO} 2$ Hydrogenation over $\mathrm{Cu} \cdot \mathrm{ZnO}$ Supported on $\mathrm{Al} 2 \mathrm{O} 3$ and $\mathrm{Nb} 2 \mathrm{O} 5$. J. CO2 Util. 2016, No. 2015, 1-6.

(125) Raudaskoski, R.; Niemela, M. V.; Keiski, R. L. The Effect of Ageing Time on Co-Precipitated $\mathrm{Cu} / \mathrm{ZnO} / \mathrm{ZrO} 2$ Catalysts Used in Methanol Synthesis from $\mathrm{CO} 2$ and H2. Top. Catal. 2007, 45 (1-4), 57-60.

(126) Guo, X.; Mao, D.; Wang, S.; Wu, G.; Lu, G. Combustion Synthesis of CuO-ZnO-ZrO2 Catalysts for the Hydrogenation of Carbon Dioxide to Methanol. Catal. Commun. 2009, 10 (13), 16611664.

(127) Zhang, Y.; Fei, J.; Yu, Y.; Zheng, X. Methanol Synthesis from CO2 Hydrogenation over Cu Based Catalyst Supported on Zirconia Modified $\gamma$-Al2O3. Energy Convers. Manag. 2006, 47 (18-19), 3360-3367.

(128) Witoon, T.; Numpilai, T.; Phongamwong, T.; Donphai, W.; Boonyuen, C.; Warakulwit, C.; Chareonpanich, M.; Limtrakul, J. Enhanced Activity, Selectivity and Stability of a CuO-ZnO-ZrO 2 Catalyst by Adding Graphene Oxide for CO 2 Hydrogenation to Methanol. Chem. Eng.J.2018, 334 (November 2017), 1781-1791.

(129) Lei, Z.; Zou, Z.; Dai, C.; Li, Q.; Chen, B. Synthesis of Dimethyl Ether (DME) by Catalytic Distillation. Chem. Eng. Sci. 2011, 66 (14), 3195-3203.

(130) Hosseininejad, S.; Afacan, a.; Hayes, R. E. Catalytic and Kinetic Study of Methanol Dehydration to Dimethyl Ether. Chem. Eng. Res. Des. 2012, 90(6), 825-833.

(131) Frusteri, F.; Cordaro, M.; Cannilla, C.; Bonura, G. Multifunctionality of $\mathrm{Cu}-\mathrm{ZnO}-\mathrm{ZrO} 2 / \mathrm{H}-$ ZSM5 Catalysts for the One-Step CO2-to-DME Hydrogenation Reaction. Appl. Catal. B Environ. 2015, 162, 57-65.

(132) Rownaghi, A. A.; Rezaei, F.; Stante, M.; Hedlund, J. Selective Dehydration of Methanol to Dimethyl Ether on ZSM-5 Nanocrystals. Appl. Catal. B Environ. 2012, 119-120(0), 56-61.

(133) Asthana, S.; Samanta, C.; Bhaumik, A.; Banerjee, B.; Voolapalli, R. K.; Saha, B. Direct Synthesis of Dimethyl Ether from Syngas over Cu-Based Catalysts: Enhanced Selectivity in the Presence of 


\section{References}

MgO.J. Catal.2016, 334, 89-101.

(134) Lei, Z.; Zou, Z.; Dai, C.; Li, Q.; Chen, B. Synthesis of Dimethyl Ether (DME) by Catalytic Distillation. Chem. Eng. Sci. 2011, 66 (14), 3195-3203.

(135) Liu, R.; Qin, Z.; Ji, H.; Su, T. Synthesis of Dimethyl Ether from CO 2 and H 2 Using a Cu-FeZr/HZSM-5 Catalyst System. Ind. Eng. Chem. Res. 2013, 52 (47), 16648-16655.

(136) Witoon, T.; Permsirivanich, T.; Kanjanasoontorn, N.; Akkaraphataworn, C.; Seubsai, A.; Faungnawakij, K.; Warakulwit, C.; Chareonpanich, M.; Limtrakul, J. Direct Synthesis of Dimethyl Ether from $\mathrm{CO} 2$ Hydrogenation over $\mathrm{Cu}-\mathrm{ZnO}-\mathrm{ZrO} 2$ /SO 4 2- - ZrO 2 Hybrid Catalysts: Effects of Sulfur-to-Zirconia Ratios. Catal. Sci. Technol.2015, 5 (4), 2347-2357.

(137) Flores-Escamilla, G. a.; Fierro-Gonzalez, J. C. Infrared Spectroscopic Study of Dimethyl Ether Carbonylation Catalysed by $\mathrm{TiO}_{2}$-Supported Rhodium Carbonyls. Catal. Sci. Technol. 2015, 5 (2), 843-850.

(138) LCL, J.; CMBM, B.; L, N.; JR, R. Catalytic Dehydration of Methanol to Dimethyl Ether (DME) Using the Al62,2Cu25,3Fe12,5 Quasicrystalline Alloy. J. Chem. Eng. Process Technol. 2013, 4 (5), 1-8.

(139) Yu, J.; Mao, D.; Han, L.; Guo, Q.; Lu, G. Synthesis of C2 Oxygenates from Syngas over Monodispersed SiO2 Supported Rh-Based Catalysts: Effect of Calcination Temperature of $\mathrm{SiO} 2$. Fuel Process. Technol.2013, 106, 344-349.

(140) Porosoff, M. D.; Chen, J. G. Trends in the Catalytic Reduction of CO2 by Hydrogen over Supported Monometallic and Bimetallic Catalysts. J. Catal. 2013, 301, 30-37.

(141) Bouarab, R.; Cherifi, O.; Auroux, A. Reforming of Methane by CO2 in Presence of Cobalt- Based catalystsThis Work Was Presented at the Green Solvents for Catalysis Meeting Held in Bruchsal, Germany, 13-16th October 2002. Green Chem. 2003, 5(2), 209-212.

(142) Fisher, I. a; Bell, A. T. In-SituInfrared Study of Methanol Synthesis from H2/CO2over $\mathrm{Cu} / \mathrm{SiO} 2$ and $\mathrm{Cu} / \mathrm{ZrO} 2 / \mathrm{SiO} 2$.J. Catal. 1997, 172(1), 222-237.

(143) Jia, M.; Li, W.; Xu, H.; Hou, S.; Yu, C.; Ge, Q. The Effect of Additives on Cu/HZSM-5 Catalyst for DME Synthesis. Catal. Letters 2002, 84(1/2), 31-35.

(144) Samson, K.; Śliwa, M.; Socha, R. P.; Góra-Marek, K.; Mucha, D.; Rutkowska-Zbik, D.; Paul, J.-F.; Ruggiero-Mikołajczyk, M.; Grabowski, R.; Słoczyński, J. Influence of ZrO 2 Structure and Copper Electronic State on Activity of Cu/ZrO 2 Catalysts in Methanol Synthesis from CO 2. ACS Catal. 2014, 4(10), 3730-3741.

(145) van den Berg, R.; Zečević, J.; Sehested, J.; Helveg, S.; de Jongh, P. E.; de Jong, K. P. Impact of the Synthesis Route of Supported Copper Catalysts on the Performance in the Methanol Synthesis Reaction. Catal. Today 2016, 272, 87-93.

(146) Nonneman, L. E. Y.; Ponec, V. On the Problem of the Activity in Methanol Synthesis of Supported, Unpromoted Copper Catalysts. Catal. Letters 1991, 7(1-4), 213-217.

(147) Thi, T. P. T.; Nguyen, D. T.; Duong, T. Q.; Luc, H. H.; Vo, V. Facile Postsynthesis of N-Doped TiO 2 -SBA-15 and Its Photocatalytic Activity. Adv. Mater. Sci. Eng. 2013, 2013, 1-8. 
(148) Xing, M.; Fang, W.; Nasir, M.; Ma, Y.; Zhang, J.; Anpo, M. Self-Doped Ti3+-Enhanced TiO2 Nanoparticles with a High-Performance Photocatalysis. J. Catal. 2013, 297, 236-243.

(149) Schneider, J.; Matsuoka, M.; Takeuchi, M.; Zhang, J.; Horiuchi, Y.; Anpo, M.; Bahnemann, D. W. Understanding TiO 2 Photocatalysis : Mechanisms and Materials. Chem. Rev. 2014, 114, 99199986.

(150) Kuncewicz, J.; Ohtani, B. Titania Photocatalysis through Two-Photon Band-Gap Excitation with Built-in Rhodium Redox Mediator. Chem. Commun. 2015, 51 (2), 298-301.

(151) Ali, K. A.; Zuhairi, A.; Mohamed, A. R. Recent Development in Catalytic Technologies for Methanol Synthesis from Renewable Sources : A Critical Review. Renew. Sustain. Energy Rev. 2015, 44, 508-518.

(152) Słoczyński, J.; Grabowski, R.; Kozłowska, A.; Olszewski, P.; Lachowska, M.; Skrzypek, J.; Stoch, J. Effect of $\mathrm{Mg}$ and $\mathrm{Mn}$ Oxide Additions on Structural and Adsorptive Properties of $\mathrm{Cu} / \mathrm{ZnO} / \mathrm{ZrO} 2$ Catalysts for the Methanol Synthesis from CO2. Appl. Catal. A Gen. 2003, 249(1), 129-138.

(153) Sakurai, H.; Haruta, M. Carbon Dioxide and Carbon Monoxide Hydrogenation over Gold Supported on Titanium, Iron, and Zinc Oxides. Appl. Catal. A Gen. 1995, 127(1-2), 93-105.

(154) Arena, F.; Italiano, G.; Barbera, K.; Bordiga, S.; Bonura, G.; Spadaro, L.; Frusteri, F. Solid-State Interactions, Adsorption Sites and Functionality of $\mathrm{Cu}-\mathrm{ZnO} / \mathrm{ZrO} 2$ Catalysts in the $\mathrm{CO} 2$ Hydrogenation to CH3OH. Appl. Catal. A Gen. 2008, 350 (1), 16-23.

(155) Wang, G.; Zuo, Y.; Han, M.; Wang, J. Copper Crystallite Size and Methanol Synthesis Catalytic Property of Cu-Based Catalysts Promoted by Al, Zr and Mn. React. Kinet. Mech. Catal.2010, 101 (2), 443-454.

(156) Degirmenci, V.; Uner, D.; Cinlar, B.; Shanks, B. H.; Yilmaz, A.; Santen, R. A.; Hensen, E. J. M. Sulfated Zirconia Modified SBA-15 Catalysts for Cellobiose Hydrolysis. Catal. Letters 2010, 141 (1), 33-42.

(157) Masoud, N.; Delannoy, L.; Schaink, H.; van der Eerden, A.; de Rijk, J. W.; Silva, T. A. G.; Banerjee, D.; Meeldijk, J. D.; de Jong, K. P.; Louis, C.; de Jongh, P. E. Superior Stability of $\mathrm{Au} / \mathrm{SiO} 2$ Compared to $\mathrm{Au} / \mathrm{TiO} 2$ Catalysts for the Selective Hydrogenation of Butadiene. ACS Catal. 2017, 7(9), 5594-5603.

(158) Xin-Chao, S.; Lin-Hai, D.; Yu-Ye, W.; Wen-Guang, Q.; YU, Y.-C.; Yuan, W.; Huai-Lei, L.; ZhaoLin, S.; Li-Juan, S. Effect of Surface Acidity of CuO-SBA-15 on Adsorptive Desulfurization of Fuel Oils. 2012, 28(6), 1467-1473.

(159) Prieto, G.; Meeldijk, J. D.; De Jong, K. P.; De Jongh, P. E. Interplay between Pore Size and Nanoparticle Spatial Distribution: Consequences for the Stability of $\mathrm{CuZn} / \mathrm{SiO} 2$ methanol Synthesis Catalysts. J. Catal. 2013, 303, 31-40.

(160) Twigg, M. V; Spencer, M. S. Deactivation of Supported Copper Metal Catalysts for Hydrogenation Reactions. Appl. Catal. A Gen. 2001, 212 (1-2), 161-174.

(161) Saltzman, W. M. Drug Delivery: Engineering Principles for Drug Therapy; Topics in Chemical Engineering; Oxford University Press, 2001. 
(162) Park, K. Controlled Drug Delivery Systems: Past Forward and Future Back. J. Control. Release 2014, 190, 3-8.

(163) Doadrio, A. L.; Sousa, E. M. B.; Doadrio, J. C.; Pérez Pariente, J.; Izquierdo-Barba, I.; Vallet-Reg1 , M. Mesoporous SBA-15 HPLC Evaluation for Controlled Gentamicin Drug Delivery.J. Control. Release 2004, 97(1), 125-132.

(164) Jain, K. K. Drug Delivery Systems; 2008; Vol. 437.

(165) Perrie, Y.; Rades, T. Pharmaceutics: Drug Delivery and Targeting; Fast Track Series; Pharmaceutical Press, 2009.

(166) Martinho, N.; Damgé, C.; Reis, C. P. Recent Advances in Drug Delivery Systems. J. Biomater. Nanobiotechnol.2011, 2(5), 510-526.

(167) Vallet-Regí, M.; Ruiz-González, L.; Izquierdo-Barba, I.; González-Calbet, J. M. Revisiting Silica Based Ordered Mesoporous Materials: Medical Applications. J. Mater. Chem. 2006, 16 (1), 2631 .

(168) Wang, X.; Chen, D.; Cao, L.; Li, Y.; Boyd, B. J.; Caruso, R. a. Mesoporous Titanium Zirconium Oxide Nanospheres with Potential for Drug Delivery Applications. ACS Appl. Mater. Interfaces 2013, 5, 10926-10932.

(169) Barich, D. H.; Munson, E. J.; Zell, M. T. Physicochemical Properties, Formulation, and Drug Delivery. In Drug Delivery; John Wiley \& Sons, Inc.: Hoboken, NJ, USA, 2005; pp 57-71.

(170) Lao, L. L.; Peppas, N. a.; Boey, F. Y. C.; Venkatraman, S. S. Modeling of Drug Release from BulkDegrading Polymers. Int.J. Pharm. 2011, 418(1), 28-41.

(171) Holowka, E. P.; Bhatia, S. K. Drug Delivery; 2014.

(172) Costa, P.; Sousa Lobo, J. M. Modeling and Comparison of Dissolution Profiles. Eur. J. Pharm. Sci. 2001, 13(2), 123-133.

(173) Aucoin, H.; Wilson, A.; Wilson, A.; Ishihara, K.; Guiseppi-Elie, A. Release of Potassium Ion and Calcium Ion from Phosphorylcholine Group Bearing Hydrogels. Polymers (Basel). 2013, 5 (4), $1241-1257$.

(174) Siepmann, J.; Peppas, N. A. Higuchi Equation: Derivation, Applications, Use and Misuse. Int.J. Pharm. 2011, 418(1), 6-12.

(175) Dash, S.; Murthy, P. N.; Nath, L.; Chowdhury, P. Kinetic Modeling on Drug Release from Controlled Drug Delivery Systems. Acta Pol. Pharm. 2010, 67 (3), 217-223.

(176) Petrescu, M.; Mitran, R. A.; Luchian, A. M.; Matei, C.; Berger, D. Mesoporous Ceria-Silica Composites as Carriers for Doxycycline. UPB Sci. Bull. Ser. B Chem. Mater. Sci. 2015, 77(3), 1324.

(177) Berger, D.; Bajenaru, L.; Nastase, S.; Mitran, R.-A.; Munteanu, C.; Matei, C. Influence of Structural, Textural and Surface Properties of Mesostructured Silica and Aluminosilicate Carriers on Aminoglycoside Uptake and in Vitro Delivery. Microporous Mesoporous Mater. 2015, 206, $150-160$. 
(178) Bhatia, S. Nanoparticles Types, Classification, Characterization, Fabrication Methods and Drug Delivery Applications. In Natural Polymer Drug Delivery Systems; Springer International Publishing: Cham, 2016; pp 33-93.

(179) Jadhav, S.; Gaikwad, S.; Nimse, M.; Rajbhoj, A. Copper Oxide Nanoparticles: Synthesis, Characterization and Their Antibacterial Activity.J. Clust. Sci. 2011, 22, 121-129.

(180) Ding, C.; Li, Z. A Review of Drug Release Mechanisms from Nanocarrier Systems. Mater. Sci. Eng. C2017, 76, 1440-1453.

(181) De Jong, W. H.; Borm, P. J. A. Drug Delivery and Nanoparticles: Applications and Hazards. Int.J. Nanomedicine 2008, 3(2), 133-149.

(182) Wang, Z.; Chen, B.; Wu, Q. Increasing the Oral Bioavailability of Poorly Water- Soluble Carbamazepine Using Immediate-Release Pellets Supported on SBA-15 Mesoporous Silica. 2012, 5807-5818.

(183) Vallet-regí, M.; Balas, F.; Arcos, D. Minireviews Mesoporous Materials for Drug Delivery. 2007, $7548-7558$.

(184) Vallet-Regí, M.; Balas, F. Silica Materials for Medical Applications. Open Biomed. Eng.J.2008, 2, $1-9$.

(185) Vallet-Regi, M.; Ramila, A. A New Property of MCM-41: Drug Delivery System. Chem. Mater. 2001, No. 11,308-311.

(186) Rosenholm, J. M.; Sahlgren, C.; Lindén, M. Towards Multifunctional, Targeted Drug Delivery Systems Using Mesoporous Silica Nanoparticles--Opportunities \& Challenges. Nanoscale 2010, $2(10), 1870-1883$.

(187) García, A.; Colilla, M.; Izquierdo-Barba, I.; Vallet-Regí, M. Incorporation of Phosphorus into Mesostructured Silicas: A Novel Approach to Reduce the SiO2 Leaching in Water. Chem. Mater. 2009, 21 (18), 4135-4145.

(188) Song, S.-W.; Hidajat, K.; Kawi, S. Functionalized SBA-15 Materials as Carriers for Controlled Drug Delivery: Influence of Surface Properties on Matrix-Drug Interactions. Langmuir 2005, 21 (21), 9568-9575.

(189) de Jongh, P. E.; Eggenhuisen, T. M. Melt Infiltration: An Emerging Technique for the Preparation of Novel Functional Nanostructured Materials. Adv. Mater. 2013, 25 (46), 6672-6690.

(190) Slowing, I. I.; Vivero-Escoto, J. L.; Wu, C.-W.; Lin, V. S.-Y. Mesoporous Silica Nanoparticles as Controlled Release Drug Delivery and Gene Transfection Carriers. Adv. Drug Deliv. Rev. 2008, $60(11), 1278-1288$.

(191) Kato, N.; Kato, N. High-Yield Hydrothermal Synthesis of Mesoporous Silica Hollow Capsules. Microporous Mesoporous Mater. 2016, 219, 230-239.

(192) Takai, C.; Ishino, T.; Fuji, M.; Shirai, T. Rapid and High Yield Synthesis of Hollow Silica Nanoparticles Using an NH4F Catalyst. Colloids Surfaces A Physicochem. Eng. Asp. 2014, 446, $46-49$.

(193) Tsai, C.-P.; Chen, C.-Y.; Hung, Y.; Chang, F.-H.; Mou, C.-Y. Monoclonal Antibody- 
Functionalized Mesoporous Silica Nanoparticles (MSN) for Selective Targeting Breast Cancer Cells. J. Mater. Chem. 2009, 19 (32), 5737.

(194) Moritz, M.; Łaniecki, M. SBA-15 Mesoporous Material Modified with APTES as the Carrier for 2-(3-Benzoylphenyl)propionic Acid. Appl. Surf. Sci. 2012, 258 (19), 7523-7529.

(195) Rosenholm, J. M.; Penninkangas, A.; Lindén, M. Amino-Functionalization of Large-Pore Mesoscopically Ordered Silica by a One-Step Hyperbranching Polymerization of a SurfaceGrown Polyethyleneimine. Chem. Commun. (Camb).2006, No. 37, 3909-3911.

(196) Aznar, E.; Marcos, M. D.; Martínez-Máñez, R.; Sancenón, F.; Soto, J.; Amorós, P.; Guillem, C. $\mathrm{pH}-$ and Photo-Switched Release of Guest Molecules from Mesoporous Silica Supports. J. Am. Chem. Soc. 2009, 131 (19), 6833-6843.

(197) Lai, C.-Y.; Trewyn, B. G.; Jeftinija, D. M.; Jeftinija, K.; Xu, S.; Jeftinija, S.; Lin, V. S.-Y. A Mesoporous Silica Nanosphere-Based Carrier System with Chemically Removable CdS Nanoparticle Caps for Stimuli-Responsive Controlled Release of Neurotransmitters and Drug Molecules. J. Am. Chem. Soc. 2003, 125 (15), 4451-4459.

(198) Samuel, S. P.; Li, S.; Mukherjee, I.; Guo, Y.; Patel, A. C.; Baran, G.; Wei, Y. Mechanical Properties of Experimental Dental Composites Containing a Combination of Mesoporous and Nonporous Spherical Silica as Fillers. Dent. Mater. 2009, 25, 296-301.

(199) Fullriede, H.; Timpe, N.; Borchers, L.; Stiesch, M.; Menzel, H.; Behrens, P.; Chemie, A.; Hannover, L. U.; Chemie, T.; Braunschweig, T. U.; Prothetik, Z. A NTIBACTERIAL SILICA NANOPARTICLES WITH P H-SENSITIVE RELEASE PROPERTIES AS FILLERS FOR DENTAL DENTA L COMPOSITE MATERIALS. 2013, 58, 9-10.

(200) Bowen, R. L.; Reed, L. E. Semiporous Reinforcing Fillers for Composite Resins: I. Preparation of Provisional Glass Formulations. J. Dent. Res. 1976, 55 (5), 738-747.

(201) Vallet-Regi, M.; Doadrio, J. C.; Doadrio, A. L.; Izquierdo-Barba, I.; Perez-Pariente, J. Hexagonal Ordered Mesoporous Material as a Matrix for the Controlled Release of Amoxicillin. Solid State Ionics 2004, 172 (1-4), 435-439.

(202) Ng, J. B. S.; Kamali-Zare, P.; Brismar, H.; Bergstr??m, L. Release and Molecular Transport of Cationic and Anionic Fluorescent Molecules in Mesoporous Silica Spheres. Langmuir 2008, 24 (19), 11096-11102.

(203) Demuth, P.; Hurley, M.; Wu, C.; Galanie, S.; Zachariah, M. R.; Deshong, P. Mesoscale Porous Silica as Drug Delivery Vehicles: Synthesis, Characterization, and $\mathrm{pH}$-Sensitive Release Profiles. Microporous Mesoporous Mater. 2011, 141 (1-3), 128-134.

(204) Hisbergues, M.; Vendeville, S.; Vendeville, P. Review Zirconia: Established Facts and Perspectives for a Biomaterial in Dental Implantology. J. Biomed. Mater. Res. - Part B Appl. Biomater. 2009, 88, 519-529.

(205) Asadpour, E.; Boroushaki, M. T.; Ghorbani, A.; Sadeghnia, H. R. Effect of Zirconium Dioxide Nanoparticles on Glutathione Peroxidase Enzyme in PC12 and N2a Cell Lines. Iran. J. Pharm. Res. 2014, 13(4), 1141-1148.

(206) Otero-González, L.; García-Saucedo, C.; Field, J. A.; Sierra-Álvarez, R. Toxicity of $\mathrm{TiO}_{2}, \mathrm{ZrO}_{2}$, 
$\mathrm{Fe}^{0}, \mathrm{Fe}_{2} \mathrm{O}_{3}$, and $\mathrm{Mn}_{2} \mathrm{O}_{3}$ Nanoparticles to the Yeast, Saccharomyces Cerevisiae. Chemosphere 2013, $93(6), 1201-1206$.

(207) Karunakaran, G.; Suriyaprabha, R.; Manivasakan, P.; Yuvakkumar, R.; Rajendran, V.; Kannan, N. Screening of in Vitro Cytotoxicity, Antioxidant Potential and Bioactivity of Nano- and MicroZrO2 and -TiO2 Particles. Ecotoxicol Env. Saf2013, 93, 191-197.

(208) Jangra, S. L.; Stalin, K.; Dilbaghi, N.; Kumar, S.; Tawale, J.; Singh, S. P.; Pasricha, R. Antimicrobial Activity of Zirconia (ZrO2) Nanoparticles and Zirconium Complexes. J. Nanosci. Nanotechnol. 2012, 12(9), 7105-7112.

(209) Grass, G.; Rensing, C.; Solioz, M. Metallic Copper as an Antimicrobial Surface. Appl. Environ. Microbiol.2011, 77(5), 1541-1547.

(210) Konieczny, J.; Rdzawski, Z. Antibacterial Properties of Copper and Its Alloys. Arch. Mater. Sci. Eng. 2012, 56(2), 53-60.

(211) Argueta-Figueroa, L.; Morales-Luckie, R. A.; Scougall-Vilchis, R. J.; Olea-Mejía, O. F. Synthesis, Characterization and Antibacterial Activity of Copper, Nickel and Bimetallic $\mathrm{Cu}-\mathrm{Ni}$ Nanoparticles for Potential Use in Dental Materials. Prog. Nat. Sci. Mater. Int.2014, 24(4), 321328.

(212) Raffi, M.; Mehrwan, S.; Bhatti, T. M.; Akhter, J. I.; Hameed, A.; Yawar, W.; Ul Hasan, M. M. Investigations into the Antibacterial Behavior of Copper Nanoparticles against Escherichia Coli. Ann. Microbiol. 2010, 60, 75-80.

(213) Esteban-Cubillo, A.; Pecharromán, C.; Aguilar, E.; Santarén, J.; Moya, J. S. Antibacterial Activity of Copper Monodispersed Nanoparticles into Sepiolite. J. Mater. Sci. 2006, 41, 5208-5212.

(214) Cioffi, N.; Torsi, L.; Ditaranto, N.; Tantillo, G.; Ghibelli, L.; Sabbatini, L.; Bleve-Zacheo, T.; D'Alessio, M.; Zambonin, P. G.; Traversa, E. Copper Nanoparticle/polymer Composites with Antifungal and Bacteriostatic Properties. Chem. Mater. 2005, 17(7), 5255-5262.

(215) Pinto, R. J. B.; Daina, S.; Sadocco, P.; Neto, C. P.; Trindade, T. Antibacterial Activity of Nanocomposites of Copper and Cellulose. Biomed Res. Int. 2013, 2013.

(216) Chatterjee, A. K.; Chakraborty, R.; Basu, T. Mechanism of Antibacterial Activity of Copper Nanoparticles. Nanotechnology2014, 25, 135101.

(217) Silva, H. F. O.; Lima, K. M. G.; Cardoso, M. B.; Oliveira, J. F. a.; Melo, M. C. N.; Sant'Anna, C.; Eugênio, M.; Gasparotto, L. H. S. Doxycycline Conjugated with PolyvinylpyrrolidoneEncapsulated Silver Nanoparticles: A Polymer's Malevolent Touch against Escherichia Coli. RSC Adv. 2015, 5 (82), 66886-66893.

(218) Ren, G.; Hu, D.; Cheng, E. W. C.; Vargas-Reus, M. a.; Reip, P.; Allaker, R. P. Characterisation of Copper Oxide Nanoparticles for Antimicrobial Applications. Int. J. Antimicrob. Agents 2009, 33, 587-590.

(219) Kovtun, A.; Kozlova, D.; Ganesan, K.; Biewald, C.; Seipold, N.; Gaengler, P.; Arnold, W. H.; Epple, M. Chlorhexidine-Loaded Calcium Phosphate Nanoparticles for Dental Maintenance Treatment: Combination of Mineralising and Antibacterial Effects. RSCAdv. 2012, 2 (3), 870. 
(220) do Amorim, C. V. G.; Aun, C. E.; Mayer, M. P. A. Susceptibility of Some Oral Microorganisms to Chlorhexidine and Paramonochlorophenol. Braz. Oral Res. 2004, 18(3), 242-246.

(221) McDonnell, G; Russell, A. Antiseptics and Disinfectants : Activity, Action, and Resistance. Am. Soc. Microbiol. 1999, 12 (1), 147-179.

(222) Attin, T.; Abouassi, T.; Becker, K.; Wiegand, A.; Roos, M.; Attin, R. A New Method for Chlorhexidine (CHX) Determination: CHX Release after Application of Differently Concentrated CHX-Containing Preparations on Artificial Fissures. Clin. Oral Investig. 2008, 12 (3), 189-196.

(223) Russell, A. D.; Day, M. J. Antibacterial Activity of Chlorhexidine. J. Hosp. Infect. 1993, 25 (4), 229-238.

(224) Deo, V.; Ansari, S.; Mandia, S.; Bhongade, M. Therapeutic Efficacy of Subgingivally Delivered Doxycycline Hyclate as an Adjunct to Non-Surgical Treatment of Chronic Periodontitis. J. Oral Maxillofac. Res. 2010, 2 (1), 1-7.

(225) Al Hulami, H.; Babay, N.; Awartani, F.; Anil, S. The Effect of Locally Delivered Doxycycline as an Adjunctive Therapy to Scaling and Root Planing in Smokers. Saudi Dent. J. 2011, 23 (3), 143148.

(226) Machion, L.; Andia, D. C.; Lecio, G.; Nociti, F. H.; Casati, M. Z.; Sallum, A. W.; Sallum, E. A. Locally Delivered Doxycycline as an Adjunctive Therapy to Scaling and Root Planing in the Treatment of Smokers: A 2-Year Follow-Up. J. Periodontol. 2006, 77(4), 606-613.

(227) Condon, J. B. Surface Area and Porosity Determinations by Physisorption; Elsevier, 2006.

(228) Sing, K. S. W. Physisorption of Nitrogen by Porous Materials. J. Porous Mater. 1995, 2 (1), 5-8.

(229) Thommes, M.; Kaneko, K.; Neimark, A. V.; Olivier, J. P.; Rodriguez-Reinoso, F.; Rouquerol, J.; Sing, K. S. W. Physisorption of Gases, with Special Reference to the Evaluation of Surface Area and Pore Size Distribution (IUPAC Technical Report). Pure Appl. Chem. 2015, 87 (9-10), 1051-1069.

(230) Condon, J. B. (total pdf). Surface Area and Porosity Determinations by Physisorption, Measurements and Theory; 2006.

(231) Xiao Jiang, Naoto Koizumi, A.; Guo, X.; Song, and C. Bimetallic Pd-Cu Catalysts for Selective $\mathrm{CO} 2$ Hydrogenation to Methanol.

(232) Jaroniec, M.; Solovyov, L. A. Improvement of the Kruk-Jaroniec-Sayari Method for Pore Size Analysis of Ordered Silicas with Cylindrical Mesopores. Langmuir 2006, 22 (16), 6757-6760.

(233) Kruk, M.; Jaroniec, M.; Ko, C. H.; Ryoo, R. Characterization of the Porous Structure of SBA-15. Chem. Mater. 2000, 12 (7), 1961-1968.

(234) Kruk, M.; Jaroniec, M.; Sayari, A. Application of Large Pore MCM-41 Molecular Sieves to Improve Pore Size Analysis Using Nitrogen Adsorption Measurements. Langmuir 1997, 7463 (12), 6267-6273.

(235) Condon, J. B. Surface Area and Porosity Determinations by Physisorption; Elsevier, 2006. 
(236) Webb, P. A. Introduction to Chemical Adsorption Analytical Techniques and Their Applications to Catalysis. 2003, No. January.

(237) Gallacher, P. K. Handbook of Thermal Analysis and Calorimetry; 1998; Vol. 1.

(238) Webb, P.; Orr, C.; Corporation., M. I. Analytical Methods in Fine Particle Technology; Micromeritics Instrument Corp.: Norcross, Ga., 1997.

(239) Jenkins, R. X-Ray Techniques: Overview. Encycl. Anal. Chem. 2000, 13269-13288.

(240) Ingham, B. X-Ray Scattering Characterisation of Nanoparticles. Crystallogr. Rev. 2015, 21 (4), 229-303.

(241) Patterson, A. L. The Scherrer Formula for X-Ray Particle Size Determination. Phys. Rev. 1939, 56 (10), 978-982.

(242) Egerton, R. F. Physical Principles of Electron Microscopy; Springer US: Boston, MA, 2005; Vol. 24.

(243) Stuart, B. H. Infrared Spectroscopy: Fundamentals and Applications; Analytical Techniques in the Sciences; John Wiley \& Sons, Ltd: Chichester, UK, 2004; Vol. 8.

(244) Armaroli, T.; Bécue, T.; Gautier, S. Diffuse Reflection Infrared Spectroscopy (Drifts): Application to the in Situ Analysis of Catalysts. Oil Gas Sci. Technol.2004, 59(2), 215-237.

(245) Harrick, N. J.; Beckmann, K. H. Internal Reflection Spectroscopy. In Characterization of Solid Surfaces; Kane, P. F., Larrabee, G. B., Eds.; Springer US: Boston, MA, 1974; pp 215-245.

(246) Harvey, D. Modern Analytical Chemistry; McGraw-Hill, 1999.

(247) Watts, J. F.; Wolstenholme, J. An Introduction to Surface Analysis by XPS and AES; John Wiley \& Sons, Ltd: Chichester, UK, 2003; Vol. 27.

(248) Briggs, D. Handbook of X-Ray Photoelectron Spectroscopy C. D. Wanger, W. M. Riggs, L. E. Davis, J. F. Moulder and G. E.Muilenberg Perkin-Elmer Corp., Physical Electronics Division, Eden Prairie, Minnesota, USA, 1979. 190 Pp. \$195. Surf. Interface Anal. 1981, 3 (4), v-v.

(249) Hajšlová, J.; Čajka, T. Gas Chromatography-mass Spectrometry (GC-MS). In Food Toxicants Analysis; Elsevier, 2007; pp 419-473.

(250) Stashenko, E.; Ren, J. Gas Chromatography-Mass Spectrometry. In Advances in Gas Chromatography; InTech, 2014; pp 1-38.

(251) de Hoffmann, E.; Stroobant, V. Mass Spectrometry: Principles and Applications; Wiley, 2007.

(252) Glish, G. L.; Vachet, R. W. The Basics of Mass Spectrometry in the Twenty-First Century. Nat. Rev. Drug Discov. 2003, 2(2), 140-150. 


\section{Papers}

The papers associated with this thesis have been removed for copyright reasons. For more details about these see:

http://urn.kb.se/resolve?urn=urn:nbn:se:liu:diva-147308 